\title{
PROMOTER-DRIVEN SPLICING REGULATION IN FISSION YEAST
}

\author{
Alberto Moldón Vara \\ Tesis Doctoral
}

Barcelona, Octubre 2008

Oxidative Stress and Cell Cycle Group

Departament de Ciències Experimentals i de la Salut

Universitat Pompeu Fabra

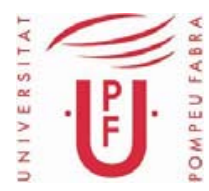


Memoria presentada por

Alberto Moldón Vara

Para obtar al título de Doctor en Biología Molecular por la Universitat Pompeu Fabra

\section{PROMOTER-DRIVEN SPLICING REGULATION IN FISSION YEAST}

Trabajo dirigido por el Dr. José Ayté del Olmo

Oxidative Stress and Cell Cycle Group

Departament de Ciències Experimentals i de la Salut Programa de Doctorat en Ciències de la Salut i de la Vida Universitat Pompeu Fabra 


\section{AgRAdecimientos}


Durante toda esta tesis veía clarísimo todo lo que escribir en este apartado y ahora que llega el momento me quedo en blanco... Debe ser la presión de saber que va a ser la sección más leída...

Primero agradecer a José y a Elena el poder haber trabajado en este laboratorio durante este tiempo. Han sido casi dos tesis, sí, sí, mi primera página del cuaderno de laboratorio data del 19 de Abril del 2000, todavía recuerdo el primer día, lo primero que hice fue rotular eppendorfs con una temblorosa mano, cuántos nervios. Después de trabajar en muchos temas, momentos difíciles y agradables, odiosos y entrañables, mudanzas, meetings, reuniones, cenas y mil otros recuerdos que me llevo puedo decir que me va a costar estar lejos de este lugar. Un abrazo muy fuerte a los dos!!

Mis compañeros de laboratorio, pasados, presentes y futuros, desde aquel chico de la UAB que me enseñó como utilizar una enzima de restricción hasta el chico nuevo que todavía no conozco... No tengo palabras. Habéis sido mi familia todo este tiempo: A la pequeña Ester que me ha cuidado desde el principio como una hermana mayor. A Ana con la que el odio y el cariño se entrelazaban continuamente, muy buena conversadora y con gran ojo crítico. A Carine cuya breve estancia me dejó entrever que hay más de una manera de hacer ciencia. A Jordi (MalaP), compañero de adversidades y aventuras. A Mercè, cuyo apoyo logístico y moral ha sido imprescindible. A Alice, símbolo de la ternura y de la filología italiana, ya se sabe, a caballo donato... A Miriam, una de las mejores personas que conozco, sensata, seria y muy inteligente, una gran científica. A Mónica, maestra de artes marciales y colis. A Blanca, la dulzura personificada y buen público para los chistes. A Nati, también compañera de poyata, penas y alegrías, una post-doc todavía sin título. A Isabel, la catol... una gran amiga y compañera de ChIPs, tranquila que las cosas se van arreglando solas! A Sarela, un meiga pero de las buenas y a Iván (el granaíno), que con su corta pero intensa estancia nos alegró las largas horas de laboratorio. A todos gracias por apoyarme, aguantarme y porque nadie mejor que vosotros sabe lo que supone esta tesis.

Al resto de gente de la UPF, los vecinos de laboratorio, especialmente el laboratorio de Señalización Celular (o cariñosamente llamados "los posas") con los que hemos compartido más que un laboratorio, Inmunología (Mari, Bea, Mingui, Julia, Rosa, etc.), grandes amigos dentro y fuera de la UPF, y todos los demás grupos del departamento.

Siguiendo la ampliación de espacio, gracias también a toda la gente del PRBB que han ayudado a que estos años se hicieran más amenos. Gracias a ellos se materializó 
la mejor terapia antiestrés, el voley, gracias a los Rabenessen de Caramel (incluido Iván, sí, podrás venir al pica pica de mi tesis, jeje).

Gracias a mis compañeros de licenciatura, con ellos inicié este camino y espero seguir sendas cercanas a las suyas.

A la gente del laboratorio de Paul Nurse en New York, gracias por haberme hecho pasar una de las mejores experiencias de mi vida, gracias por las interminables charlas sobre ciencia y sobre la vida, por los consejos y el apoyo. Thanks Fran!!

Mención especial para Alba Diz, Laia Pibernat, Francesc López y Luis Magano. Que han sido unos grandes modelos a seguir y consejeros y que en la cercanía y la lejanía siempre han estado ahí para apoyarme en todo. Os quiero.

Al resto de gente que ha hecho posible este proyecto y que no están en primera página: A Montse, Enri y Chelo por su buen humor y su paciencia, a todos los de administración e incluso a Pepe y Manolo, que hacen los mejores bocadillos de baconqueso del mundo!

El mayor agradecimiento de todos, por méritos propios se lo lleva mi familia. A mis abuelos por poner esas velitas, a todos mis tíos y tías por el apoyo, a mi hermano porque sé que siempre estará ahí pero sobretodo a mis padres, porque sin ellos esto no sería más que un sueño. En mi corazón siempre sabré que esta tesis tiene tres co-autores y aunque sólo este escrito mi nombre también deberían aparecer el de Petra Vara y Martín Moldón. Os quiero! 
A mis padres, con todo el afecto del mundo 
$\mathrm{Si}$ es que cuando te pones hasta sacas resultados bonitos Alba Diz 
INDEX 
INTRODUCTION

Schizosaccharomyces pombe 3

Life Cycle of Fission Yeast

Vegetative Growth 6

$\underline{\text { Regulation of } \mathrm{Cdc} 2 \text { by phosphorylation }} \quad 6$

$\begin{array}{ll}\text { Regulation of Cde2 by cyclins } & 7\end{array}$

$\underline{\text { Regulation of Cdc } 2 \text { by other proteins }} \quad 8$

$\begin{array}{lr}\text { Sexual reproduction } & 9\end{array}$

$\begin{array}{ll}\text { Exit from mitotic cell cycle } & 9\end{array}$

$\begin{array}{ll}\text { Initiation of meiosis } & 9\end{array}$

a) G1 arrest 10

b) Ste11 expression $\quad 10$

The pheromone pathway 11

$\begin{array}{ll}\text { Meiotic cell cycle program } & 12\end{array}$

Different waves of expression 13

a) Starvation and pheromone-induced genes $\quad 13$

b) Pre-meiotic S phase and recombination genes $\quad 13$

c) Meiotic divisions and early steps of spore formation 14

d) Spore maturation $\quad 14$

Expression and selective elimination of meiosis-specific $\quad 14$ $m R N A s$ in vegetative growth

$\begin{array}{ll}\text { Forkhead transcription factors } & 16\end{array}$ 
$\begin{array}{ll}\text { General Mechanisms } & 19\end{array}$

$\begin{array}{ll}\text { Introduction } & 19\end{array}$

Molecular mechanisms 20

Regulation of splicing $\quad 22$

$\begin{array}{ll}\text { Alternative splicing } & 25\end{array}$

$\begin{array}{ll}\text { Inter-speccific splicing } & 27\end{array}$

Importance of studying splicing 28

Pre-mRNA splicing in Schizosaccharomyces pombe 29

$\begin{array}{ll}\text { Rem1 } & 33\end{array}$

$\begin{array}{ll}\text { OBJECTIVES } & 35\end{array}$

RESULTS 39

$\begin{array}{lr}\text { rem1 regulation } & 41\end{array}$

$\begin{array}{ll}\text { Transcription and splicing of rem1 } & 41\end{array}$

3’ UnTranslated Region $\quad 42$

5’ Splice site 42

Regulation by the same product 43

Promoter and 5' UnTranslated Region 44

Analysis of the promoter function $\quad 46$

Cis elements $\quad 46$

Trans elements 47

a) Forkhead transcription factors $\quad 47$ 
b) RNA polymerase II $\quad 51$

c) Splicing factors $\quad 53$

$\begin{array}{ll}\text { Protein stability } & 55\end{array}$

Regulation of other meiotic intron-containing genes 57

$\begin{array}{lc}\text { Mei4 and Fkh2 regulation } & 61\end{array}$

$\begin{array}{ll}\text { Transcription of mei4 and fkh2 } & 61\end{array}$

$\begin{array}{ll}\text { Protein expression of Mei4 and Fkh2 } & 61\end{array}$

$\begin{array}{ll}\text { Phosphorilation by Cig2 } & 62\end{array}$

$\underline{\text { in silico structure of Mei4 and Fkh2 }} 65$

$\begin{array}{ll}\text { Rem1 function } & 67\end{array}$

$\begin{array}{ll}\text { Cyclin function } & 67\end{array}$

$\begin{array}{ll}\text { Recombination function } & 68\end{array}$

MATERIALS AND METHODS $\quad 71$

$\begin{array}{ll}\text { Methodology } & 73\end{array}$

$\begin{array}{lr}\text { Strains } & 80\end{array}$

$\begin{array}{lr}\text { Plasmids } & 81\end{array}$

$\begin{array}{lr}\text { Oligonucleotides } & 82\end{array}$

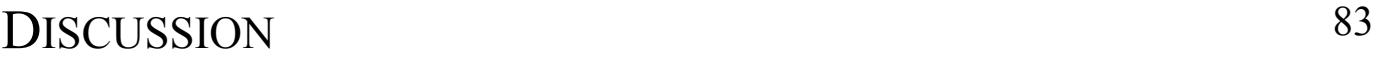

$\begin{array}{lr}\text { rem1 regulation } & 85\end{array}$

Regulation of other meiotic intron-containing genes 88

$\begin{array}{lr}\text { Mei4 and Fkh2 regulation } & 89\end{array}$

$\begin{array}{lr}\text { Rem1 function } & 91\end{array}$ 
CONCLUSIONS

BIBLIOGRAPHY 


\section{INTRODUCTION}

Figure 1. The fission yeast Schizosaccharomyces pombe has become today one of the most important model organisms.

Figure 2. Complete cell cycle of Schizoscharomyces pombe.

Figure 3. Two independent kinase pathways are needed to exit mitotic cell cycle.

Figure 4. The pheromone pathways.

Figure 5. Different waves of transcription at meiosis

Figure 6. Structure of the Forkhead domain.

Figure 7. Schematic representation of introns and pre-mRNA splicing.

Figure 8. Dynamics of the spliceosome

Figure 9. Splicing silencers and enhancers

Figure 10. Function of the RS-domain-containing

Figure 11. Involvement of RNA pol II in different steps of pre-mRNA

processing

Figure 12. Two alternative models for putative interactions between SR proteins bound to an exon enhancer (SE ,hatched box) with transcription proteins.

Figure 13. Representation of the four known models of alternative splicing. 
Figure 14. Aligment of the cyclin domain of rem1 and three other B-type cyclins 33 of S. pombe.

Figure 15. Characterization of Rem1.

\section{RESULTS}

Figure 1. Gene structure of rem1

Figure 2. rem $1 \mathrm{mRNA}$ splicing is not dependent on the 3 ' region of the gene.

Figure 3. Analysis of the 5' Splice Site (SS).

Figure 4. Regulation of the splicing by Rem1 protein

Figure 5. Analysis of the 5' region of rem1 gene.

Figure 6. rem1 promoter controls other genes' splicing

Figure 7. rem1 promoter controls splicing

Figure 8. Mutations at the FLEX boxes alter transcription and splicing of rem1

Figure 9. Analysis of different Forkhead Transcription Factors mutants.

Figure 10. mei4 expression in a $\Delta f k h 2$ strain.

Figure 11. Genetic interaction between Mei4 and Fkh2 in vivo.

Figure 12. In vitro binding to the FLEX motives.

Figure 13. Mei4 and Fkh2 bind to rem1 in vivo.

Figure 14. Recruitment of the RNApolymerase II is mei4-dependent

Figure 15. Loading of U1·70k, Prp11 and Cdc5 to rem1 locus depends on Mei4. 53

Figure 16. Mei4 coprecipitates with U1·70K, Prp11 and Cdc5.

Figure 17. Rem1 degradation by Mfr1.

Figure 18. Microarray analisys 
Figure 19. Validation of the candidates found.

Figure 20. Relative position of FLEX boxes. 59

$\begin{array}{lr}\text { Figure 21. FLEX consensus box. } & 60\end{array}$

Figure 22. mRNA levels of mei4 and $f k h 2$ during meiosis. 61

Figure 23. Mei4 and Fkh2 are phosphoproteins 62

Figure 24. Phosphorylation of Fkh2 by Cig2. 62

Figure 25. Cig2 phosphorylates Fkh2 at Ser481 in vitro. 63

Figure 26. Serine 481 of Fkh2 is necessary for the Cig2 specific phosphorylation 64 at meiosis I.

Figure 27. 3D structure of the DNA-binding domain of Mei4 and Fkh2. 65

Figure 28. Model of the Mei4 and Fkh2 binding to the DNA. 66

$\begin{array}{ll}\text { Figure 29. Cyclin function of Rem1 } 67 & 67\end{array}$

Figure 30. The second exon of Rem1 is not needed to have normal 68

recombination levels

\section{DISCUSSION}

Figure 1. Model of the Fkh2-Mei4 regulation of rem1 


\section{INTRODUCTION}




\section{Schizosaccharomyces pombe}

The yeast known as Schizosaccharomyces pombe was first described by P. Lindner in 1893 after isolating it from an East Africa beer. The name derives from the Swahili word for beer, pombe. S. pombe forms a rod-shaped non-motile cell that grows by elongation and divides by medial fission with a doubling time of 2-4 hours in simple culture conditions (Forsburg). It was originally classified as a fungus from the family of ascomycete due to its capacity to produce asci. Recently, it has been shown by DNA and RNA sequence analysis to differ phylogenetically from the other known budding yeast Saccaromyces cerevisiae as much as from humans (2004). The complete taxonomic classification is:

Cellular organism

Eukaryota

Fungi/Metazoa group

Fungi

Dikarya

Ascomycota

Taphrinomycotina

Schizosaccharomycetes

Schizosaccharomycetales

Schizosacharomycetaceae

Schizosaccharomyces
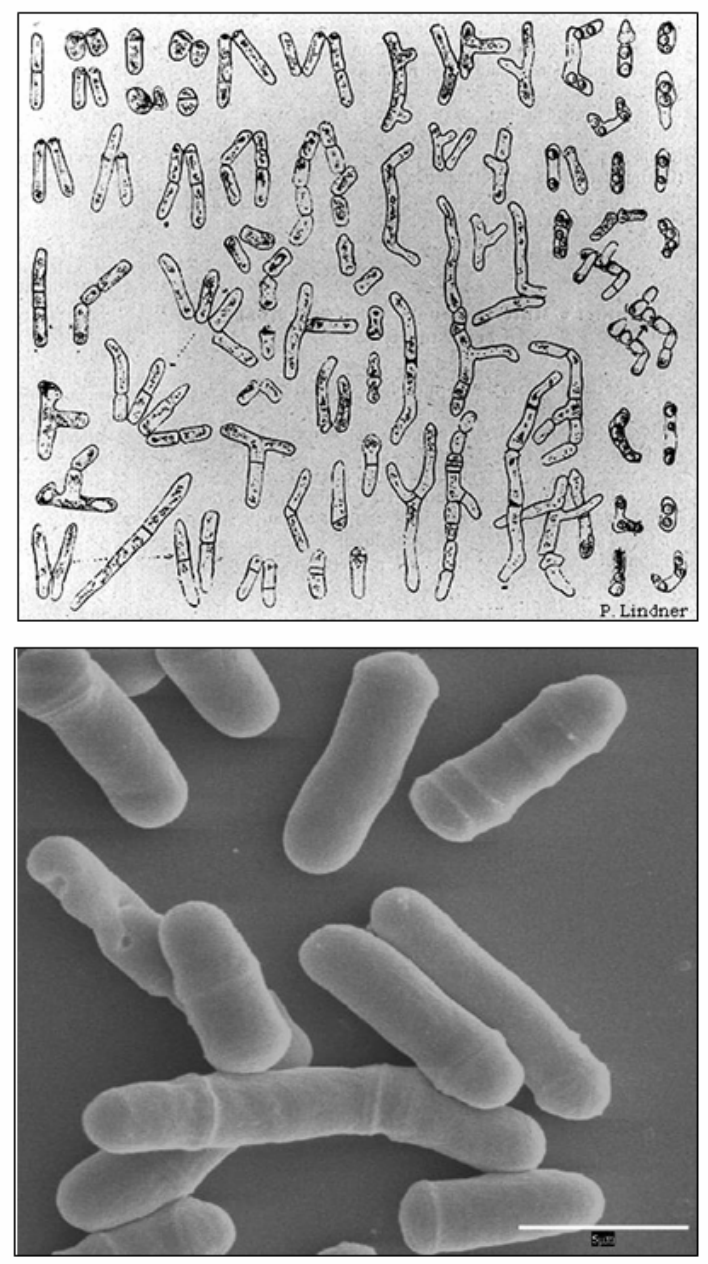

Figure 1. The fission yeast Schizosaccharomyces pombe has become today one of the most important model organisms.

Upper pannel, Lidner's draw of the isolated strain. Lower pannel, scanning electron microscopy image of some $S$. pombe cells.

\section{Schizosaccharomyces pombe}

The genetic material of $S$. pombe is organised in three chromosomes. The entire genome is completely sequenced containing 4824 genes in about $14 \mathrm{Mb}$ of total DNA, making it the smallest free-living eukaryote (Wood et al., 2002). The S. pombe genome does not have many duplicated genes, making functional genetics very approachable. 
Significantly, several groups of genes are conserved in S. pombe and humans, but missing in S. cerevisiae, including genes involved in heterochromatin and telomere function, some splicing genes, and components of the RNAi machinery (2004).

With simple culture conditions, $S$. pombe is easily adapted to any molecular biology laboratory. At present, S. pombe is one of the most important model organisms to study multiple cellular processes, such as cell cycle regulation, metabolism, cell signaling, transcription, splicing... The main reasons for this are its easy growing, maintainance and manipulation in the laboratory and its great molecular similarity to higher eukaryote cells. In the 50s, Murdoch Mitchison started his studies in cell cycle, cell division and growth; in the 70s this studies were linked with Paul Nurse's genetic approach and this led up to well-earned recognition by the award of the 2001 Nobel Prize (2004).

S. pombe is also known as fission yeast because its division is by bipartition. The study of the cell cycle is based basically in this type of division: microscopically it is possible to know in which cell cycle phase a cell is or in which moment of the cell cycle the cell is misfunctioning. 


\section{Life Cycle of fission yeast}

During normal growing conditions, S. pombe can proliferate through mitotic cell cycles as a haploid cell, but this is just one of the three alternative fates that $S$. pombe may choose depending on the environmental conditions. When nutrient availability is reduced, fission yeast can undergo quiescent stationary phase (glucose deprivation) or conjugate with a cell of the opposite mating type and undergo meiosis (nitrogen deprivation). After conjugation, cells can grow as diploids if the media conditions change and enter in a diploid mitotic cycle, although they are very unstable and tend to haploidize. Meiotic progression finishes with the formation of spores that are specialized cells prepared to resist unfavourable environmental conditions. When the conditions improve, spores can germinate and re-enter mitotic cell cycle as haploid cells.

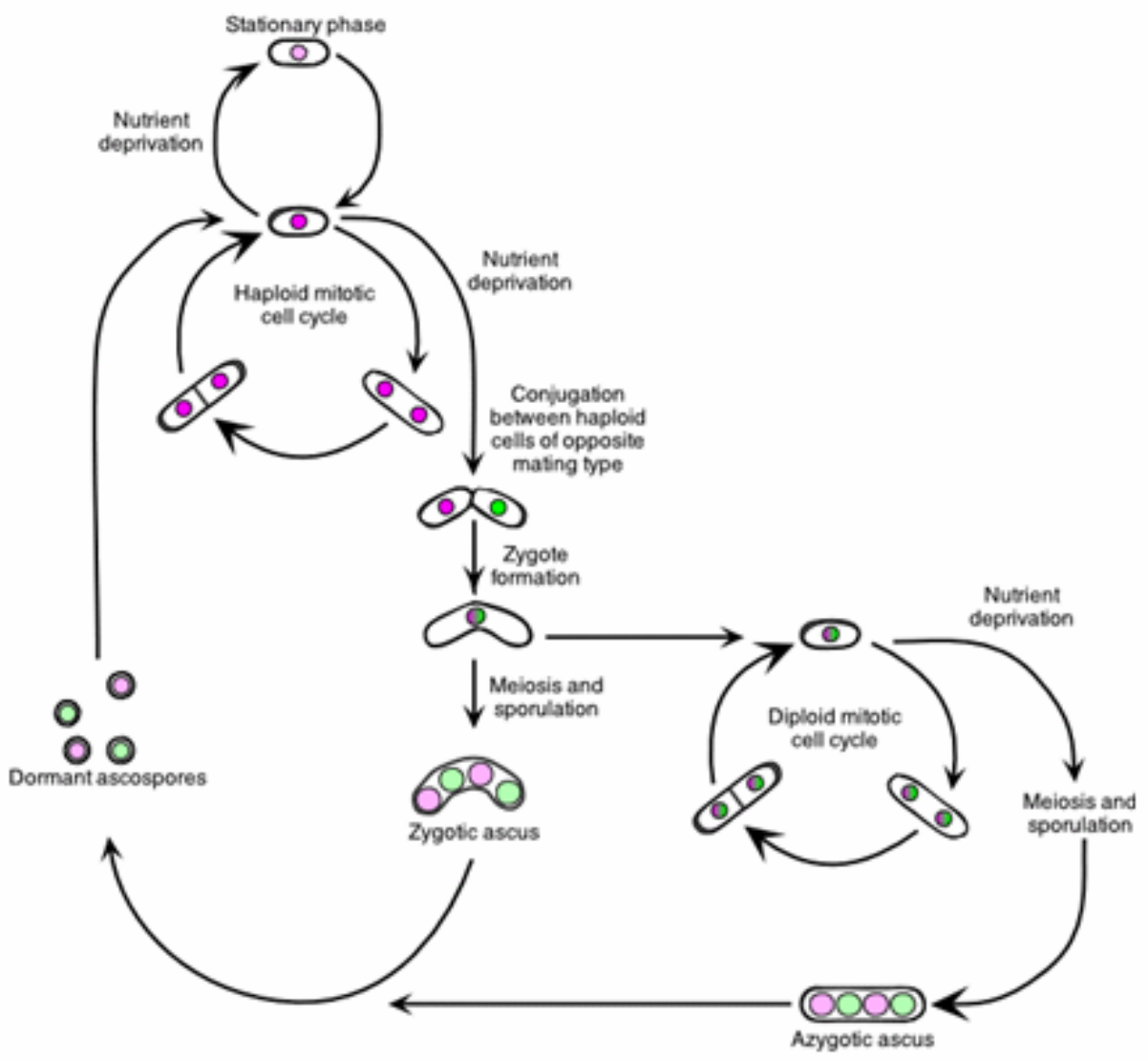

Figure 2. Complete cell cycle of Schizosccharomyces pombe. 


\section{Vegetative growth}

Schizosaccharomyces pombe has a typical cell cycle, with an S phase when DNA replicates and an $\mathrm{M}$ phase when the cell segregates the chromosomes into two different nuclei. These two phases ( $\mathrm{S}$ and $\mathrm{M}$ ) alternate with cell growing gaps, known as G1 and G2. Noticeably, the cytokinesis takes place just before next cycle S phase, so daughter cells remain together during nearly all G1 phase (2004).

During the vegetative growth, the onset of $\mathrm{S}$ and $\mathrm{M}$ phases is under tight regulation to ensure that they alternate and that they are coupled in the right order (Moser and Russell, 2000). There are more than 100 protein kinases in S. pombe that are have a function in cell cycle progression but none of them is as important as Cdc2 (Homo sapiens Cdk1). Cdc2 is the unique cyclin-dependent kinase (CDK) in S. pombe and is required for both DNA replication and mitosis (Nurse and Thuriaux, 1980). Fission yeast cells require $\mathrm{Cdc} 2$ for passage through Start (restriction point in higher eukariots), at which cells commit to progress throught the mitotic cell cycle. Cdc2 is also essential for the G2-M transition, at which cells initiate the processes of chromosome segregation and cytokinesis (Nurse and Bissett, 1981).

Thought $\mathrm{Cdc} 2$ abundance is invariant during the cell cycle, its activity fluctuates, being low during G1 phase, moderate during S and G2 phases and high during M phase. This activity is regulated by phosphorylation, inhibitor proteins (CKIs) and mainly by its associated cyclins (Alfa et al., 1989).

\section{$\underline{\text { Regulation of Cdc2 by phosphorylation }}$}

The specific phosporylation status of the cyclin/Cdk complexes is very important for their function in any living organism. While Cdc2 phosphorylation in Threonine 167 (T167) of the T-loop is necessary for its activity (Gould et al., 1998), the phosphorylated form of Tyrosine 15 in the ATP-binding domain inhibits its function (Gould and Nurse, 1989).

Cdc2 Y15 dephosphorylation is essential to trigger mitotic entry. This is a key

target for checkpoints in case of unreplicated or damaged DNA. This Y15 phosphorylation is carried out by the kinases Wee1 and Mik1. In the absence of these 
kinases Cdc2 activity cannot be inhibited and cells undergo mitotic-catastrophe because of its uncontrolled premature entry into mitosis (Russell and Nurse, 1987). At the same time there are other proteins controlling the activity of Wee1 and Mik1. Wee1 is inhibited by Cdr1 as a response to nutrients limitation (Belenguer et al., 1995) and Mik1 activity is regulated in response to S-phase checkpoints.

On the other hand, $\mathrm{Cdc} 25$ is the most important phosphatase that dephosphorylates this residue. Cdc25 is also a target of checkpoint kinases that inhibit its funtion. Cdc25 accumulates just before $\mathrm{M}$ phase and its levels decrease after mitosis (Gautier et al., 1991).

\section{$\underline{\text { Regulation of Cdc2 by Cyclins }}$}

The only essential cyclin in S. pombe is Cdc13, a member of the B-type cyclin family. Cdc13 abundance is low in G1 and increases during G2 until Anaphase, when its ubiquitin-directed degradation is necessary to separate sister chromatides. Cdc13 degradation is directed by proteins from the APC complex, which recognize the Destruction Box (DB) present in some cyclins. Three known APC-complex proteins in S. pombe are Slp1, in mitosis, Ste9, in G1 and Mfr1/Fzr1 present during meiosis and sporulation (Asakawa et al., 2001; Blanco et al., 2001; Kitamura et al., 1998; Matsumoto, 1997; Yamada et al., 2000; Yamaguchi et al., 1997). Cdc13 main function is to promote the events of mitosis and avoid re-initiation of $\mathrm{S}$ phase (endoreduplication).

S. pombe has two other B-type cyclins, Cig1 and Cig2. They are important in G1/S transition, when the kinase activity of the Cdc2/Cig2 complex peaks. Cig1 also participates in G1 although is a minor cyclin whose function is still not very well understood (Fisher and Nurse, 1996; Martin-Castellanos et al., 1996; Mondesert et al., 1996). Pucl is another S. pombe G1 cyclin and it is supposed to couple initiation of $\mathrm{S}$ phase to the achivement of a critical size although its role is covered, under physiological conditions, by the function of Cig1 and Cig2 (Martin-Castellanos et al., 2000).

Importantly, Cdc13 can substitute all of the other cyclins. A cig1-cig2 double deletion or a cig1-cig2-puc1 triple deletion only causes a small delay at the G1/S 
transition while cells with a cdc13-cig1-cig2 triple deletion cannot perform DNA synthesis.

\section{$\underline{\text { Regulation of Cdc2 by other proteins }}$}

Cdk proteins can also be regulated by inhibitors (CKIs). Rum1 inactivates $\mathrm{Cdc} 2 / \mathrm{Cdc} 13$ and $\mathrm{Cdc} 2 / \mathrm{Cig} 2$ complexes in G1. Its function is necessary for cells to arrest in G1 in response to mating factors (pheromones) and conjugate (Labib and Moreno, 1996; Martin-Castellanos and Moreno, 1996; Moreno and Nurse, 1994). Cdkactivating kinases (CAKs) phosphorylate T167, activating the Cdks. This phosphorylation increases the interaction between $\mathrm{Cdc} 2$ and the different cyclins. In $\mathrm{S}$. pombe, the Mcs6/Mcs2 complex is able to phosphorylate (at least partially) Cdc2. In fission yeast, Csk1 is also considered a CAK protein because phosphorylates $\mathrm{Cdc} 2$, although some authors consider Csk1 as a CAKAK (CAK Activating Kinase) because can phosphorylate and activate Mcs6, which has a Cdk protein structure. 


\section{Sexual Reproduction}

Under conditions of nutritional deprivation, specially the nitrogen source, fission yeast differenciate into ascospores. Spores represent a dormant state which is more resistant to unfavorable conditions. In this process, haploid G1 cells of opposite mating types $\left(\mathrm{M}\right.$ or $\mathrm{h}^{-}$and $\mathrm{P}$ or $\left.\mathrm{h}^{+}\right)$first mate to form a diploid zygote which will undergo meiosis and sporulation. This process will give rise to four haploid spores that will germinate when the nutritional conditions improve. Meiosis drives a specialized cell cycle that consists of one round of of DNA synthesis followed by two successive rounds of $M$ phase and is the main exception to the otherways tight $S / M$ alternancy.

Meiotic differentiation includes complex progressive events. It can be divided into two parts: 1) exit from the mitotic cell cycle and 2) induction of the alternative cell cycle program. The former has been characterized as a complex network of activator and inhibitor factors which are regulated at different levels of transcription, posttranslational modifications and degradation (Yamamoto, 1996). This network also involves many feedback loops to intesify the commitment of meiosis.

The latter process is achived by a highly coordinated transcription induction of numerous genes that are specifically required for meiosis (Mata et al., 2002). These genes codify products required (1) to modify the basic machinery that operates in the mitotic cell cycle to ensure the DNA synthesis is followed by the two successive nuclear divisions and (2) to reorganize the cell and nuclear morphology to give rise to an asci containing four haploid spores.

\section{$\underline{\text { Exit from mitotic cell cycle }}$}

The initiation of meiosis is mediated by two signal transduction patways, one responding to the nutritional deprivation and the other to the mating pheromones.

\section{Initiation of meiosis}

After Nitrogen starvation, Tor2 kinase appears to decrease its activity inducing the switch between cell growth and cell differentiation (Alvarez and Moreno, 2006; 
Uritani et al., 2006; Weisman et al., 2007). Nitrogen starvation results in the G1 arrest and the transcriptional activation of ste11 (Maeda et al., 1990; Mochizuki and Yamamoto, 1992; Sugimoto et al., 1991):

a) Starvation-induced G1 arrest requires the inactivation of the Cdc2-Cig2 complex, which promotes S phase and the Cdc2-Cdc13 complex, which can take over Cig2 function in its absence (Fisher and Nurse, 1996). Degradation of Cig2 delays G1/S transition, which allows the accumulation of Rum1. Rum1 will promote the degradation of both cyclins via APC/Cste9 (Correa-Bordes and Nurse, 1995).

Both PKA and Sty1 pathways are necessary to promote this degradation: A reduction in PKA activity relieves the inhibitory phosphorylation of APC/C facilitating the degradation of Cig2 and Cdc13. Starvation of nutrients activates the stressresponsive Sty1 MAPK pathway (Shiozaki and Russell, 1997). The mechanism by which the stress pathway induces the G1 arrest is not yet known. It has been recently proposed, based in the fact that nitrogen starvation speeds up mitosis, that rapid mitosis results in smaller newborn G1 cells. These small newborn cells stay longer in $\mathrm{G} 1$ since it takes longer to reach the critical size to enter $\mathrm{S}$ phase. Thus, the length of G1 is increased, leading to the accumulation of Rum1 and the CDK inhibition.

b) Ste11 is a transcription factor that activates genes requiered for pheromone communication, mating and meiosis. Both, PKA and stress pathways are responsible fot the induction of Ste11 expression: Rst1, a target of PKA is inactivated when is phosphorylated by PKA (Higuchi et al., 2002). The unphosphorylated form of Rst1 stimulates transcription

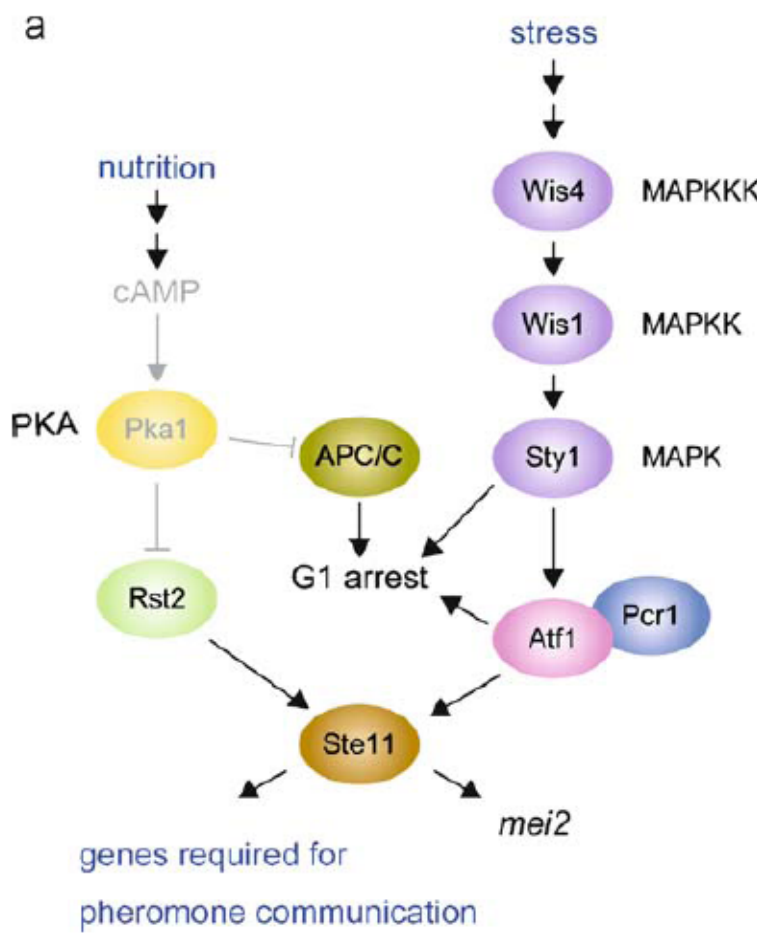

Figure 3. Two independent kinase pathways are needed to exit mitotic cell cycle.

Pka pathway promotes Cig2 degradation and Sty1 pathway promotes Ste11 transcription, although both patwayhs form an interconnected network. 
of ste11. Atf1, a substrate of the stress MAPK Sty1, forms a heterodimeric transcription factor with Pcr1, which also regulates ste11 transcription.

\section{The pheromone pathway}

The pheromone system in fission yeast is based on the reciprocal recognition of specific proteins by the other mating type cell. S. pombe cells have two mating types; $\mathrm{h}^{+}$or $\mathrm{h}^{-}$. This is genetically determined by the mat1 locus (Egel, 1976b). In $\mathrm{h}^{+}$cells, two different genes are expressed from the mat1 locus: mat1-Pc, which controls the sexual differentiation, and mat1-Pm, which controls the initiation of meiosis. Similarly, $\mathrm{h}^{-}$cells express mat1-Mc, which also controls the sexual differentiation, and mat1-Mm, needed to enter meiosis (Kelly et al., 1988).

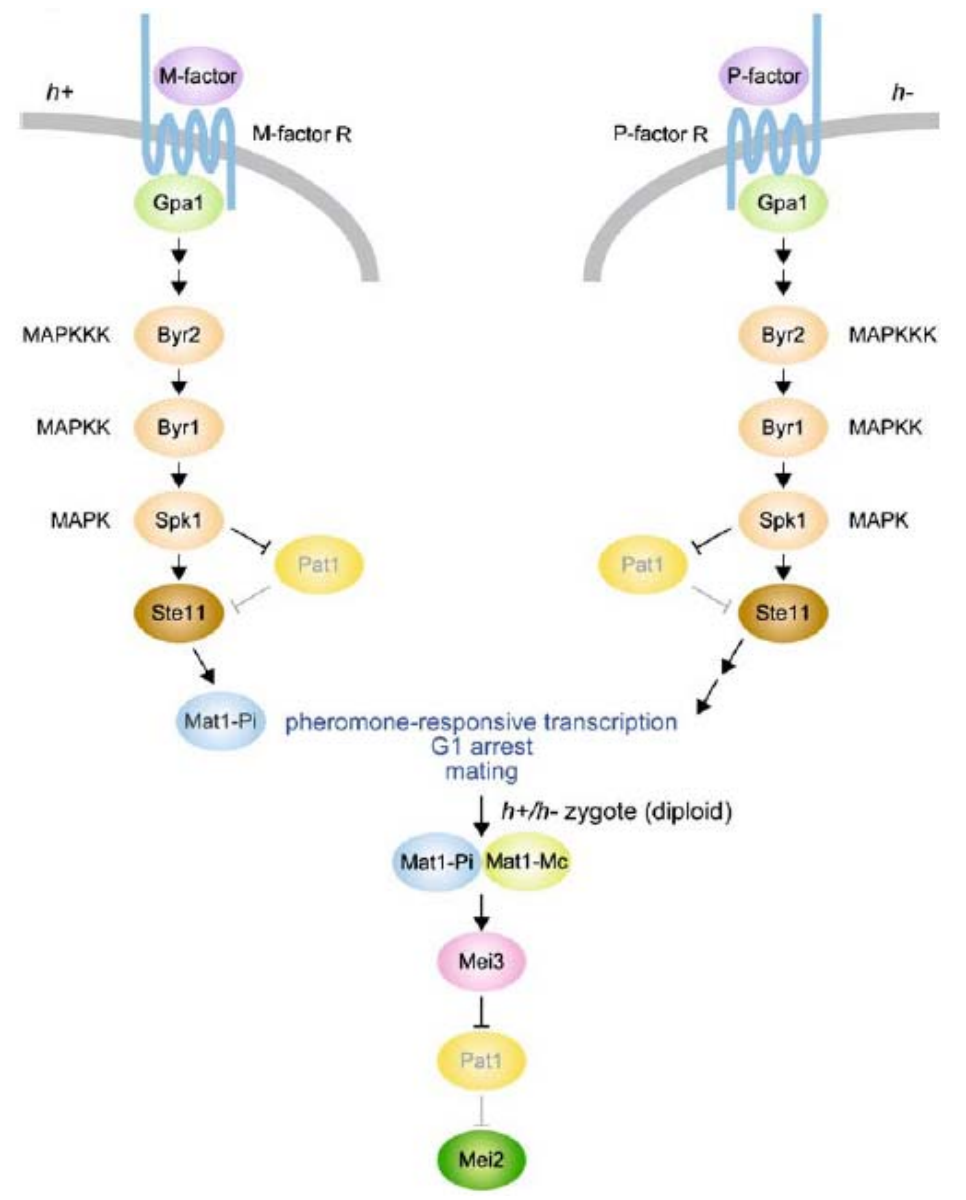

\section{Figure 4. The pheromone} pathways.

Both pheromone pathways activate when two opposite mating type cells conjugate. Binding of the opposite pheromone to the receptor triggers a MAPK cascade that triggers Ste11 transcription and inhibit the kinase Pat1. After the mating and the conjugation has taken place, Mat1-Pi and Mat1-Mc heteodimer promote Mei3 transcription which will avoid the inhibitory phosphorylation of Pat1 to Mei2..

The original isolated S. pombe strain was a homothallic $\mathrm{h}^{90}$ strain (opposed to $\mathrm{h}^{-}$ or $\mathrm{h}^{+}$heterothallic strains), in which cells were switching from $\mathrm{h}^{+}$to $\mathrm{h}^{-}$and viceversa. Changes in the mat1 locus genetic information are controlled by the mat2-P and mat3$M$ genes. Transposing of the genetic material is the basis of this mechanism and it is 
called "switching". mat2- $P$ and mat3- $M$ are never transcribed because they are located in areas of silenced chromatin. These two genes are limited by homologue sequences also found in the boundaries of the mat1 locus. These regions of homology will allow the recombination and the switch of information of mat1 locus (Egel, 1976a). The switching is performed in the second generation of daughter cells. During DNA replication in S-phase, a single stranded break (SSB) is produced at the mat1 locus and as a consequence one of the daughters will be switchable for changing its mating type (Arcangioli, 1998). Afterwards, this daughter cell will produce a double strand break in the mat1 locus permitting the recombination with mat2-P or mat3-P and switching the mating type of the cell.

The reciprocal binding of the pheromones to their receptors leads to the activation of the Spk1 MAPK pathway which also induces ste11 expression. Ste11 is the transcription factor of the master regulator of meiosis, Mei2. Mei2 is kept inhibited during vegetative growth by the kinase Pat1. After mating, in the zygote, Mat1-Pm $\left(\mathrm{h}^{+}-\right.$ specific) and Mat1-Mm ( $\mathrm{h}^{-}$-specific) form a heterodimeric transcription factor that cooperatively induce the transcription of mei3. This cooperation is important to assure that meiosis will only be induced in heterozygous diploid cells. Mei3 binds and inhibits the Pat1 kinase (McLeod and Beach, 1988; Van Heeckeren et al., 1998) thereby liberating Mei2 from the inhibitory phosphorylation and triggering the initiation of meiosis. There is a mutant Pat1 protein commonly used in the laboratory to perform sincronous meiosis: the pat1-114 mutant allele encodes a temperature-sensitive version of Pat1 that becomes inactive at high temperature inducing ectopic meiosis even in haploid cells (Iino and Yamamoto, 1985).

\section{$\underline{\text { Meiotic cell cycle program }}$}

At the level of cyclin-cdks complexes, meiosis is regulated differentially depending on the meiotic step. As in the mitotic cell cycle, $\mathrm{Cdc} 2$ is essential to drive the meiotic G1/S transition and the

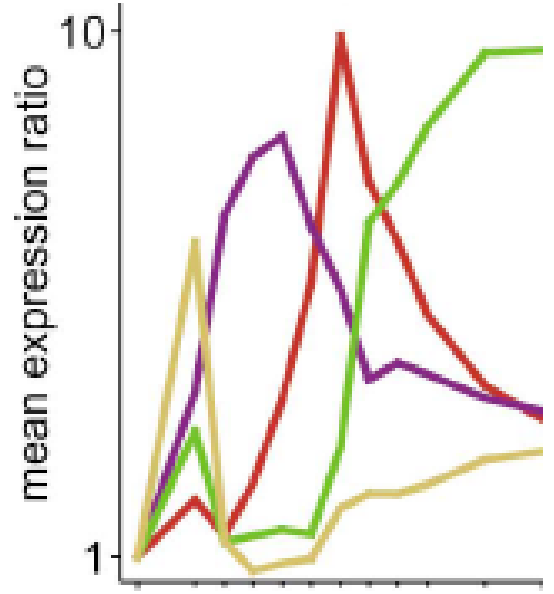

Figure 5. Different waves of transcription at meiosis. Yellow line represents early genes, purple line represents S-phase genes, red line represents meiosis I genes and green line represents meiosis II and sporulation genes (Mata et al., 2002). 
second meiotic division and is not clear its role during the first meiotic division (Iino et al., 1995). Regarding its cyclin partners, $\mathrm{Cdc} 2$ is bound to Cig2 to promote pre-meiotic S phase (Borgne et al., 2002) and to Cdc13 in the two meiotic divisions. In spite of the cyclin-cdk complexes regulation, meiosis is strongly regulated by several waves of transcription factors.

\section{Different waves of expression}

The transcriptional program that drives sexual differentiation in S. pombe was studied extensively by the Bähler group using microarrays technology (Mata et al., 2002).

They found that the expression of hundreds of genes is modulated in successive waves during meiosis and sporulation and several known transcription factors are critical for these processes. All the genes that are upregulated during meiosis can be classified in four clusters, according to their time of transcription. These clusters represent successive waves of expression coinciding with the most important biological events of meiosis:

a) Starvation and pheromone-induced genes

This group is mainly regulated by the Ste11 transcription factor. These genes participate in the pheromone patway and the first stages of meiosis.

b) Pre-meiotic $\mathrm{S}$ phase and recombination genes

During pre-meiotic S phase, two subclusters of genes are simultaneously expressed. (1) A group that is also expressed in mitotic G1 phase, required for DNA synthesis (cdc18, cdt1, cdc22...) and (2) a meiosis-specific group involved in recombination (rec genes) (Fox and Smith, 1998; Mata et al., 2002). Both groups are regulated by the MBF (MluI-binding factor) complex. This complex is formed by Cdc10, Res1, Res2 and the meiosis-specific Rep1 protein. This transcription factor regulates aproximately $53 \%$ of the genes needed in this meiotic step. 
c) Meiotic divisions and early steps of spore formation

The forkhead-family transcription factor Mei4 is essential for progression through the first meiotic division and has been reported to activate the expression of some middle genes. $55 \%$ of the middle genes are completely Mei4-dependent and this percentage increases until 92\% if expression-reduced genes are considered (Mata et al., 2007). Cdc25 is under the regulation of Mei4 and its expression is necessary to progress through the meiotic divisions. $\Delta$ mei4 strains are blocked just before meiosis I, but cells can undergo meiosis if Cdc25 is expressed ectopically (Murakami-Tonami et al., 2007).

d) Spore maturation

The late-genes cluster is regulated by two bZIP transcription factors, Atf21 and Atf31. They control the expression of aproximately $55 \%$ of the sporulation genes. Atf 21 and Atf 31 seem to cooperate to induce this cluster of genes, probably by forming a heterodimer.

The alternation between transcriptional waves also requires that each wave is inactivated before the following wave is induced. It was found that the reduction in the levels of early genes that normally coincides with the induction of the middle genes did not occur in $\Delta$ mei4 mutants. This effect has been previously observed for a small number of recombination genes. Similarly, Rep1, which is involved in the activation of a subset of early genes, is specifically required for the down-regulation of some of the genes induced in response to nitrogen starvation and pheromone signaling following entry into meiosis. These dependencies between transcription factors ensure the ordered, uni-directional succession of transcriptional waves.

Expression and selective elimination of meiosis-specific mRNAs in vegetative growth.

Until now, there have been descrived three mechanisms to control ectopic expression of meiotic-specific genes. The most important mechanism is based on the 
absence/presence of specific transcription factors. For example Mei4, a general transcription factor of mid-meiosis genes is not present in mitotic cell cycle and is highly expressed on the onset of meiosis I.

It has recently been described that some meiotic-specific mRNAs, such as mei4 and rec8 mRNAs have a cis-acting region in the 3' end of the gene called DSR (determinant of selective removal) which is responsible for the block of the mRNA accumulation in vegetative growing cells (Harigaya et al., 2006). Mmil binds DSRcontaining mRNAs promoting their degradation by the exosome. mmi1 deletion is lethal which indicates that this system is not a mere safeguard mechanism to avoid accidental transcription of these genes, rather, cells should keep the system constantly active to curtail the expression of meiotic genes.

Another mechanism to avoid expression is based in the fact that some meioticspecific genes contain introns. Genes such as rem 1 and crs 1 are only spliced in a very specific temporal window before meiosis I. Their transcription is mainly Mei4dependent but in mitotic growing cells and in early stages of meiosis splicing seems to be actively repressed (Averbeck et al., 2005; Malapeira et al., 2005). 


\section{Forkhead transcription factors}

The Forkhead Domain, also known as Winged Helix, is a B-DNA binding structure present in proteins of many different organisms, we can find them in eukaria, prokaria, and virus. Its structure was determined in 1993 (Clark et al., 1993) by X-ray crystallography. Forkhead transcription factors are part of the family of helix-turn-helix binding proteins (Gajiwala and Burley, 2000). Forkhead domain interacts with the DNA backbone throught direct and watermediated major and minor groove base contacts. The central alfa helix (H3) contacts the major groove of the DNA while the two "wings" (W1 and W2) (formed by alfa helixs, beta strands and random coiled aminoacids) contact the base pairs in the minor groove of the DNA.(Gajiwala and Burley, 2000)

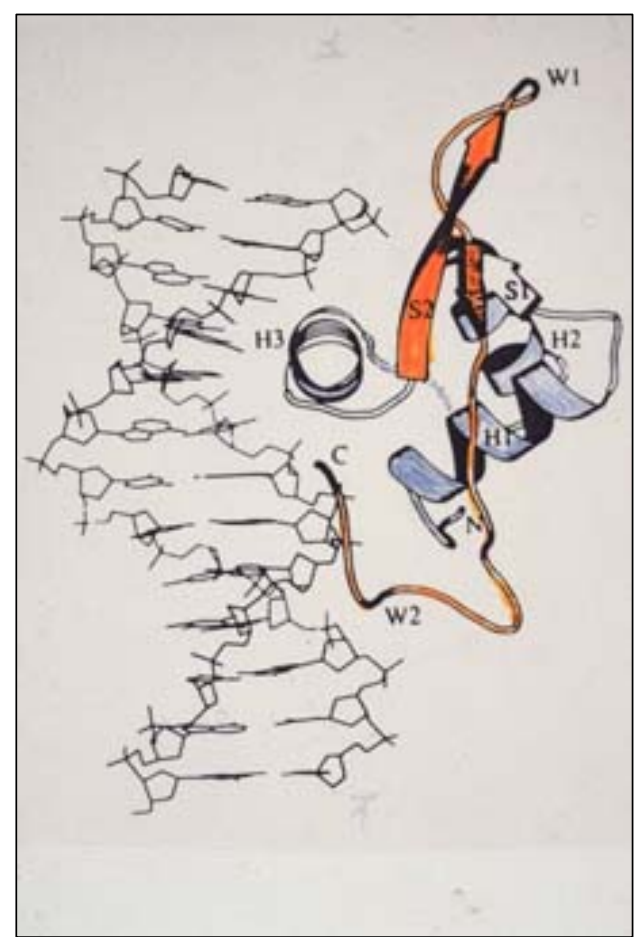

Figure 6. Structure of the Forkhead domain. Helix 3 (H3) is shown binding to the major groove of the DNA, Wing 1 (W1) and Wing 2 (W2) contact the minor groove and recognize de DNA sequence.

Members of the forkhead-box family of transcription factors are present in almost all eukaryotes but not in plants (Mazet et al., 2003). More than 50 proteins that share homology in the winged-helix DNA-binding domain have been identified in higher eukaryotes (Shimada et al., 2007). This family of transcription factors is implicated in the regulation of a variety of cellular processes, including cell cycle, apoptosis, DNA repair, stress resistance, aging and metabolism.

In the human genome at least 100 genes encoding forkhead domains can be found, classified in many subgroups depending on the sequence (Mazet et al., 2003).

Due to the great range of functions of this family, the pathology associated to them is also really broad. FOXO subfamily, for example is implied in diabetes, obesity 
and other metabolic failures, neurodegeneration and cancer (Partridge and Bruning, 2008).

In budding yeast there are 4 genes of this family. FKH1, FKH2 and HCM1 participate in the regulation of various cell cycle processes (Kumar et al., 2000), FKH1 and $\mathrm{FKH} 2$ coordinate in opposing ways elongation and concomitant phosphorylation of Ser2 of the CTD domain of RNApol II (Morillon et al., 2003). FHL1 and IFH1 are part of the rRNA processing machinery, these two members bound the DNA through an anchoring protein called RAP1 (Hermann-Le Denmat et al., 1994),(Rudra et al., 2007).

In fission yeast there are also 4 forkhead transcription factors. Fkh2, Fhl1, Sep1 and Mei4. The two former contain a Forkhead domain and a Forkhead associated domain (FHA) while the two latter contain just the Forkhead domain (Szilagyi et al., 2005).

Sep1 is a transcription factor that regulates cytokinesis and septation, it seems to be the link between nuclear and cell division (Grallert et al., 1998),(Ribar et al., 1997).

Fkh2 has many functions, sometimes opposite functions have been descrived. It is involved in septum formation, cytokinesis, nuclear structure and mitotic spindle function (Bulmer et al., 2004). It was also suggested that Fkh2 was implicated in the periodic gene expression of M and G1 phases (Buck et al., 2004), (when it is phosphorylated (Buck et al., 2004)) by negatively regulating the transcription of a cluster of genes (Rustici et al., 2004). The null mutant displays longer length, coldsensitive, heat-sensitive and slow-growing phenotypes (Buck et al., 2004),(Bulmer et al., 2004). Regarding meiosis, a null mutant presents low levels of ste11 mRNA, dephosphorylation at Fkh2 residues T314 and S462 is required for binding to ste11 promoter region and induction of ste11 transcription during nitrogen starvation (Shimada et al., 2007).

The function of Fhll is still not very well understood. The null mutant is more resistant to Methyl methanesulfonate treatment compared to wild type. The homologous protein in S. cerevisiae is involved in rRNA transcription and processing (Rudra et al., 2007). 
Mei4 is the main transcription factor of mid-meiosis (Mata et al., 2002) and it is also a repressor of the previous transcriptional wave in meiosis (Mata et al., 2007). It is necessary to complete meiosis I because it controls the transcription of $\mathrm{Cdc} 25$, necessary for this progression (Murakami-Tonami et al., 2007). Its expression is completely avoided in vegetative growing cells by specifically degradation of meiotic mRNAs by the mmi1 system (Harigaya et al., 2006). Mei4 has been reported to bind in vitro to the FLEX motif GTAAAYA (Horie et al., 1998). 


\section{Splicing}

One of the most important conclusions of the post-genomic era is that in spite of the limited number of genes, a great protein complexity can be achieved. Mechanistically is possible that one gene can increase its coding capacity to many protein products, pre-mRNAs have alternative coding (exons) and non-coding sequences (introns) that can be processed combinatorially to increase the protein output variability. An extreme example is the Drosophila Dscam gene, which codes for a cell surface protein involved in neuronal connectivity. Its pre-mRNA is alternatively spliced and can potentially generate 38.016 different protein isoforms, more than twice the number of genes in the entire Drosophila genome.

\section{$\underline{\text { General mechanisms }}$}

\section{Introduction}

Most primary messenger RNA transcripts (pre-mRNAs) of RNA polymerase II in eukaryotes contain intervening sequences that must be precisely removed to generate a functional mRNA. The excision of the intervening sequences, the introns, from a premRNA and the concomitant joining of the flanking sequences, the exons, is called premRNA splicing. Pre-mRNA splicing takes place in large highly dynamic ribonucleoprotein (RNP) complexes, the spliceosome. It consists of five small nuclear RNAs (snRNAs) called U1, U2, U4, U5 and U6 and a great quantity of proteins (Kambach et al., 1999). RNA-RNA, RNA-protein and protein-protein interactions are involved in the recognition of the 5' splice site, 3' splice site, branch point, etc. and the intron removal from the pre-mRNA.

The splicing reaction can be functionally divided into several steps, including spliceosome assembly, activation, catalysis, and disassembly/recycling of the spliceosomal machinery. Many of these functional aspects have been investigated using in vitro splicing systems of mammalian cells and the budding yeast Saccharomyces cerevisiae. The picture emerging from these studies shows the spliceosome as a highly 
dynamic machinery in which the snRNAs are rearranged multiple times concomitantly with a changing composition of the RNA and protein components (Bottner et al., 2005).

\section{Molecular mechanism}

This reaction takes places in the nucleus and can occur co- or posttranscriptionally. Afterwards, the mature mRNA is transported to cytoplasm to be

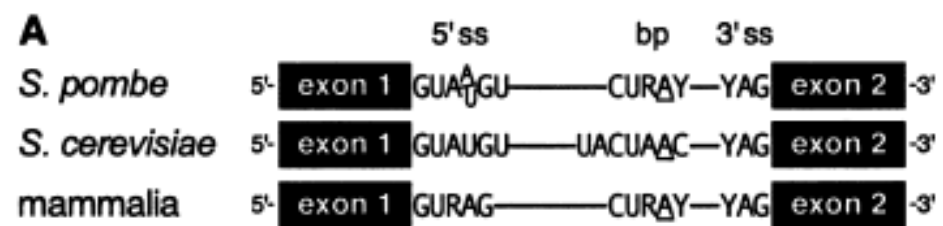

B pre-mRNA

products

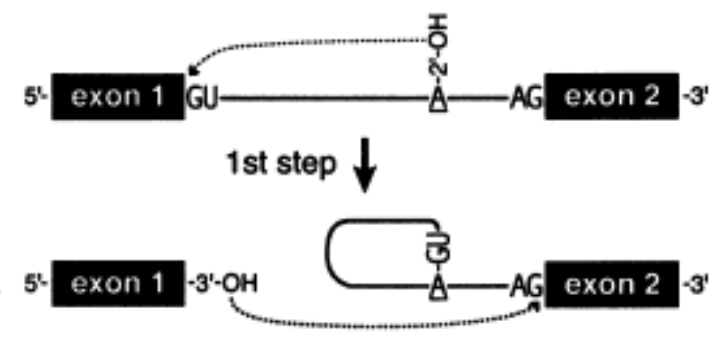

2nd step $\downarrow$

\section{exon 1 exon 2}

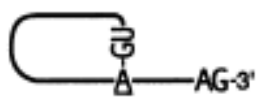

Figure 7. Schematic representation of introns and pre-mRNA splicing.

(A) 5' and 3' Splice Site (SS) and branch point consensus sequences in $S$. pombe, $S$. cerevisiae and mammalia.

(B) The two catalytic reactions in splicing and the products obtained. In the first step a nucleophylic atac of the brach site to the 5' SS produces a phosphodiester bond; in the second step, the $3^{\prime}$ hydroxyl group of the $5^{\prime}$ exon attacks the $3^{\prime}$ splice site, resulting in the displacement of the lariat intron and the ligation of the exons (Kuhn and Kaufer, 2003).

translated.

In vitro studies demonstrated the mechanism by which introns are removed from the pre-mRNA. The process is based on two transesterification reactions: it is initiated by a nucleophilic attack of the 2' hydroxyl group of the adenosine at the branch site on the 3',5'-phosphodiester bond at the 5' splice site. Concomitant with cleavage, the 5' terminal guanosine of the intron is covalently attached to the branch site adenosine in a 2',5'-phosphodiester bond. The splicing intermediates thus formed are the cleaved-off $5^{\prime}$ exon and the intron-3' exon intermediate in a branched circular, or lariat, configuration. The second step proceeds by attack of the $3^{\prime}$ hydroxyl group of the $5^{\prime}$ exon on the phosphodiester bond at the 3 ' splice site, resulting in the displacement of the lariat intron and the concurrent ligation of the exons. 
The catalytic steps are preceded by the assembly of the pre-mRNA into a splicing-competent structure. The first specific stage in spliceosome assembly is the binding of U1 snRNP to the pre-mRNA, which occurs in an ATP- and temperatureindependent fashion and involves base pairing of the 5 ' end of U1 snRNA to conserved sequences at the $5^{\prime}$ splice site. U1 snRNP binding is essential for the subsequent binding of U2 snRNP and for the commitment of the pre-mRNA to the splicing pathway.

Pre-splicing complex A is formed upon binding of U2 snRNP to the branch site. This step, as well as all subsequent stages of the splicing reaction, is ATP-dependent. The U4/U6 and U5 snRNPs interact with complex A in the form of a U4/U6.U5 trisnRNP complex to generate splicing complex B, which is converted into the catalytically active complex $\mathrm{C}$ after a conformational rearrangement. One of the consequences of this structural change is the destabilization of the extensive base pairing interaction between U4 and U6 snRNAs. The transesterification reactions are initiated during or subsequent to the structural reorganization of the spliceosome. The liberated intron remains associated with U2, U5, and U6 snRNAs, whereas the spliced mRNA is released from the spliceosome.

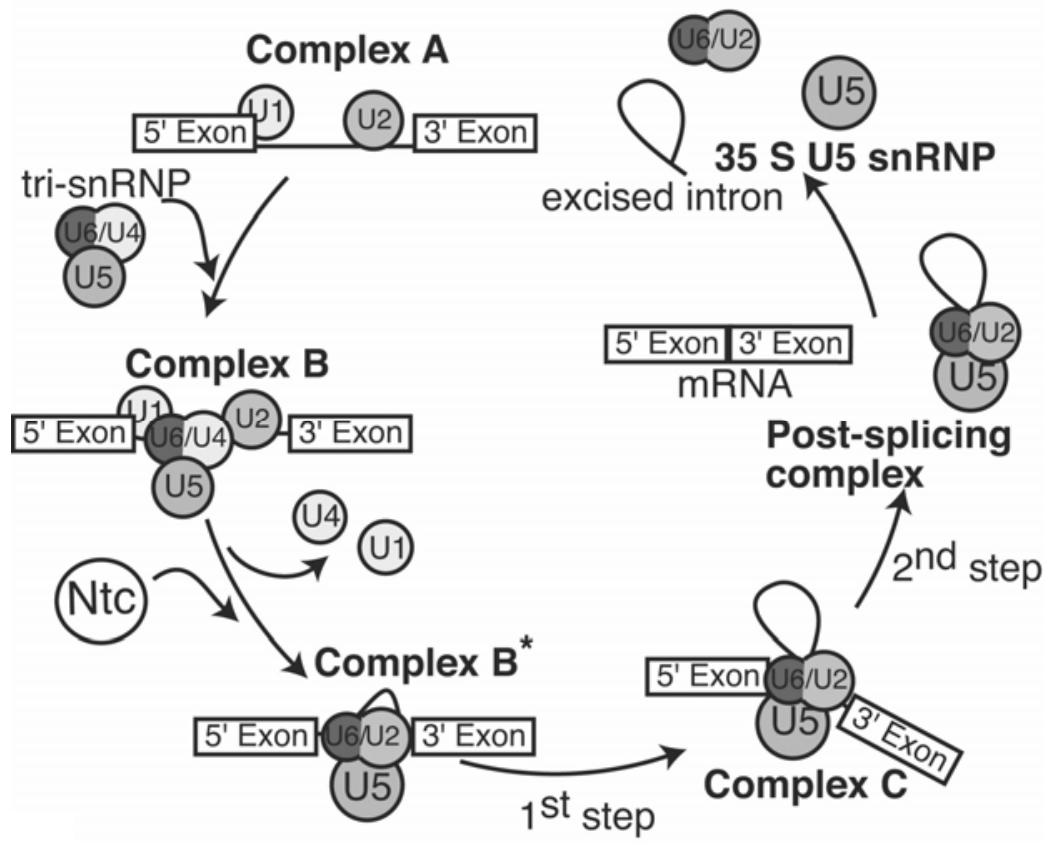

Figure 8. Dynamics of the spliceosome. Binding of the different snRNAs at the different complexes. The activated spliceosome complex is marked with an asterisk. The catalytic steps and the products are shown.

Spliceosome disassembly represents an active process that requires at least one protein factor and ATP. Subsequent to the release of the snRNPs, the intron lariat is 
linearized by a debranching enzyme that specifically cleaves the 2',5'-phosphodiester bond at the branch site followed by degradation of the intron (Kramer, 1996).

\section{Regulation of splicing}

Splicing and/or alternative splicing has been shown to be regulated in multiple ways. An interplay of cis-acting sequences and trans-acting factors modulates splicing by the interaction of many complexes, proteins, DNA domains, etc.

A first degree of regulation is achieved by the 5' and 3' splice site sequences and the branch point. Specifically, splicing efficiency is dependent on their level of consensus with an optimal sequence. But there are other sequences in the pre-mRNA that can modulate the intron inclusion or exclusion.

- The Exonic Splicing Enhancers (ESEs) are motifs that promote the exclusion of the exon that contain the ESE.

- The Exonic Splicing Silencers have the opposite function of the ESEs.

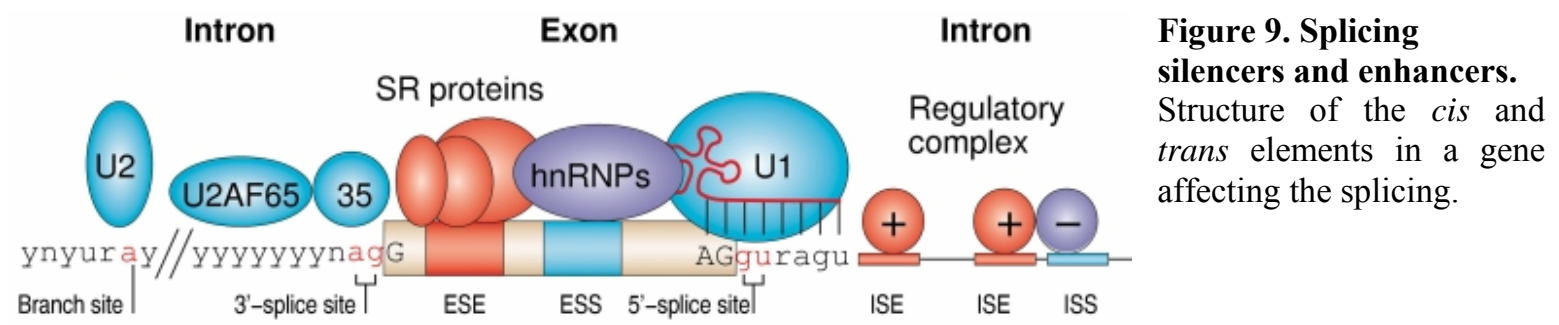

These motifs can also be found in the introns, so there are in a parallel way, Intronic Splicing Enhancers and Silencers. The trans-elements that participate in this regulation are mainly the SR family of proteins and the heterogeneous nuclear ribonucleoproteins (hnRNP).

The SR-proteins are highly conserved in eukayotes, they are requiered for constitutive splicing and modulate alternative splicing. This family of proteins has one or two RNA-recognition motifs (RRM) and a Serine/Arginine rich domain (the SR domain) in the C-terminal region. There is a subtype of proteins called SR-related proteins (SRrps) which include, among others, the U1-70k protein and both subunits of 
U2AF. The SR family and SR-related proteins function in the recognition of the ESEs leading to the activation of suboptimal adjacent 3' splice sites. The hnRNP represses splicing by ESSs binding. There are two hypotetical models to explain this mechanism, the "U2AF recruitment model", where the SR proteins recruit the smaller subunit of the $\mathrm{U} 2 \mathrm{AF}$ complex, $\mathrm{U} 2 \mathrm{AF}^{35}$, which will promote the binding of the U2snRNP to the adjacent intron promoting splicing or, the "inhibitor model", where the inhibiting function of the hnRNPs over U2AF is inhibited at the same time by the SR proteins (Caceres and Kornblihtt, 2002; Cartegni et al., 2002).

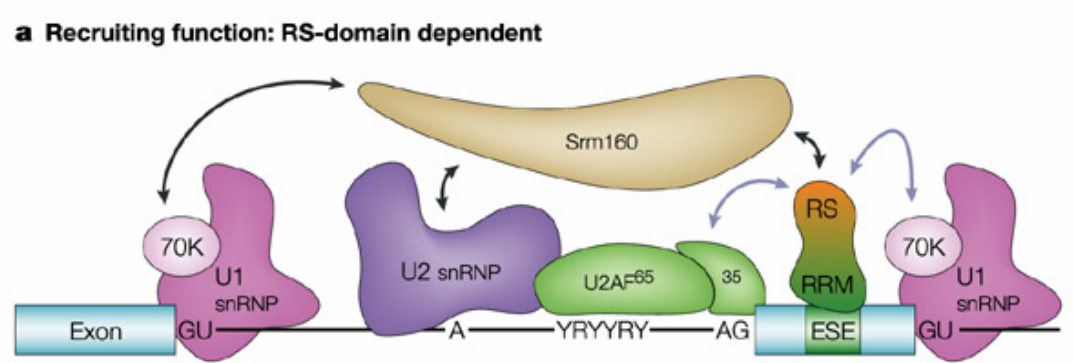

Figure 10. Function of the RS-domain-containing proteins. The recruting $(\mathrm{A})$ and the antagonist (B) function are shown. (Cartegni et al., 2002)

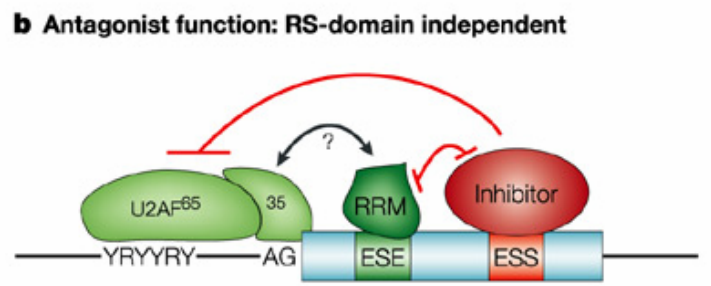

SR and hnRNP protein activities are modulated by phosphorylation, this way protein kinases related to splicing can have important roles in linking extracellular signalling to splicing regulation.

There are other groups of proteins that regulate splicing such as polypyrimidine tract proteins (PTB), the CELF protein family and other tissue-specific factors.

An important, although not very well known, mechanism to regulate splicing is through the RNApolymerase II. RNApol II transcribes mRNAs and some snRNAs. In the case of mRNAs, transcription is coordinated with other processes needed for the maturation of the mRNA. Capping at the 5' end minimizes degradation and permits its interaction with the ribosome, the 3' end polyadenilation increases the stability and the introns are removed. Transcription and all these processes are coordinated in time and space. RNApol II is a multimeric protein, in which its largest subunit is characterized 
by a C-terminal domain (CTD) composed by numerous repeats of the heptad consensus peptide YSPTSPS. The CTD and the phosphorylation of the Serines 2 and 5 mediate the recruitment of many proteins and complexes involved in this process and link the mRNA synthesis with the splicing machinery (McCracken et al., 1997). The phosphorylated form of CTD stimulates the early steps of spliceosome assembly while the hipophosphorylated form inhibits the formation of these complexes. The CTD is preferentially phosphorylated at Ser 5 when pol II is recruited at the promoter sites but becomes phosphorylated at Ser 2 when located at the coding region (Cho et al., 2001; O'Brien et al., 1994). This change of phosphorylation pattern might be relevant for the recruitment of splicing factors (Kim et al., 1997).

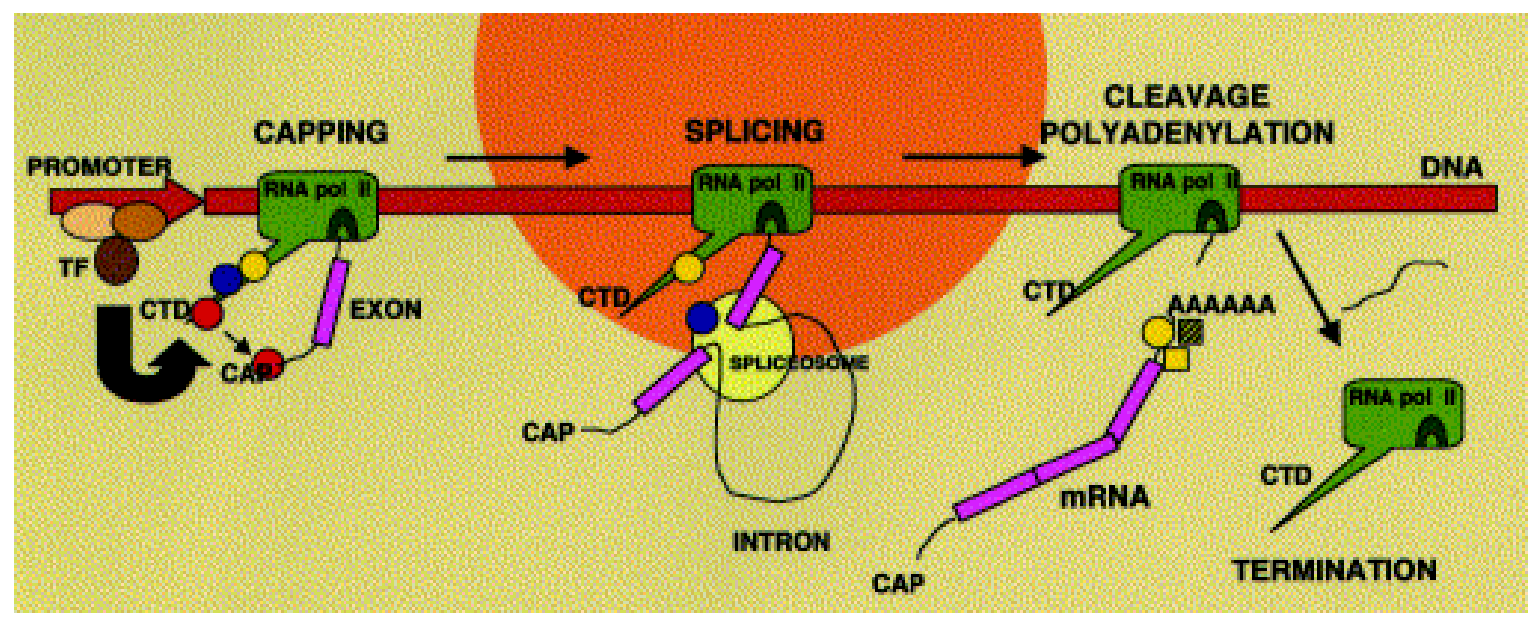

Figure 11. Involvement of RNA pol II in different steps of pre-mRNA processing. TF: transcription factors. Small circles represent proteins involved in pre-mRNA processing that interact with RNA pol II, participating in capping (red), splicing (blue) or cleavage/polyadenylation (yellow) mechanisms. Yellow squares represent factors involved in cleavage/polyadenylation which do not interact with RNA pol II (Cramer et al., 2001).

The promoter of any given gene, because it is responsible for the RNApol II recruitment, is also supposed to have a paper in the coordination between transcription and splicing. That is to say, the structure of a promoter can affect alternative splicing of the gene. Moreover, since promoters are not modifiable elements, the only conceivable way by which promoters architecture could control splicing in vivo should be the differential occupation of promoters by transcription factors with different properties and/or functions (Cramer et al., 2001; Morillon et al., 2003).

Two alternative, but not exclusive, models that could explain the promoter control of splicing are: 
- The promoter itself is responsible for recruiting splicing factors, such as SR proteins, to the site of transcription or the recruitment of factors that have a dual function in transcription and splicing. That is the case of the transcriptional activator of the human papillomavirus (Lai et al., 1999).

- The promoter mediates the recrutiment of a slow or less processive RNApol II (or internal pauses) that allows the preferential elimination of the upstream intron or the recruitment of a highly elongating RNApol II (or the absence of internal pauses) which would favor the presentation of more than one intron to the splicing machinery (Caceres and Kornblihtt, 2002). That was the case of the model presented by Kadener et al in 2001 (Kadener et al., 2001).
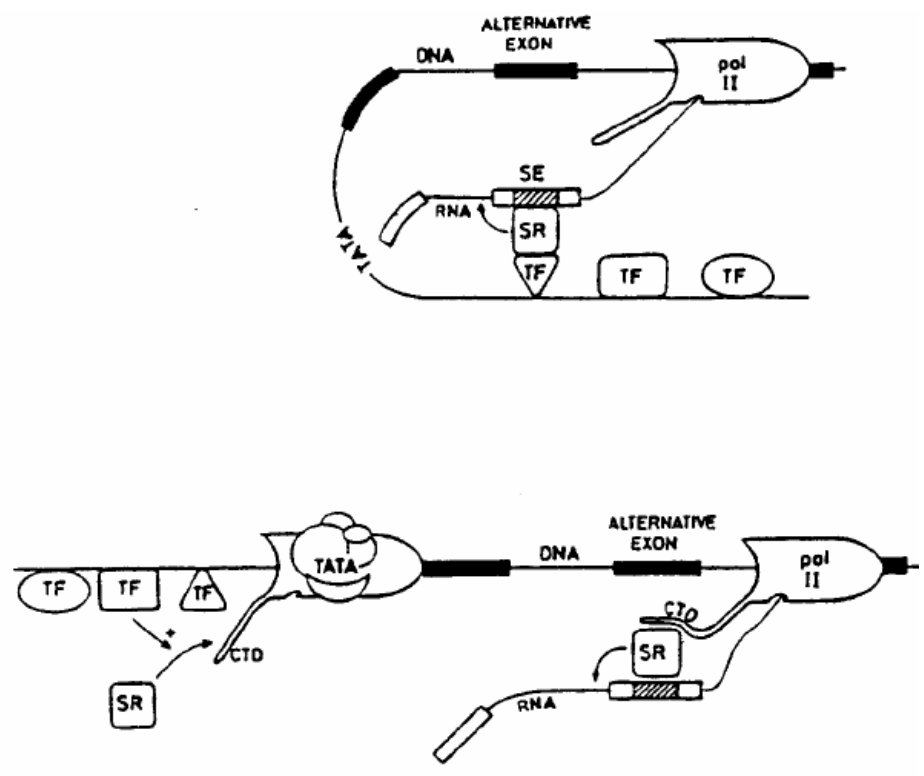

Figure 12. Two alternative models for putative interactions between SR proteins bound to an exon enhancer (SE ,hatched box) with transcription proteins. (A) SR protein activity is modulated by interaction with a regulatory transcription factor (TF) positioned on its promoter site at the time splicing occurs. (B) Regulatory transcription factors interacting with the initiation complex promote loading of SR proteins (or other transcription factors) onto the moving RNA pol II complex (Cramer et al., 1997).

In any case, the difference between promoters is not due to its strength but due to its quality (Cramer et al., 1999).

\section{Alternative splicing}

Alternative splicing is the RNA splicing variation mechanism in which the exons of the pre-mRNA are separated and reconnected so as to produce alternative mature mRNAs. In this way, alternative splicing uses genetic expression to facilitate the synthesis of a greater variety of proteins. 
There are four known modes of alternative splicing:

- Alternative selection of promoters: this is the only method of splicing which can produce an alternative $\mathrm{N}$-terminus domain in proteins. In this case, different sets of promoters can be spliced with certain sets of other exons.

- Alternative selection of cleavage/polyadenylation sites: this is the only method of splicing which can produce an alternative C-terminus domain in proteins. In this case, different sets of polyadenylation sites can be spliced with the other exons.

- Intron retaining mode: in this case, instead of splicing out an intron, the intron is retained in the mRNA transcript. However, the intron must be properly encoding for aminoacids in frame, otherwise a stop codon or a shift in the reading frame will cause the protein to be non-functional.

- Exon cassette mode: in this case, certain exons are spliced out to alter the sequence of amino acids in the expressed protein.

(a) Alternative selection of promoters (e.g., myosin primary transcript)

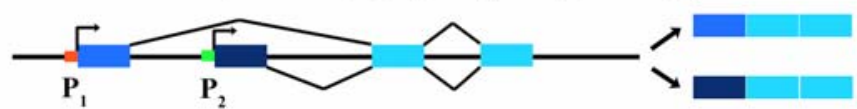

(b) Alternative selection of cleavage/polyadenylation sites (e.g., tropomyosin transcript)

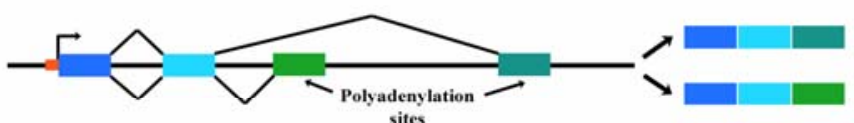

sites

(c) Intron retaining mode (e.g., transposase primary transcript)

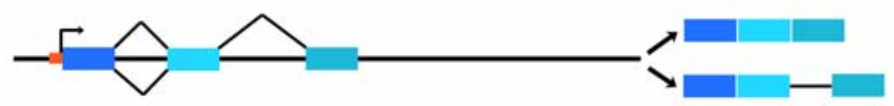

(d) Exon cassette mode (e.g., troponin primary transcript)

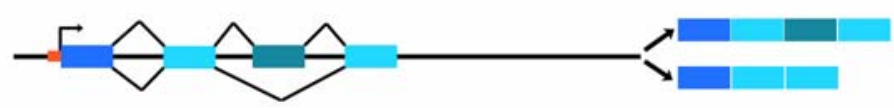

Figure 13. Representation of the four known models of alternative splicing.

Inter-specific splicing 
Splicing can be found in species of all the kingdoms: There are four major classes of introns: self-splicing group I and group II introns, tRNA and/or archaeal introns, and spliceosomal introns.

Group I introns are found in bacterial and organellar genomes, and in the ribosomal RNAs (rRNAs) in the nucleus of protists and fungi.

Group II introns, less widespread than group I introns, are present in bacteria and organellar genomes of fungi, plants, and protists; in archaea they were identified only within the genus Methanosarcina, which illustrates probable horizontal transfers from bacteria; group II introns are absent from nuclear genomes and have never been observed in animal mitochondria.

Group I and group II introns fold into distinctive ribozymic structures essential for catalyzing their own excision.

tRNA introns are found in the nuclear tRNA genes of eukaryotes; introns are also found in archaeal mRNA, rRNA, and tRNA. These introns are enzymatically removed by a cut-and-rejoin mechanism through a pathway completely different from that of spliceosomal introns.

Spliceosomal introns are confined to the nuclear genome of all eukaryotes, and - except for the signals of splicing - evolve under selective regimes that do not impose a high degree of primary sequence definition.

Two types of spliceosomal introns have been described. Canonical introns start with GU and end with AG, and are spliced by the major, U2-dependent spliceosome, and the spliceosome is the multi-protein/RNA complex that catalyses the splicing of nuclear mRNA precursors in eukaryotes. Canonical introns account for the vast majority $(>99.5 \%)$ of the spliceosomal introns in every species examined. The tiny minority remaining are noncanonical introns, which usually have AU-AC at their termini, and are spliced by the minor, U12-dependent spliceosome. U12-type introns are found in plants, insects, and vertebrates.

Taking into account the Spliceosomal canonical splicing, the function and components of this machinery appear to be highly conserved between organisms. Regarding yeasts, many distinct differences between budding and fission yeast have 
been found, emphasizing their evolutionary distance. Most interestingly, fission yeast appears to reflect the more conservative evolutionary development regarding premRNA splicing. Many spliceosomal components, including the five small nuclear RNAs, which most likely form the catalytic core of the spliceosome, show a higher degree of similarity with the components of the splicing machinery found in mammals. In addition, several regulatory components of the spliceosome detected in mammals are absent in S. cerevisiae, but present in S. pombe (Kuhn and Kaufer, 2003).

In mammals, introns usually comprise more than $95 \%$ of a pre-mRNA, they are usually larger than exons with a length of up to several kilobases long. In contrast, most fission yeast introns are only 40-75 nucleotides long. In humans, at least $70-80 \%$ of the genes have introns (Ben-Dov et al., 2008) and in S. pombe 43\%, while in S. cerevisiae it is only about 5\% (Kaufer and Potashkin, 2000).

Regarding the sequences defining an intron, both mammals and fission yeast introns have a very similar degenerated branchpoint consensus sequence, CURAY (R: purine; Y: pyrimidine) while in budding yeast is totally different (UACUAAC). The pyrimidine rich region between the branch point and the 3' splice site is very similar between mammals and S. pombe although the latter is considerably shorter (Prabhala et al., 1992). Regarding the proteins involved in pre-mRNA processing humans and fission yeast have also many similarities.

\section{Importance of studying splicing}

In humans, nearly $60 \%$ of the genes seem to be alternatively spliced and it is estimated that about $15 \%$ of all the mutations that cause genetic diseases lead to a failure in the correct splicing of the corresponding gene (Philips and Cooper, 2000). This estimate is only based on classical consensus sequences and does not consider other splicing motifs such as ESEs, so the real proportion may be closer to $50 \%$. Most single nucleotide mutations that alter constitutive splicing generate aberrant transcripts as a result of exon skipping or the use of cryptic splice sites. In many cases these result in loss of expression through generation of isoforms that lose the open reading frame and are targeted for nonsense mediated decay.

Defects in splicing are nowadays being implicated in many diseases, such as growth hormone deficiency, Frasier syndrome, Parkinson's disease, cystic fibrosis, 
retinitis pigmentosa, spinal muscular atrophy, myotonic dystrophy and a large number of cancers. Splicing defects can arise as a result of sequence mutations that disrupt splicing elements, mutations in splicing factors or through the unbalanced expression or normal alternative splice variants (Pettigrew and Brown, 2008).

A good model to study splicing at the molecular level is $S$. pombe because of its easy genetic manipulation and maintainance in the laboratory and because the similarity of the human machinery. The feasibility of using $S$. pombe in studying pre-mRNA splicing became clear when it was shown that the small T-antigen intron of the SV40 early region is properly spliced in fission yeast (Kaufer et al., 1985).

\section{Pre-mRNA splicing in Schizosaccharomyces pombe}

As explained before, pre-mRNA splicing is performed by the Spliceosome. In $S$. pombe, it consists of five small nuclear RNAs (snRNAs) called U1, U2, U4, U5 and U6 and more than 80 proteins (Kuhn et al. 2003). Regarding the proteins involved in premRNA processing, at least 20 splicing factors have been functionally identified in fission yeast, genetically and/or using a yeast two-hybrid screen with Prp2 as a bait. Some of the most important ones are:

prp1 is an essential gene that encodes a protein with 19 consecutives tetracopeptide motifs (Urushiyama et al., 1997). Prp1 is a physiological substrate of Prp4 kinase in vivo (Schwelnus et al., 2001). This interaction seems to be evolutionary conserved because the human homologues also interact in vitro and in vivo (Dellaire et al., 2002). Biochemical studies of the human homologue of Prp1 indicated that it might be a bridge between the $\mathrm{U} 5$ and the U4/U6 snRNPs in the U4/U6.U5 tri-snRNP (Makarova et al., 2002).

prp2 $\left(\mathrm{U} 2 \mathrm{AF}^{59}\right)$ encodes the counterpart of the large subunit of mammalian U2 auxiliary factor $\left(\mathrm{U} 2 \mathrm{AF}^{65}\right)$. While in fission yeast we can find the homologue of the mammalian small subunit $\mathrm{U} 2 \mathrm{AF}^{35}$, called $\mathrm{U} 2 \mathrm{AF}^{25}$, no homologue for this protein can be found in budding yeast by database analysis. The U2AF complex is involved in the recognition of the 3 ' splice site. $\mathrm{U}^{2} \mathrm{AF}^{65}$ binds to the polypyrimidine tract facilitating 
the interaction of the U2 snRNP with the branchpoint region (Zamore and Green, 1989). $\mathrm{Bbp} 1$ interacts with both subunits and its is necessary for the spliceosome formation (Huang et al., 2002).

prp4 encodes the first protein kinase described to be involved in pre-mRNA splicing. There are Prp4 homologues in many organisms. In general, this protein has an N-terminal domain characterized by containing Arginine/Serine rich domains, typically found in splicing regulators (SR proteins), but in Prp4 this domain is missing. Although genetic interactions were described with five splicing factors (Cdc5, Prp1, Prp5, Prp10 and Rnps1), Prp4 kinase appears not to be associated with any of the spliceosomal snRNPs.

Prp5 in a 40S complex which also containes the U2, U5 and U6 RNAs (McDonald et al., 1999). Prp5 consists of seven WD domains.

prp8/cdc28 is an RNA-dependent ATPase. The cdc28 mutant produces elongated cells blocked in G2 but its role in cell cycle and splicing is still unknown. The orthologue in S. cerevisiae (PRP2) is necessary just before or during the first transesterification reaction (Kim and Lin, 1993).

prp10 also shows functional interaction with prp4 (Richert et al., 2002). This protein contains consensus HEAT repeats found in regulatory subunits of the phosphatase PP2A (Habara et al., 1998). The mammalian homologue, SF3b155/SAP155 is part of the SF3b complex, part of the U2 snRNP (Wang et al., 1998). SAP155 is localized in close proximity to both sites of the branchpoint region and stabilizes the binding of the U2 snRNP with the spliceosome (Gozani et al., 1998).

prp11 encodes for an ATP-dependent RNA helicase homologue to S. cerevisiae PRP5. It is necessary for pre-spliceosome assembly in vitro, and interacts with U2snRNA in the early steps of spliceosomal assembly.

prp12 encodes a protein with high similarity to the human splicing factor SF3b130 (Habara et al., 2001). SF3b130 is part of the SF3b complex, a highly stable 
subcomplex of the U2snRNP. It is required to form a functional U2snRNP although the function of its different components is not well known.

prp31/spp13 is closely related to its human and S. cerevisiae homologues. Studies in these organisms showed that are important for tri-snRNP formation and spliceosome activation (Kuhn et al., 2002; Makarova et al., 2002; Weidenhammer et al., 1997).

cdc5 was first identified as being necessary for G2/M transition. It is also part of the complex containing the U2, U5 and U6 RNAs. It seems very likely that the 40S U2-U5.U6 complex represents a post-catalytic complex prior to the recycling of the individual snRNPs (Huang et al., 2002; McDonald et al., 1999).

$\mathrm{U} 1-70 \mathrm{k}$ is a SR-related protein that binds to U1snRNP and participates in the regulation of the pre.mRNA processing by Exonic Splicing Enhancers and Inhibitors.

Uap2 was the second U2AF associated protein identified (McKinney et al., 1997). It is most similar to $S$. cerevisiae CUS2, which is associated with U2snRNA and is probably playing a role in the proper folding of this RNA (Yan et al., 1998). Uap2 is postulated to have a function mediating the U2AF-dependent association of the U2snRNP with the intron.

spp42 was identified by supression of the temperature sensitivity of a prp4-73 mutation. Its homolgue in S. cerevisiae (PRP8) is part of the U5 snRNP, it is a highly conserved spliceosomal protein which plays a pivotal role right at the active center of the spliceosome. Spp42 human homologue (called U5-220kK/hPrp8) coordinates multiple RNA-rearrenging activities during assembly and activation of the spliceosome (Kuhn et al., 2002).

rnps1 is sinthetically lethal with prp4-73 mutation, it was first identified in the mammalian system, called RNPS1, as a general activator of splicing (Mayeda et al., 1999). It was also shown that RNPS1 remains on the mature mRNA at the position of an exon-exon junction (Le Hir et al., 2000). This complex seems to be important for the 
transport of the mRNA to the cytoplasm and also seems to have a function in differentiating premature and correct stop codons (Lykke-Andersen et al., 2001). 


\section{Rem1}

Rem1 was previosly found by our group while searching for other cyclins involved in the G1/S transition. The fact that the deletion of all the G1/S cyclins (Cig1, Cig2 and Puc1) does not avoid the DNA replication might mean that some other cyclins may be doing this function. This way rem1 (SPBC16E9.17c) was found by sequence homology and cloned. Its characterization was published by Malapeira et al, 2005.

Rem1 (equiered for Entry into Meiosis) is a B-type पDB cyclin with high homology to other cyclins of $S$. pombe. rem 1 is composed by 2 exons separated by an intron of 80 bp. The first exon, which represents $1 / 3$ of the protein has no significant homology with any other protein, except for the Destruction Box (DB)

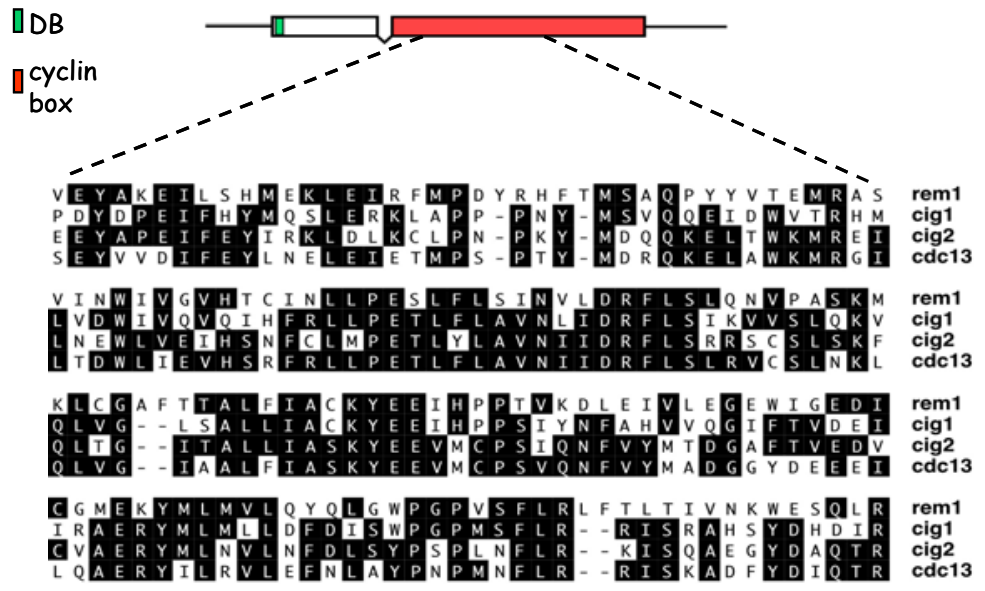

Figure 14. Aligment of the cyclin domain of rem1 and three other B-type cyclins of $S$. pombe.

located in the N-terminal

region, responsible of the degradation of the cyclin by the proteasome. The second exon encodes the cyclin domain. The intron contains a stop codon in frame, so to obtain the mature (full length) protein of Rem1 its mRNA has to be processed.

rem $1 \mathrm{mRNA}$ is nearly undetectable during vegetative growth. In fact, the only moment when rem1 is highly transcribed is in meiosis I. The mRNA can be detected some time before meiosis I but it is not spliced until the onset of meiosis I, when the protein is expressed.

If the kinase activity of Rem1 is assayed (using Histone $\mathrm{H} 1$ as a substrate) during the progression of meiosis, we can observe that the kinase activity coincides with the protein expression. Concerning the regulation of Rem1, $\Delta$ mei4 strains are blocked 
before meiosis I, rem 1 mRNA splicing was not performed and rem1 levels were decreased so Mei4 transcription factor appeared to be the main regulator or rem1, either directly or indirectly.

There were also some hints about the function of Rem1: the entrance in meiosis I was delayed $30 \mathrm{~min}$ in a rem 1 mutant strains and the levels of intragenic recombination were reduced while the levels of intergenic recombination were normal. It was shown that Rem1 has a redundant function with Cig2 cyclin. Strains deleted for rem1 or cig2 were able to complete meiosis while the double rem1/cig2 mutant was blocked before finishing pre-meiotic S phase.

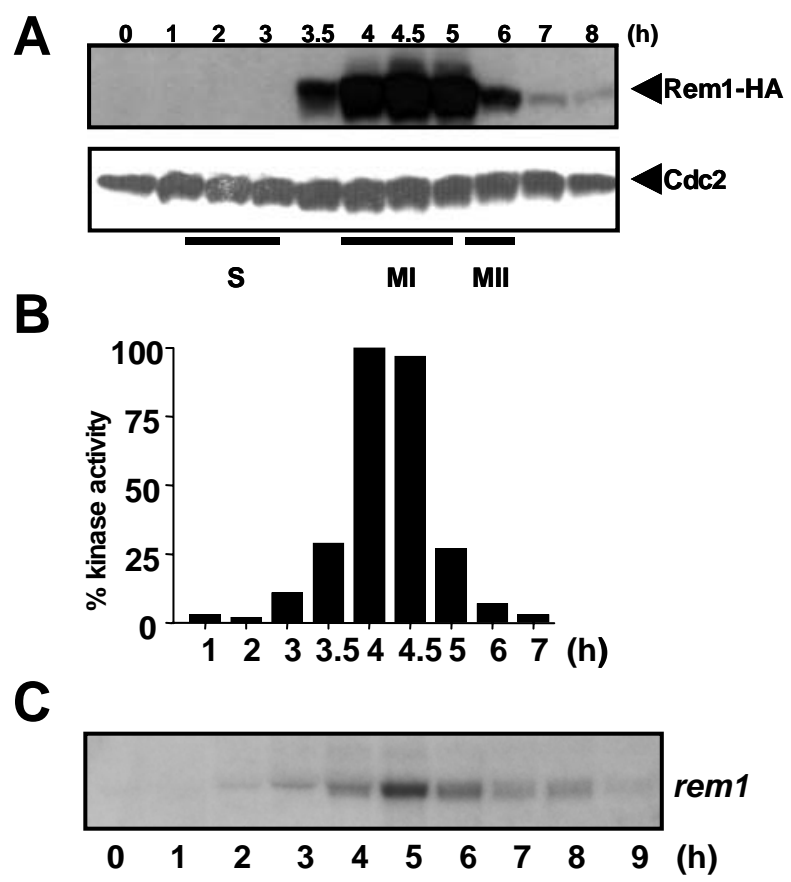

Figure 15. Characterization of Rem1.

(A) Wetern blot indicating Rem1 protein expression during meiosis, $\mathrm{Cdc} 2$ was used as a loading control. Hours at meiosis are indicated. (B) Kinase activity of inmunoprecipitated Rem1 was assayed over H1 Histone with radiolabelled phosphate, detected by radiography and quantified. Hours at meiosis are indicated. (C) rem1 northern blot during meiosis. A probe for the complete ORF was used. Hours at meiosis are indicated. (D) RNA from cells at different meiotic time points were harvested. Reverse transcriptase assay with specific oligos flanking rem1 intron were used. Both processed and non-processed products are indicated on the left. Hours at meiosis are indicated.

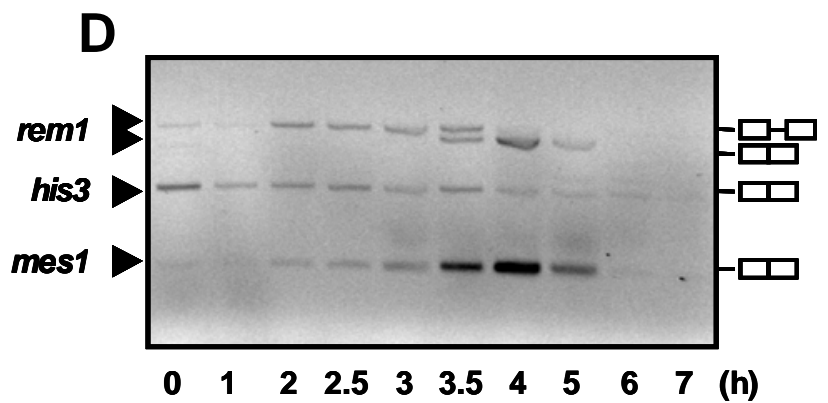




\section{OBJECTIVES}


The main objective of this project was in the begining the characterization of the meiosis-specific cyclin Rem1 in Schizosaccharomyces pombe. While advancing in the research the study became broader and the main objective change to understand the transcription and splicing regulation of a subset of genes expressed specifically in the meiotic differentiation.

The specific objectives were:

Understand regulation of rem1 transcription and splicing

Determine the regions important for this regulation

Study the promoter and the cis elements responsible of this regulation

Search for transcription factors regulating rem1

Extend the regulation model of rem1 to other meiotic intron-containing genes.

Characterization of the function of these regulators

Spatio-temporal localization in the gene

Their relationship with the RNA polymerase II

Interaction with the spliceosome

Interaction between them

Post-translational modifications of the factors.

Study Rem1 function and relate it to its regulation 
Results 


\section{rem1 regulation}

Rem1 is regulated at different levels. rem1 expression is at least regulated at the level of transcription, splicing and protein stability. This project has been focused mainly in the two former although I also will talk briefly about the last one.

\section{Transcription and splicing of rem1}

rem 1 is only expressed during meiosis, with its transcription induced early in the moment of meiotic recombination and then highly induced at the onset of meiosis $\mathrm{I}$. After meiosis II rem1 mRNA levels decrease during the rest of the meiotic process.

At the level of splicing, rem1 is only spliced at the onset of meiosis I, concomitantly to the high induction of its expression.

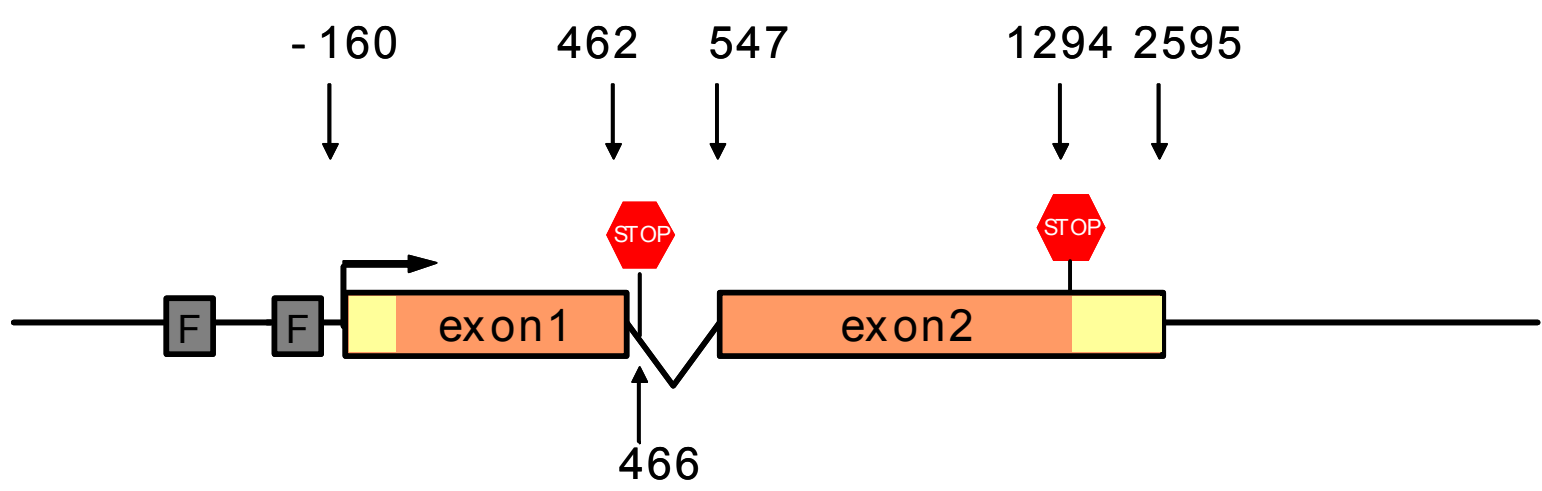

Figure 1. Gene structure of rem1. rem1 ORF is represented by brown boxes (exon1 and exon2), the Untranslated Regions (UTR) are shown as yelow boxes. F stands by the FLEX boxes and the STOP signals indicate the position of the in frame STOP codons.

The transcriptional start point (tsp) of rem1 was determined to be located at 162 bp upstream the first Methionine codon, so rem1 has a 5' Untranslated Region (UTR) of $162 \mathrm{bp}$. rem 1 belongs to the family of intron-containing genes, its first exon has $462 \mathrm{bp}$ and the second one $747 \mathrm{bp}$. Both are intervened by an intron of $85 \mathrm{bp}$. Downstream, the 3'UTR is about 88 bp (Malapeira et al., 2005).

To study the regulation of transcription and splicing we decided to analyse all these regions. 
3’ UnTranslated Region (UTR)

To analyse the paper of the 3'UTR in splicing we did modifications in the gene by substituting the 3'UTR and most of the second exon for the kannamycin cassette or adding a tag in the C-terminus to modify the region. We checked rem1 intron retention and, as shown in figure 2, wt, rem1-GST and rem1 $\Delta$ C652 mutant strains behave in a similar manner with some minimal differences at late time points. This could be indicative that the 3'UTR region does not have any paper in the splicing regulation, although it probably has a paper in the stabilization of the mRNA.

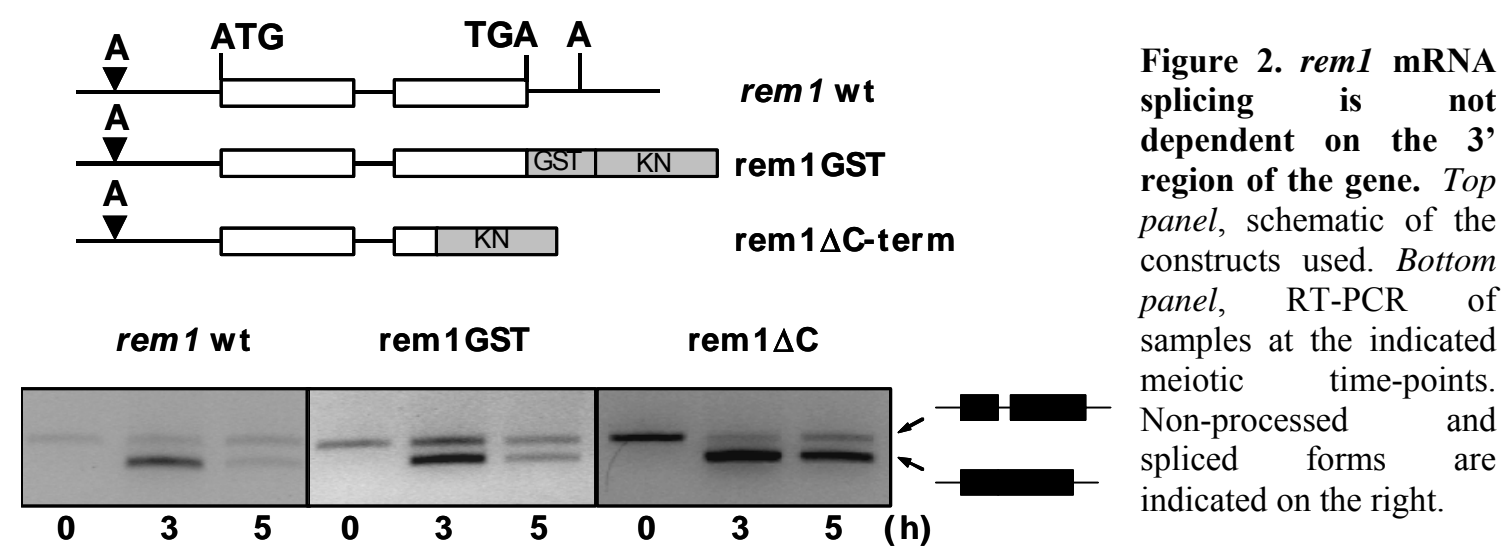

5' Splice site

The 5 ' splice site of rem1 intron (GUAUGA) is similar to the consensus sequence for $S$. pombe introns (GUAAGU). Even though, we wanted to know if by changing the two main nucleotides of the sequence (GU $\rightarrow \mathrm{AC}$ ) we could detect any difference in the intron retention. The experiment shown in figure 3 is a synchronous time course of cells entering in meiosis, both wild type strain and the mutant (GU $\rightarrow$ AC) strain (NoS) were analysed by RT-PCR for intron retention. The NoS mutant was unable to perform physiological splicing and to process rem1 mRNA. Even though, we could detect a band (Fig. 3,*) with an intermediate mobility between the unprocessed and the spliced form of rem1. This band was isolated, re-amplified and sequenced and 
the result was an mRNA spliced from a cryptic 5' splice site in which the first exon was extended $26 \mathrm{bp}$ (Fig. 3). This splicing product still contains the stop codon in frame and

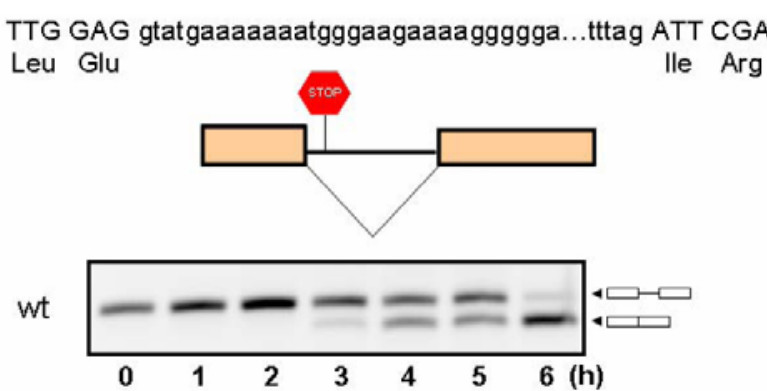

TTG GAG aca tga aaaaaatgggaagaaaaggggga...tttagATTCGA

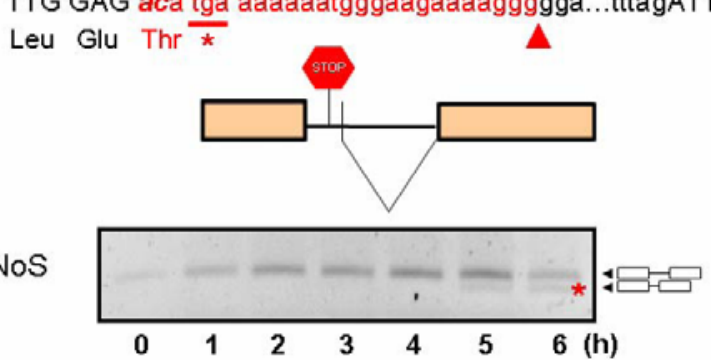

Figure 3. Analysis of the 5' Splice Site (SS). Top panel, RT- PCR of a wild type strain at the indicated meiotic time points. Bottom panel, RT-PCR of a mutant strain, carrying a GT $\rightarrow$ AC mutation in the 5'SS (NoS), at the indicated meiotic time points. In the NoS mutant there is some splicing (although very inefficient) from a criptic 5' splice site (indicated by the red arrowhead) in which the first exon is extended 26 nucleotides (in red). This splicig product contains the Stop codon (tga) and renders a truncated protein that corresponds to the first exon. The band marked with an asterisk in the NoS mutant panel (which has an intermediate mobility between spliced and unspliced bands), was excised from the gel, reamplified with primers JA71 and JA174 and sequenced.

is unable to produce a mature full-length protein. The phenotype observed in this mutant is probably not due to a paper in the regulation of rem 1 splicing but a lack of operatibility of the splicing machinery. So, the 5' splice site of rem1 doesn't have any role in splicing-specific regulation of rem1.

\section{Regulation by the same product}

Another way of regulating the splicing is by the own protein encoded by the mRNA as the case described by Macías et al (Macias et al., 2008). To study this possibility, we mutated the ATG start codon to a TAG codon disabling the possibility to translate Rem1

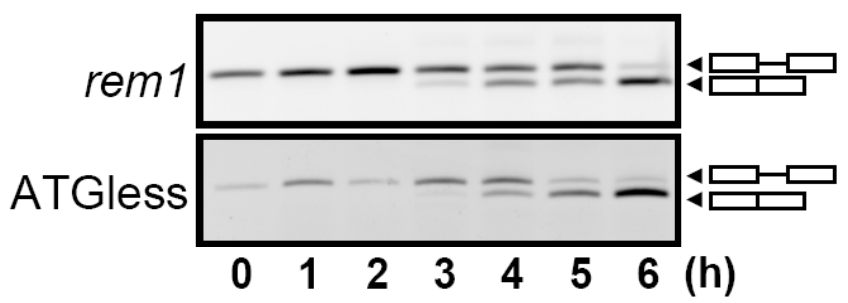

Figure 4. Regulation of the splicing by Rem1 protein. RTPCR of a wild-type (rem1) or a mutant rem1 lacking the initiation codon (ATG $\rightarrow$ TAG) (ATGless) were performed at the indicated meiotic time points. 
(ATGless mutant). Both wild type and ATGless mutant strains were induced to enter synchronous meiosis and were analysed by RT-PCR with no differences in the splicing of the pre-mRNA (Fig. 4).

\section{Promoter and 5' UTR}

Both the promoter, mediating the binding of transcription or splicing factors, and the $5^{\prime}$ untranslated region, by a specific spatial conformation, have been described for some genes as essential or important for the regulation of splicing (Shimoseki and Shimoda, 2001),(Cramer et al., 1997). We wanted to elucidate if it was the case of rem1.
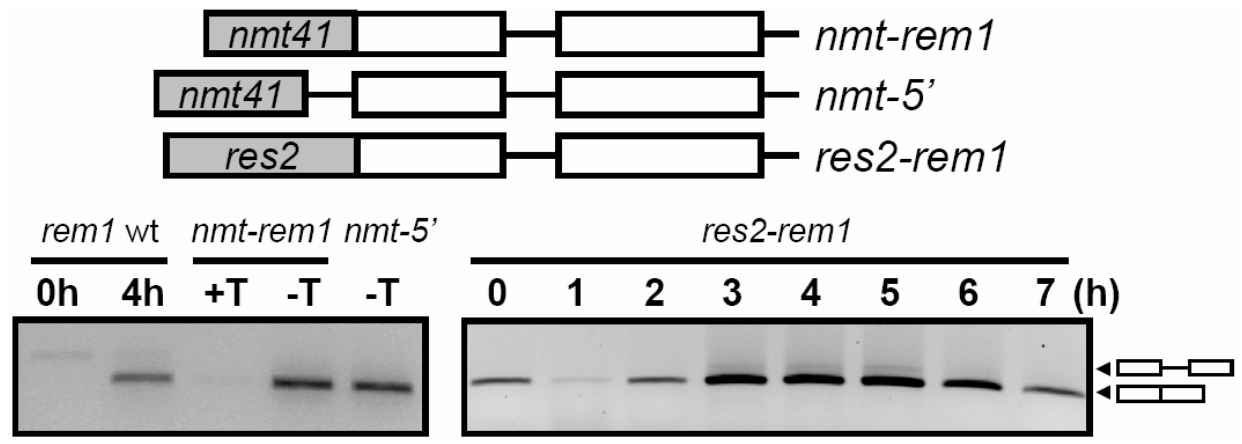

Figure 5. Analysis of the 5' region of rem1 gene. Top panel, schematic of the constructs used: the promoter was replaced by (i) the inducible $n m t 41$ promoter with (nmt-5') or without (nmt-rem1) the 5'UTR of rem 1 (shown on the diagram) and (ii) res2 promoter. Bottom panel, rem1 splicing in strains carrying the replacements described above. RNA was isolated from meiotic wild-type cells as a control (rem1 wt; 0 and 4 hours into meiosis), from cultures vegetatively growning in the presence (+T, promoter OFF) or absence ($\mathrm{T}$, promoter $\mathrm{ON}$ ) of thiamine (left panel), or from meiotic cells carrying a res2-rem1 chimaera (right panel).

Thus, we analysed intron retention of different chimaeras of rem1. First of all we studied the behaviour of rem 1 under the control of the nmt41 inducible promoter. As shown in figure 4 (left panel), when the $n m t 41$ promoter is active all the transcribed mRNA is spliced, independently of the presence or absence of the 5'UTR. Since the endogenous nmt1 gene has no introns and maybe the high levels of transcription could lead to higher splicing efficiency we decided to study the effect of a weak promoter in similar conditions as the ones suffered by rem1: meiotic progression. We fused res2 
promoter to rem1 ORF and induced synchronous meiosis (Fig. 4, right panel). Surprisingly, we could detect constitutive splicing of rem 1 mRNA, even in early time points of meiosis. This result was pinpointing the possibility that the regulation of rem1 mRNA splicing at early meiosis was based in a negative splicing factor. This factor would avoid rem1 mRNA processing until meiosis I.

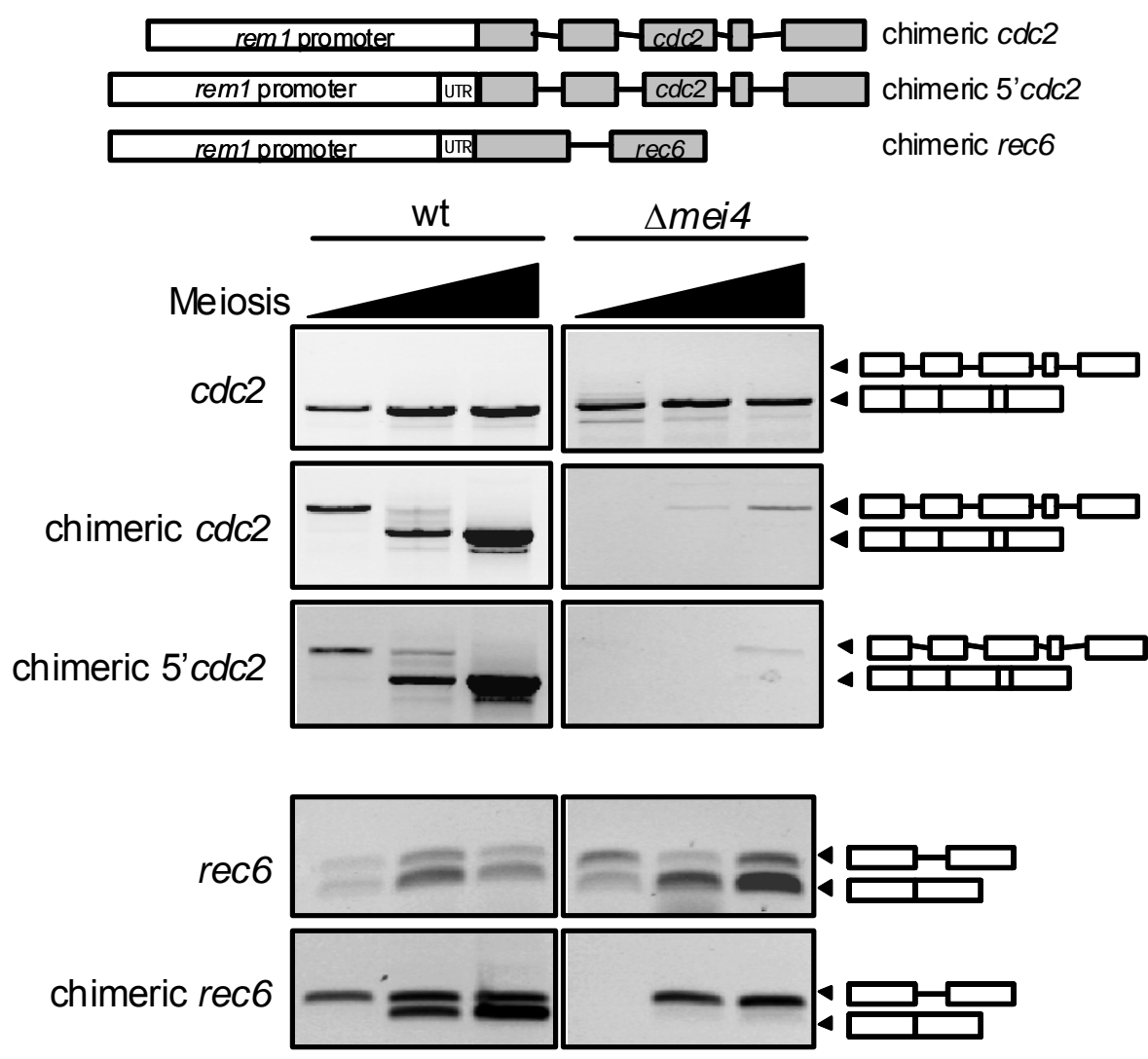

Figure 6. rem1 promoter controls other genes splicing. Top pannel, schematic of the constructs used: the ORF of rem1 was replaced by the $c d c 2$ ORF either (i) without (chimeric cdc2) or (ii) with (chimeric 5' cdc2) the 5'UTR of rem1 and (iii) replaced by rec6 ORF. Bottom pannel, RT-PCR analysis of the endogenous genes and the quimeras described above. RNA was purified from cells at 0,3 and 5 hours of meiosis.

To fully ascertain this possibility, we proceeded with a reverse strategy. We fused the promoter of rem1 to different reporter genes, like the ubiquitous cdc2 (Fig. 6 and 7, wt panels) or the meiosis-specific rec6 (Fig. 6, wt panels). Fission yeast cells were transformed with the different chimaeras and were induced to enter into synchronous meiosis. Splicing of the different chimaeras as well as the endogenous genes was followed by RT-PCR. As shown in Figures 6 and 7, rem1 promoter is 
sufficient to promote intron retention during vegetative growth and early stages of meiosis and can control the splicing of genes placed under its control. Furthermore, this regulation is dependent on mei4, directly or inderectly (Figure 6 and 7, $\Delta$ mei4 panels). We can also conclude from these experiments that the 5'UTR does not affect the regulation of rem1 splicing (Fig. 6).

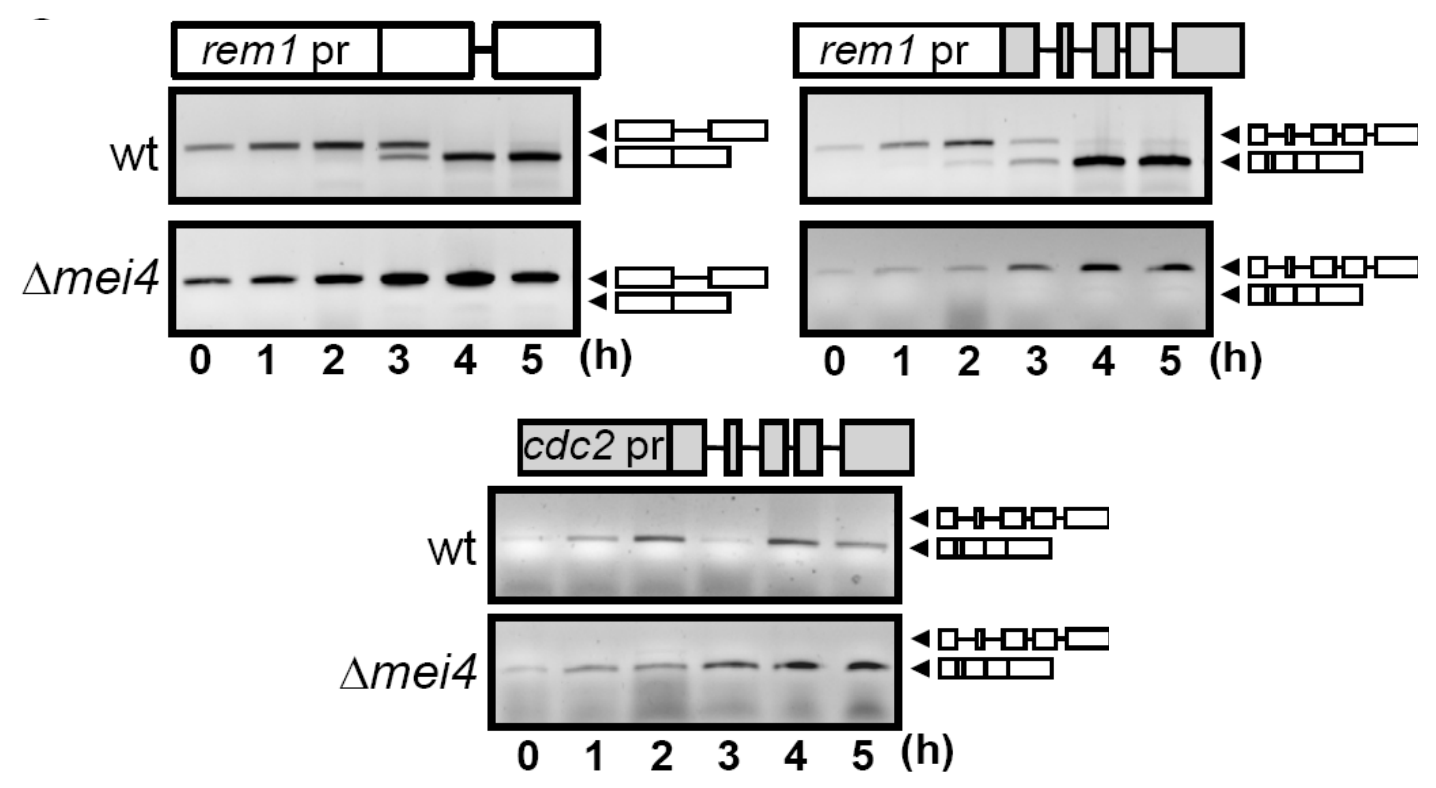

Figure 7. rem1 promoter controls splicing. RNA was isolated from wild type (wt) or $\Delta m e i 4$ cells progressing into meiosis and rem1 (top left panel) cdc2 (bottom panel) or rem1:cdc2 chimera (upper right panel) and splicing was monitored by RT-PCR with specific primers. Hours of meiosis are indicated at the bottom.

Analysis of the promoter function

As previously shown, we have determined that the promoter was the main regulator of rem1 mRNA splicing. In this section I am going to focus on the cis and trans elements of the promoter found to regulate rem1. 


\section{Cis elements}

The promoter of rem1 contains two putative FLEX boxes (Fig. 1). These sequences are described to bind forkhead transcription factors in vivo (Horie et al., 1998). Since Mei4 is known to induce transcription and splicing of rem1(Malapeira et al., 2005), we decided to mutate these FLEX boxes and study this modifications at the level of transcription and splicing. The mutations performed consisted in the complete deletion of FLEX1 (GTAAACAAA), point mutations of FLEX2 (GTAAACA $\rightarrow$
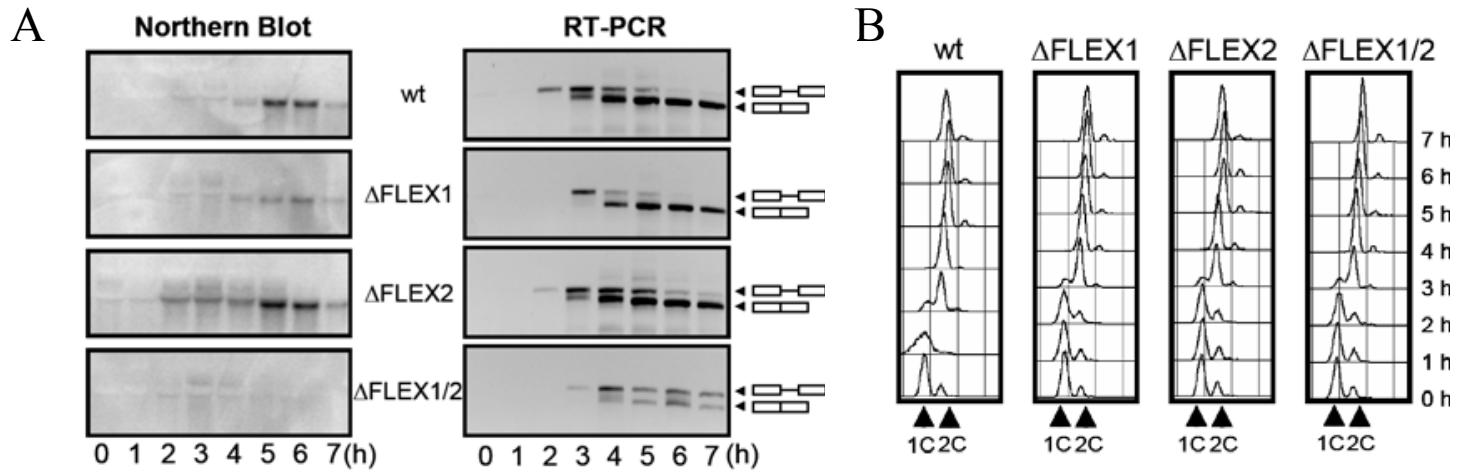

Figure 8. Mutations at the FLEX boxes alter transcription and splicing of rem1. There are two putative FLEX boxes in the rem1 promoter as shown in Figure 1. A, Transcription (Northern Blot) and splicing (RT-PCR) of rem1 was analysed in a wild-type (wt), single FLEX box mutant ( $\triangle F L E X 1$ and $\triangle$ FLEX 2) or double FLEX box mutant $(\triangle$ FLEX1/2) strains as they progressed into meiosis. $B$, synchronicity of meiosis was assessed by flow cytometry. Time in hours after the culture was shifted to $35.5^{\circ} \mathrm{C}$ is indicated on the right.

CTAATGA) or both of them. The double deletion was not used because it would lead to a destructurated promoter with no transcription (data not shown). Strains with these mutations were induced to enter meiosis synchronously and rem1 mRNA was analysed by Northern blot and by RT-PCR. In a $\triangle$ FLEX1 mutant the levels of mRNA are lower than the wild type while in a FLEX2 mutation rem1 seems to be expressed earlier, with increased basal levels. In the double mutant the transcription is nearly abolished (Fig. 8, A, Northern Blot). Concerning splicing, both of the single mutants seem to have not significant differences with the wild type while the doble mutant has impaired splicing with only residual processing of the pre-mRNA (Fig. 8, A, RT-PCR). This experiment indicates that the most important elements of the promoters regulating transcription and splicing of rem 1 are the FLEX boxes. Even though, we cannot discard additional elements co-regulating or modulating the expression of rem1. 
Trans elements

a) Forkhead transcription factors

A

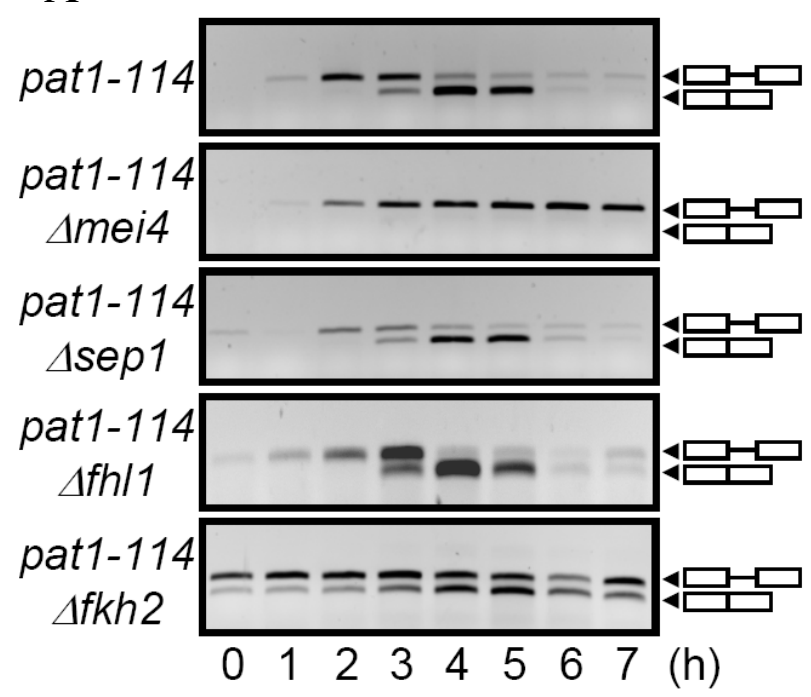

$\mathrm{C}$
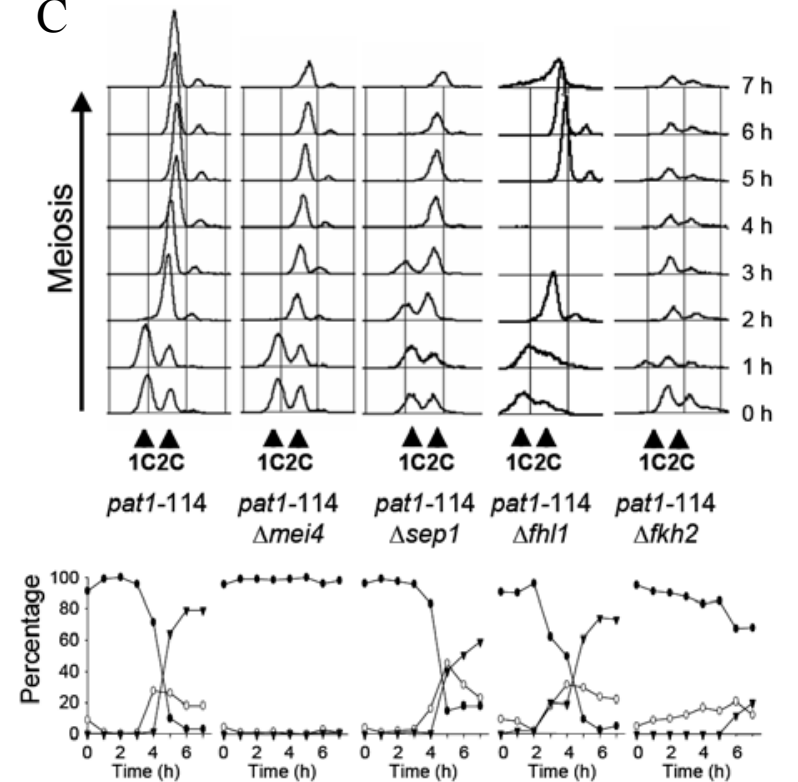

B

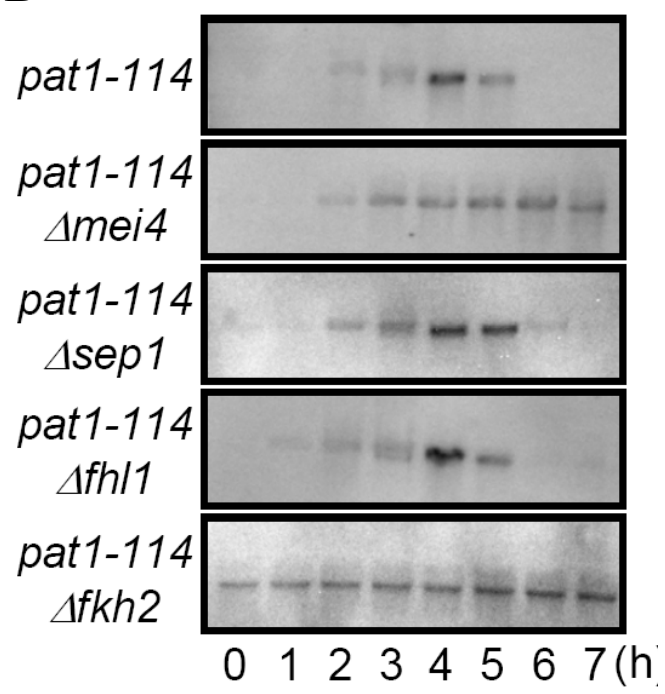

Figure 9. Analysis of different Forkhead Transcription Factors mutants. The rate of splicing $(A)$ and accumulation of rem1 mRNA $(B)$ was analysed by RT-PCR and Northern blot in the indicated strains. Hours of meiosis are indicated at the bottom. Syncrony of the culture was assessed by flow cytometry $(C$, top panels) and count of DAPI-stained nuclei $(C$, bottom panel). Meiotic time-points and strains ares indicated.

As explained before, FLEX boxes are the cis elements recognized by the forkhead family of transcription factors. We have observed that rem 1 expression is regulated mainly by the FLEX boxes (Fig. 8) and that rem1 regulation is based on a two-component factor (Fig. 5, 6 and 7), negative in early meiosis and positive (Mei4, Figure 6 and 7 and (Malapeira et al., 2005)) in Meiosis I. To search the negative 
regulator, we studied the winged-helix forkhead transcription factors present in $S$. pombe. In fission yeast, there are four genes coding for forkhead proteins: sep1, fhl1, mei4 and fkh2.

We have characterized the effect of the other forkhead transcription factors on transcription and splicing of rem1 during meiosis (Fig. 9). While deletion of sep1 and fhl1 had no effect neither in transcription nor in splicing regulation, cells without Fkh2 showed constitutive splicing, during vegetative growth as well as during early time points of meiosis (bottom panels of Fig. 9), pointing to a direct role of Fkh2 in the regulation of rem1 splicing.

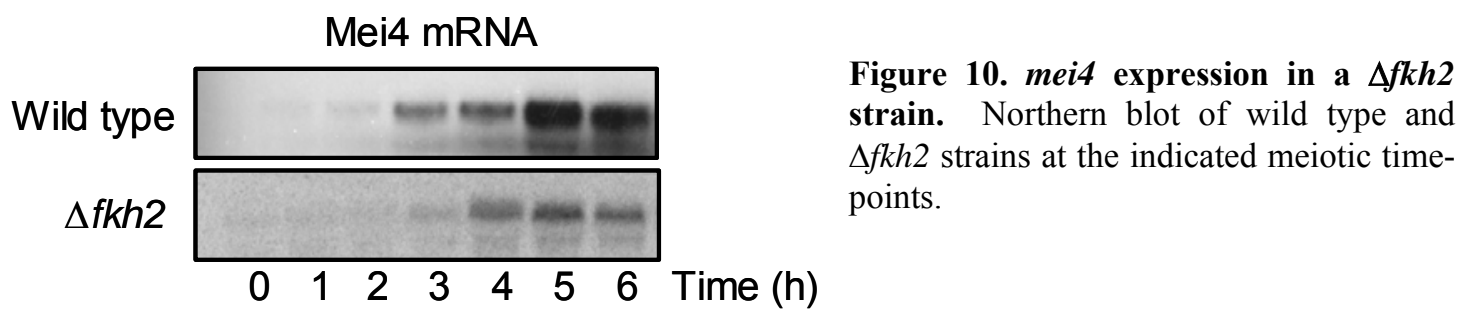

To discard the possibility that the constitutive pattern of splicing of rem1 mRNA in a $\Delta f k h 2$ strain was due to the ectopic presence of Mei4, we determined the levels of mei4 mRNA by northern blot in $\Delta f k h 2$ cells during meiosis. As shown in Figure 10, mei4 mRNA behaves similarly in a wild type and a $\Delta f k h 2$ strain, being absent in early meiotic time points.

After determining that Fkh2 and Mei4 are the main regulators of rem1, we wanted to search if there was any residual regulation after deleting both factors. Surprisingly, in the double mutant $\Delta f k h 2 \Delta m e i 4$, although we expected the same behaviour than in a $\Delta f k h 2$ strain, rem 1 mRNA was spliced in early meiosis but the efficiency of splicing instead of be maintained as the the $\Delta f k h 2$ single mutant, was decreasing along meiosis (Fig. 11). 


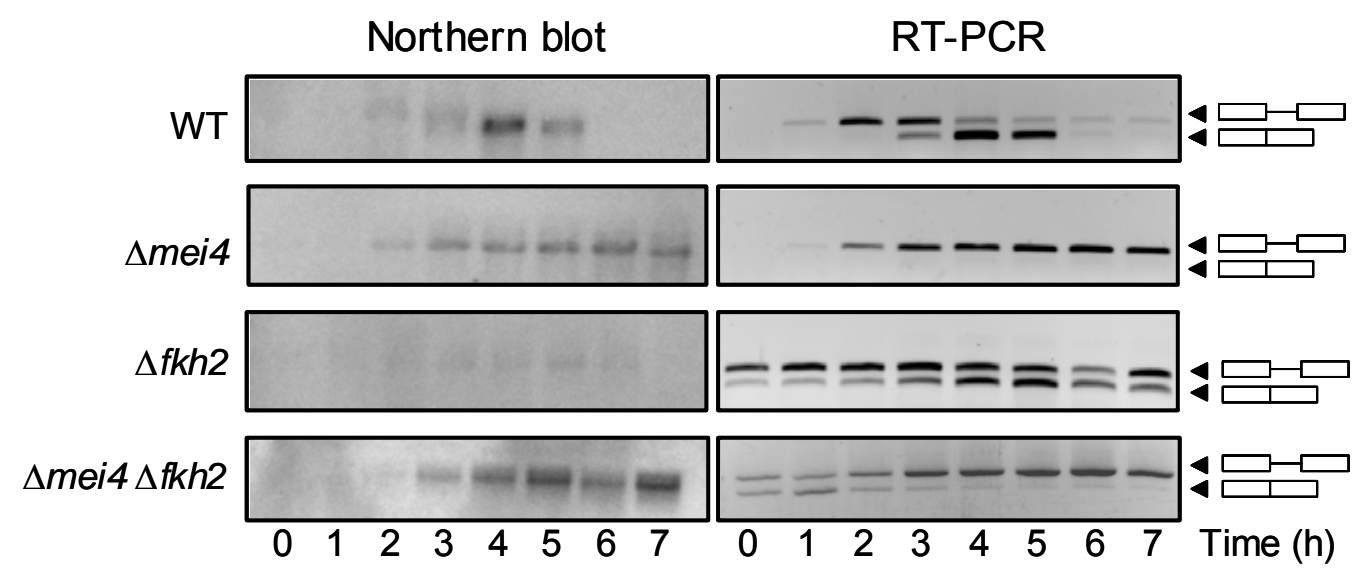

Figure 11. Genetic interaction between mei4 and $\boldsymbol{k h} 2$ in vivo. Northen blot (left panels) and RTPCR (right panels) analysis of a wild type strain, single $\Delta$ mei4 and $\Delta f k h 2$ mutants and the double $\Delta m e i 4 \Delta f k h 2$ mutant. Meiotic time-points are indicated.

To confirm the direct function of Mei4 in rem1 promoter, in vitro experiments were performed. Binding of recombinant GST-Mei4 (DNA-binding domain) to a probe containing part of rem1 promoter was studied by electrophoretic mobility shift assay (EMSA). We can observe a shift in the mobility of the probe in the presence of GSTMei4 and a supershift if we add a specific antibody (Fig. 12, left panel), with similar
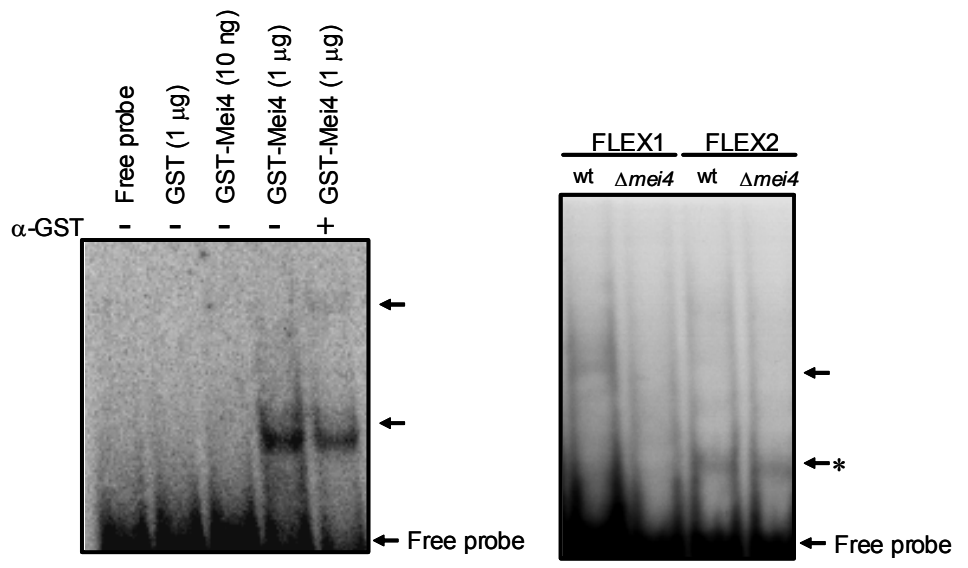

Figure 12. In vitro binding to the FLEX motives. Left panel, electrophoretic mobility shift assay (EMSA) of recombinant GST-Mei4 with a radiolabelled probe containing FLEX1. Right panel, EMSA of meiotic extracts from wild type and $\Delta$ mei4 strains with radiolabelled FLEX1 and FLEX2 probes. The asterisk indicates an unspecific band .

results to the ones obtained by C. Shimoda's group previously (Horie et al., 1998). A similar assay was performed with native extracts of wt and $\Delta m e i 4$ strains at 4 hours of meiosis (Fig. 12, right panel). We can observe a shift of the FLEX1 probe after adding wild type extracts but not with extracts from cells lacking mei4. For the FLEX2 probe, we observed no differences between both strains. We can observe an unspecific band 
that can be Fkh2 but it has not been checked. These results indicate that Mei4 can bind directly to rem1 promoter in vitro and gave us some hints of its binding in vivo.

To analyse the binding of Mei4 and Fkh2 to rem1 in vivo, we applied the chromatin immunoprecipitation methodology (ChIP). We expressed tagged versions of Mei4 and Fkh2 on their own loci and performed synchronous meiosis. Cross-linked extracts were immunoprecipitated with specific antibodies and quantitative PCR reactions of different regions of rem1 (Fig. 13 A) were performed. As shown in Figure 13 B, Fkh2 and Mei4 bind specifically to rem1 promoter (compare Fig. 13, I and IV) in a time-specific manner. Concerning the timing, while Fkh2 increase its binding gradually along meiosis, Mei4 has a narrow window of interaction with the promoter, just at the onset of meiosis I. Interestingly, while Fkh2 seems to remain bound to the promoter, Mei4 has a more ubiquous positioning along the entire gene, meaning that Mei4 is probably travelling with the RNApolymerase (pol) II in the process of transcription.

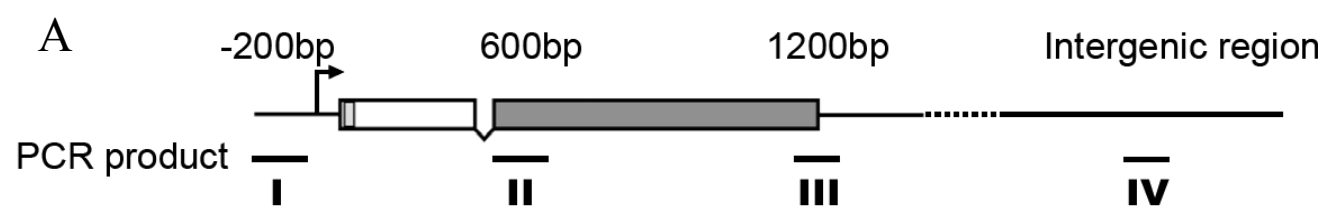

B
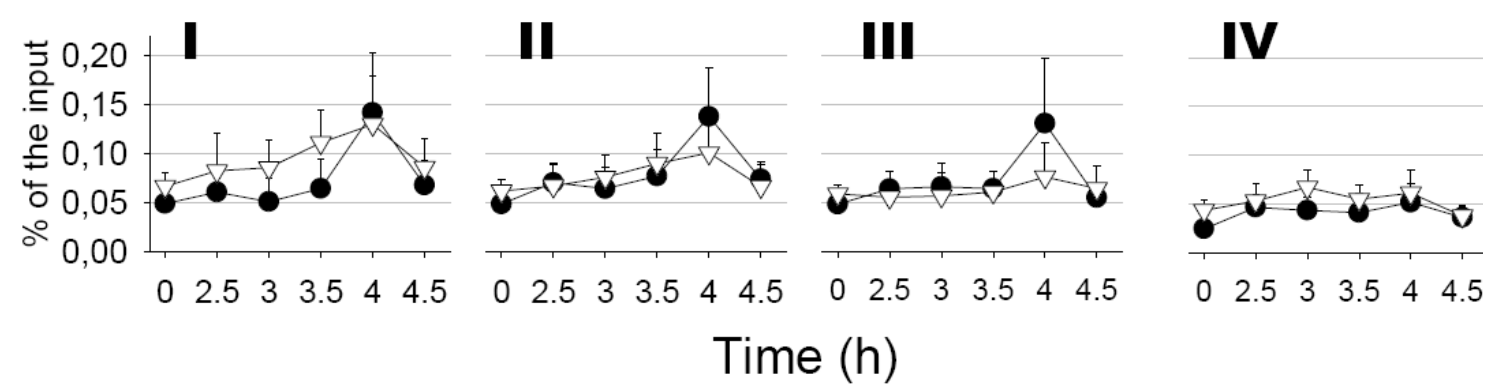

Figure 13. Mei4 and Fkh2 bind to rem1 in vivo. (A) Schematic of rem1 with the position of the quantitative PCR products (I to IV). (B) Recruitment of Mei4 and Fkh2 to rem1 promoter and coding regions (I to III) during meiosis. Cross-linked cell extracts from a wild-type strain expressing chromosomal Mei4-13Myc (closed circles) or Fkh2-HA (open triangles) were immunoprecipitated, and assayed for the presence of rem1. Hours of meiosis are indicated at the bottom. Data represent the mean and standard error of the mean of three independent experiments.

b) RNApolymerase II 
To further investigate the relationship of the RNApol II with Mei4, we performed ChIPs of the RNApol II with different antibodies in wild type and $\Delta$ mei4 strains. It has been described that the phosphorylation of the C-terminal domain (CTD)
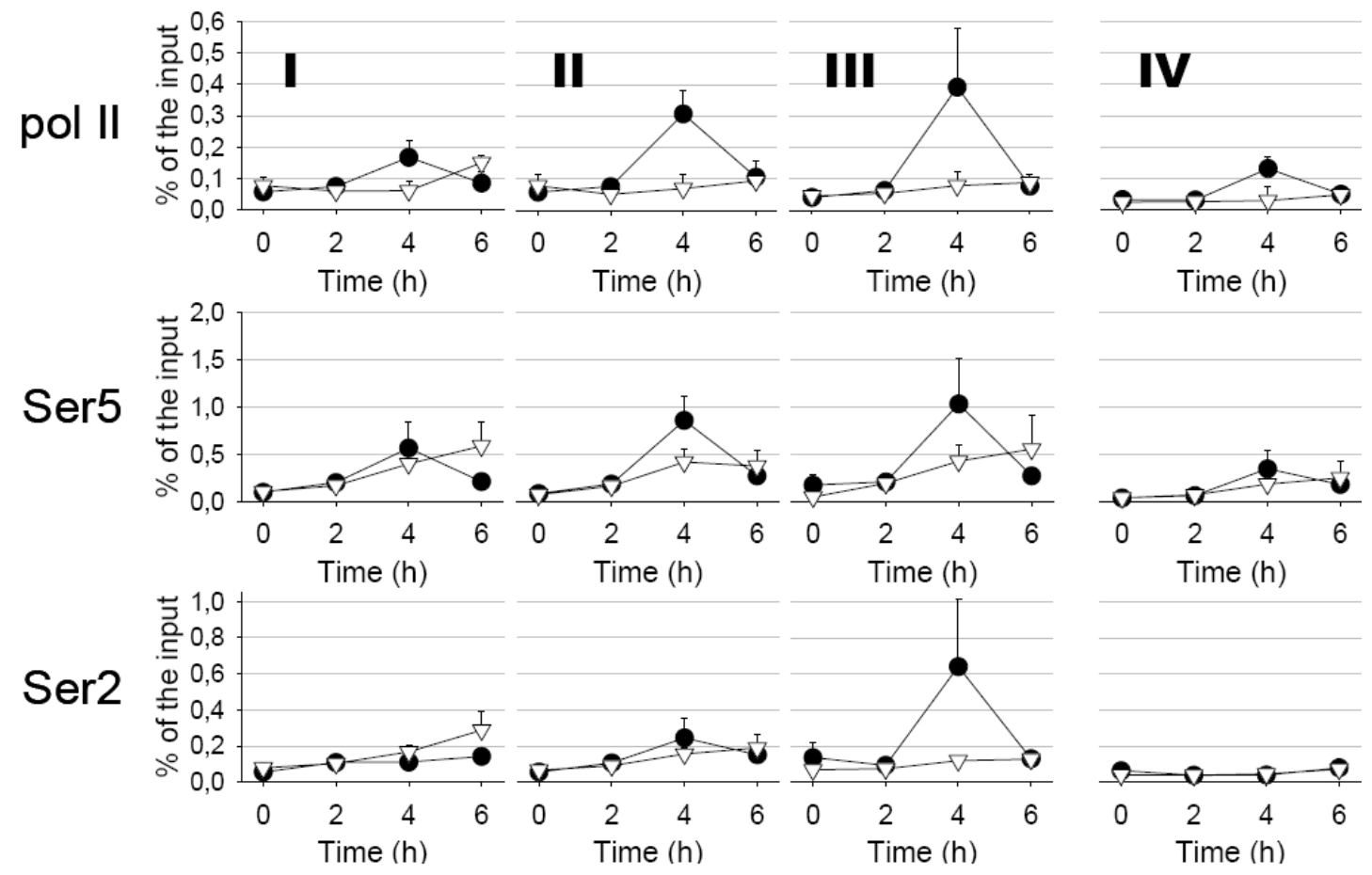

Figure 14. Recruitment of the RNApolymerase II is mei4-dependent. Loading of RNApol II during meiosis. Extracts from a wild type (closed circles) or $\Delta$ mei4 (open triangles) strain were immunoprecipitated with antibodies against pol II (top panels), phosphor-Ser5 (middle panels) or phosphorSer2 (bottom panels), and assayed for the presence of different regions (shown in Figure 13,A) of rem1. Time in hours after meiosis was induced is indicated at the bottom. Data represent the mean and standard error of the mean of three independent experiments.

repeats (YSPTSPS) of the polymerase are indicative of the activity of the RNApol II. (see Introduction).

Phosphorylation of Ser5 of the heptapeptide is indicative of the initiation of transcription, that is to say, the loading of the RNApol II to the promoter and 5' end of genes and does not correlate with spliceosome assembly. On the other hand, phosphorylation of Ser2 of the heptapeptide is indicative of the active elongating form of the RNApol II, the phosphorylation of this residue correlates with the recruitment of elongating factors and spliceosome (see Introduction). We have chromatin immunoprecipitated RNApol II from extracts of wild type or $\Delta m e i 4$ meiotic progressing cells with an antibody recognizing total RNApol II, specifically phosphoserine-5 and specifically phosphoserine-2. As shown in Figure 14, RNApol II acumulates 
specifically in rem 1 gene at 4 hours of meiosis in a mei4-dependent manner. For the phosphoserine-5 isoform of RNApol II, we can also see differences between wild type and $\Delta$ mei4 strains. In the $\Delta$ mei4 mutant it can be loaded to some extend to the promoter and induce some transcription (see Figure 14, Ser5 panel,) but the accumulation in the promoter lead us to suspect there are some problems in the elongation. This unefficient loading fails to elongate in the mutant strain as confirmed in the ChIP for Ser2 (Figure 14, Ser2 panel). The problems of the RNApol II to elongate at rem1 gene in a $\Delta$ mei4 strain could have consequences in coupling transcription to pre-mRNA processing.

c) Splicing Factors

A

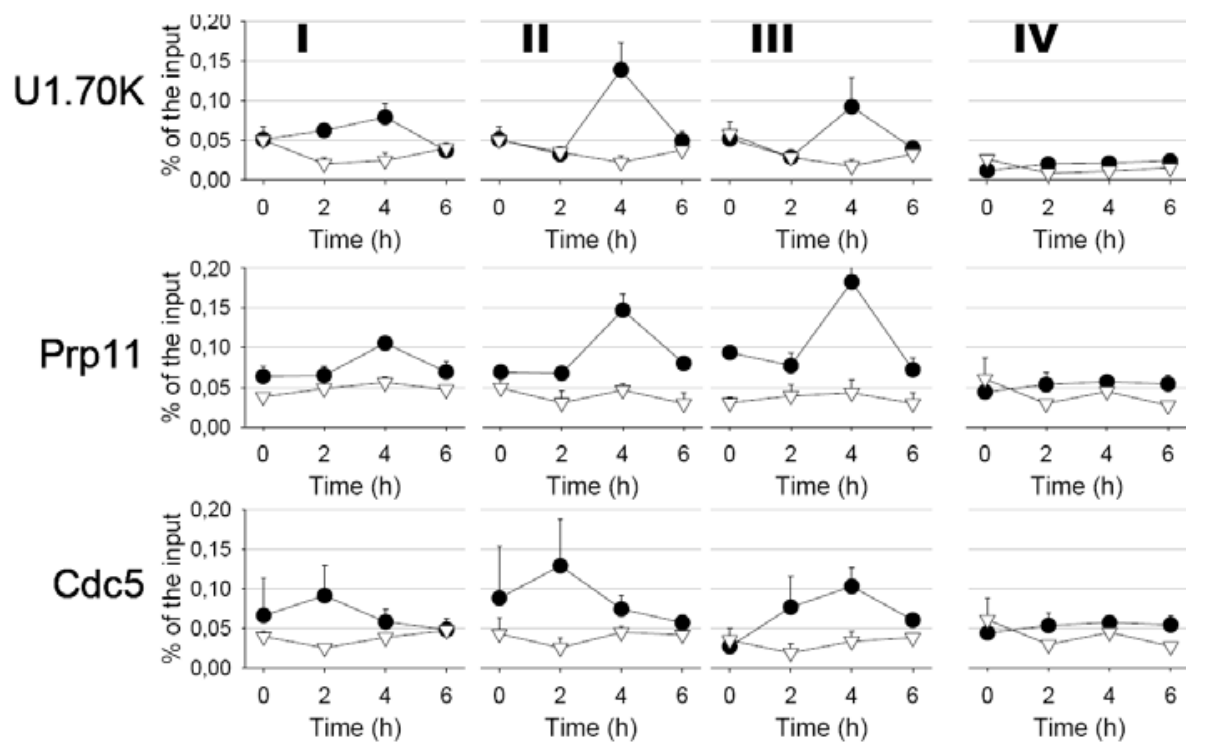

$\mathrm{B}$

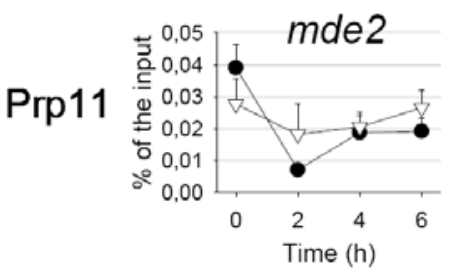

Figure 15. Loading of U1·70k, Prp11 and Cdc5 to rem1 locus depends on Mei4. (A) Wild-type strains (closed circles) containing TAP tagged U1·70k, Prp11 or Cdc5 or their $\Delta$ mei4 counterparts (open triangles) were induced into meiosis (time indicated at the bottom), and samples for ChIP assay were analysed for the presence of different regions (shown in Figure 13A) of rem1 by real-time PCR. (B) Loading of Prp11-TAP on mde2, an intronless mei4-dependent gene. Closed circles correspond to wild-type strain and open triangles to $\Delta$ mei4 strain. Note the different scale used compared to $(A)$. Data represent the mean and standard error of the mean of at least 3 independent experiments. 
We have determined that cells lacking Mei4 can not promote an efficient transcription of rem1 because although RNApol II can be recruited to the promoter, no efficient elongation can be achived.

Regarding the splicing regulation, we wanted to know if Mei4 and/or Fkh2 can recruit the spliceosome to specific promoters. To answer this question we used the same approach as for the RNApol II, we performed ChIPs of some components of the spliceosome. U1.70k, which is one of the 16 proteins of the U1 snRNP; Prp11, a complex B component, also known as PRP5 in other organisms; and Cdc5, a component of the ninteen complex (NTC) were tagged with TAP and chromatin immunoprecipitated from extracts of wild type or $\Delta$ mei4 meiotic progressing cells. We could detect U1·70k, Prp11 and Cdc5 bound to the rem1 ORF with an enrichment around the intron at 4 hours of meiosis in wild type cells. However, in the absence of Mei4, binding of U1·70k, Prp11 or Cdc5 was abolished (Figure 15 A).

A

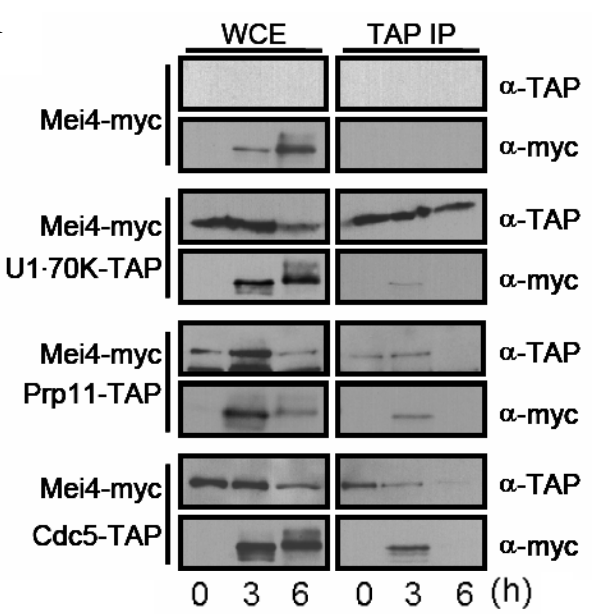

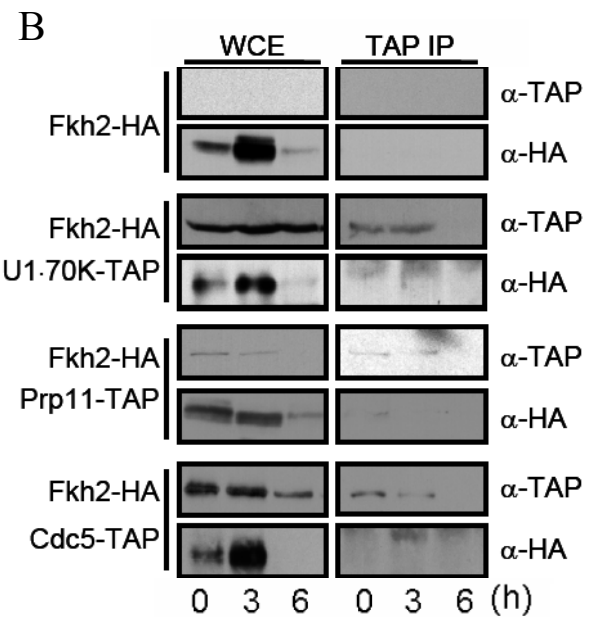

Figure 16. Mei4 coprecipitates with U1·70K, Prp11 and Cdc5. (A) Strains expressing Mei4-13Myc alone or co-expressing U1·70K-TAP, Prp11-TAP or Cdc5-TAP were induced into synchronous meiosis (time in hours is indicated at the bottom). (B) Strains expressing Fkh2-3HA alone or co-expressing U1.70K-TAP, Prp11-TAP or Cdc5-TAP were induced into synchronous meiosis (time in hours is indicated at the bottom). Extracts $(8 \mathrm{mg})$ containing tagged $\mathrm{U} 1 \cdot 70 \mathrm{~K}$, Prp 11 or Cdc5 were pulled down with IgGsepharose beads and Mei4 $(A)$ or Fkh2 $(B)$ were detected by western blotting using antibodies against Myc or HA, respectively (right panels, TAP IP). Expression of the different proteins was analysed on $50 \mu \mathrm{g}$ of total extracts (left panels, WCE).

Mei4, thus, is able to recruit RNApol II and the splicing machinery to specific genes on the onset of meiosis I.

Furthermore, to check if Mei4 was able to recruit the splicing machinery constituvely or just on intron-containing genes, we performed ChIP of Prp11 and assayed the presence of the Mei4-dependent intron-lacking gene mde2. As shown in 
figure $15 \mathrm{~B}$, we cannot detect the presence of the spliceosome in mde2 open reading frame, so Mei4 is only recruiting the spliceosome in intron-containing genes.

We have seen that Mei4 and the splicing machinery colocalize in rem1 gene in meiosis. We wondered now if Mei4 could interact physically with the splicing machinery to recruit it. To determine this interaction, we performed CoImmunoprecipitations (CoIPs) from nativ, A acts of cells progressing into meiosis. We pulled down U1·70k-TAP, Prp11-TAP and Cdc5-TAP and analysed the presence of Mei4 or Fkh2 in the immunoprecipitates. As shown in Figure 16, A, Mei4 can CoIP with the three members of the spliceosome studied, meaning the direct or indirect physical interaction between the transcription factor and the spliceosome. On the other hand, we can not detect at all Fkh2 in the immunoprecipitates of the spliceosome components (Figure 16, B).

Taking into account all these results, Mei4 seems to be promoting the transcription of rem 1 by recruitment of RNApol II on the onset of Meiosis I, travelling with it and stabilizing the elongation through the gene. Mei4 also seems to recruit the spliceosome to rem1 gene in mid-meiosis, promoting the processment of rem1 premRNA.

\section{$\underline{\text { Protein stability }}$}

Rem1 is also regulated at the level of protein. As in mitosis, the APC complex is necessary to trigger the anaphase and separate the sister chromatides in the two new cells or spores. Mfr1 is a fizzy-related protein exclusively expressed in meiosis that activates the APC in meiosis II inducing the degradation of Cdc13 (Blanco et al., 2001).

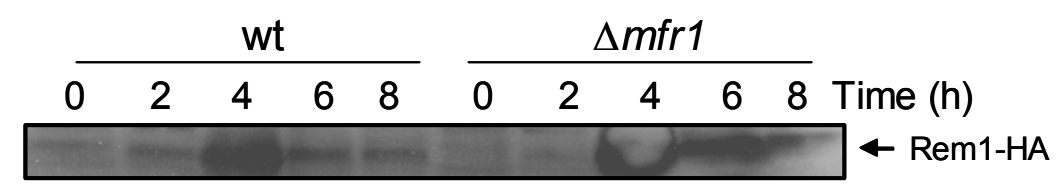

Figure 17. Rem1 degradation by Mfr1. Western blot of meiotic boiled extracts from wild-type and $\Delta m f r 1$ strains carrying Rem1-HA. 
We have shown that Mfr1 also regulates Rem1 stability since in a strain lacking $m f r 1$, we can detect Rem1 for a longer time in meiosis (Figure 17). This indicates a usual cyclin-like regulation for Rem1. The other APC-related E3 ubiquitin ligases expressed in vegetative cycle are not able to degrade Rem1 (Hiro Yamano, personal communication), this could partially explain the toxicity presented in cells expressing ectopically full length Rem1. 


\section{Regulation of other meiotic intron-containing genes}

We have determined that Fkh2 seems to avoid intron processing and keep rem1 at low transcription levels at early meiosis and on the onset of meiosis I, Mei4 promotes high levels of transcription and splicing of the intron allowing the expression of the full length protein. To examine whether intron retention was a common feature of other meiosis-specific genes apart from rem1, we decided to use whole-genome microarray analysis to compare transcriptional profile and intron retention of wild-type and $\Delta$ mei4 strains. These strains were induced to enter synchronous meiosis and cells were harvested at 0 and 4 hours after the temperature shift. RNA was isolated and sended to Dr. Chris Seidel's laboratory, at Stowers Institute (Kansas City). There, Madelaine Gogol, processed the samples and the microarray data was collected as described in Material and Methods. The microarray consisted of 8785 70-mer oligonucleotides representing 6918 exons, 1521 introns and 333 3' Untranslated Regions. Although the microarrays only included oligonucleotides for $31 \%$ of the total introns, the analysis showed that a set of genes presented intron retention in the absence of Mei4. First of all

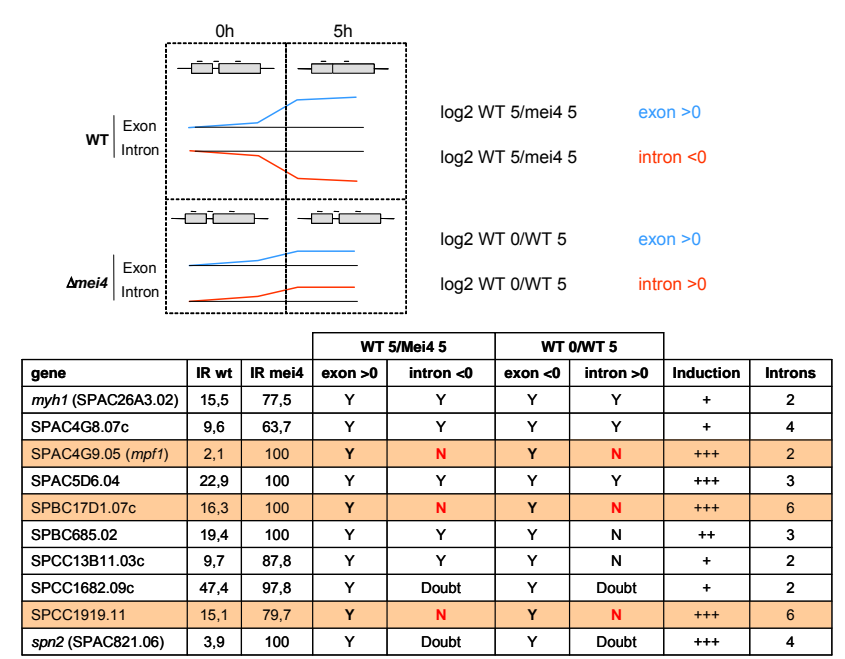

Figure 18. Microarray analisys. Mathematical criteria followed to search the candidate genes from the microarrays. we calculated the Intron Retention Rate (IR) of all the genes with plotted exons and introns with the data from the microarrays. We considered the signal from the exon as the total mRNA (processed and unprocessed mRNA) and the signal from the intron as the non-processed mRNA. So we had IR=intron/exon. Then, we compared the IR of the wt and the $\Delta$ mei4 samples.

Considering Mei4 dependence, induction in Meiosis, the IR and genes matching the criteria presented in Figure 18, we could find some candidate genes. After cheking all of them by RT-PCR, we noticed that not all of them behavied has rem1. Comparing the results back to the microarrays and considering new criteria derived from the positive ones, we restarted the search (we found that from the criteria at Fig. 18, the 
conditions 1 and 3 should be real). In the new search we looked for genes with "exon $>$ 0 " in the " $\log 2($ wt $5 \mathrm{~h} / \mathrm{mei} 45 \mathrm{~h})$ " values (meaning Mei4-dependance) and "exon $>0$ " in the " $\log 2($ wt $0 \mathrm{~h} / \mathrm{wt} 5 \mathrm{~h})$ " values (meaning induction in meiosis I) and genes with a FLEX motif similar to the first 3 positive genes (GTAAAYAAAYAAA and reverse), all of them were afterwards checked by RT-PCR. At the end of the process we could define a list of 10 rem1-like genes, behaving similarly in a wt, a $\Delta m e i 4$ and a $\Delta f k h 2$ strains (Figure 19).

A
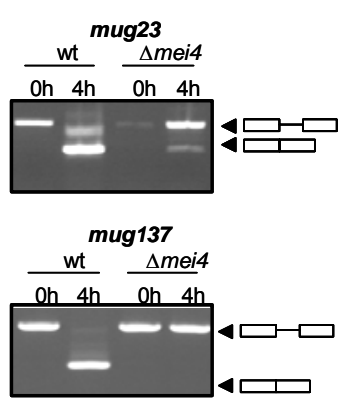

mde3
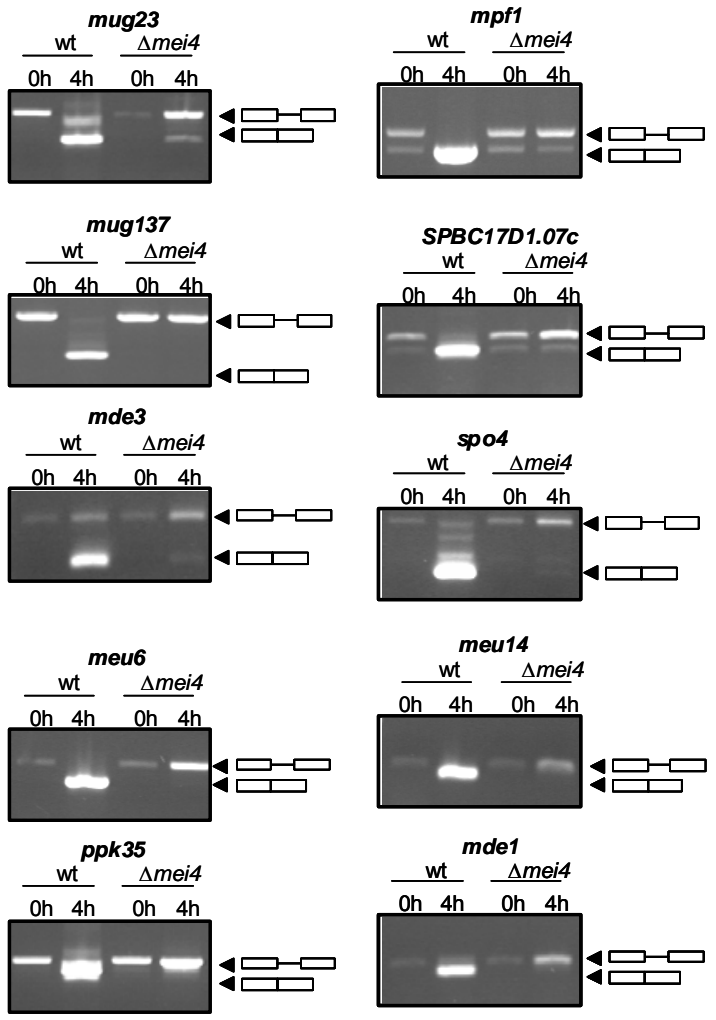

\begin{tabular}{lrcc}
\hline Gene Name & IR wt & IR $\Delta$ mei4 & FLEX box position \\
\hline mug23 & 18.8 & 56.5 & $-269,-125$ \\
mpf1 & 2.1 & 100.0 & $-192,-173$ \\
mug137 & 15.1 & 79.7 & $-905,-184$ \\
SPBC17D1.07c & 16.3 & 100.0 & $-166,-114$ \\
mde3 & 16.2 & 29.6 & $-251,-75$ \\
spo4 & 11.2 & 38.8 & $-413,-193,-97$ \\
rem1 & & & $-223,-182$ \\
meu6 & & & $-607,-135$ \\
meu14 & & & $-189,-12$ \\
ppk35 & & & $-294,-176$ \\
mde1 & & $-440,-181$ \\
\hline
\end{tabular}

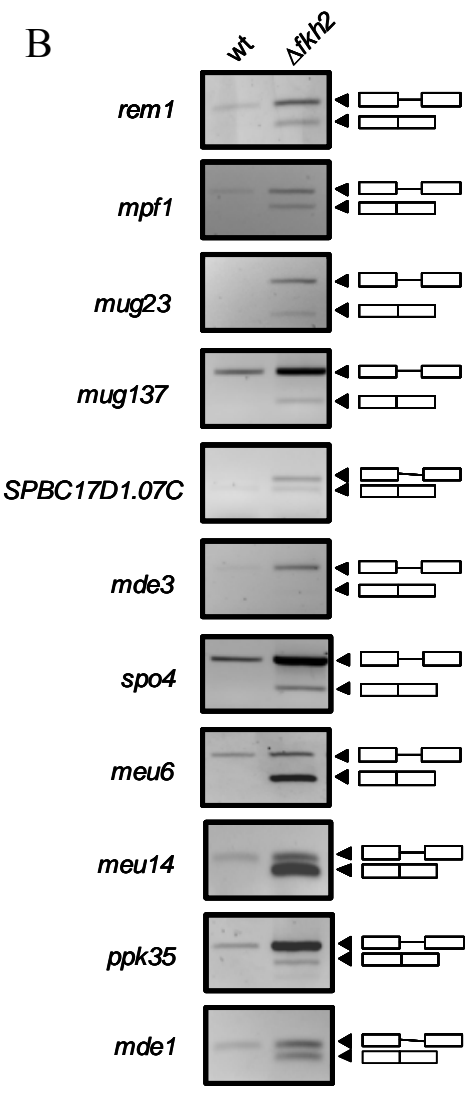

Figure 19. Validation of the candidates found. (A) RT-PCR of wild-type and $\Delta$ mei4 strains at 0 and 4 hours of meiosis with specific oligonucleotides for each gene. (B) RT-PCR of wild-type and $\Delta f k h 2$ strains vegetatively growing with specific oligonucleotides for each gene. (C) Table with the candidate genes, the intron retention rates from wild-type and $\Delta$ mei4 strains and the FLEX boxes position relative to the starting codon.

These results indicate that the regulation studied here for rem 1 is not only an individual case but a general mechanism regulating gene expression in meiosis. 
Even though, it remained unclear which was the difference between the group of genes found to behave as rem1 and the one behaving differently. To analyse the possibility that the difference may be in the promoter region we mapped the FLEX motives of both groups. The results are shown in Figure 20, where it is shown a scheme of the promoters with the localization, sense and length of the FLEX motif. We could observe that nearly all the FLEX boxes were localized between -200 and -50 from the ATG with a great variability regarding the length and direction of the motif. Though, we could not find any difference between both groups.
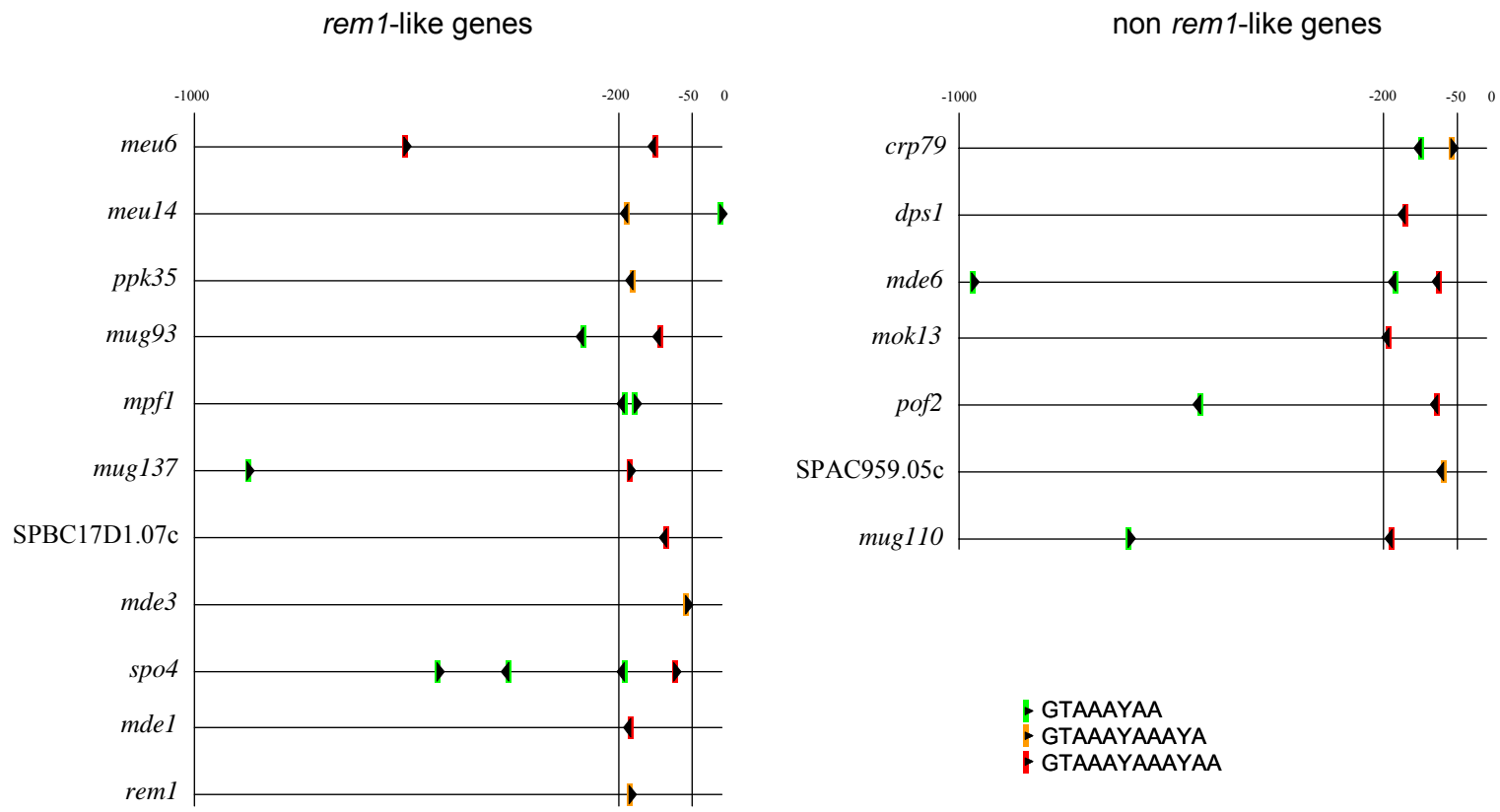

Figure 20. Relative position of FLEX boxes. Arrowheads indicate the orientation of the box and the colours indicate the length of the box. Positions are relatve to the start codon

Although, previously a consensus FLEX box was described (Horie et al., 1998), we have used the list of 11 genes to align their FLEX sequences and define a new and longer weigth matrix FLEX consensus box represented in Figure 21.

After defining this new FLEX box we decided to search the spreading among all the promoters of $S$. pombe with an algorithm designed for Microsoft Excel. We have found that 214 gene promoters have at least one copy of the nonamer GTAAACAAA, from which 9 have two copies of the FLEX box. Searching for the reverse sequence, we found that 332 gene promoters have at least one copy of the nonamer TTTGTTTAC, from which 23 gene promoters have 2 copies and 1 gene promoter has three FLEX boxes. 
Taking into account all these results we can conclude that the regulation of splicing is a general mechanism to control gene expression in meiosis.

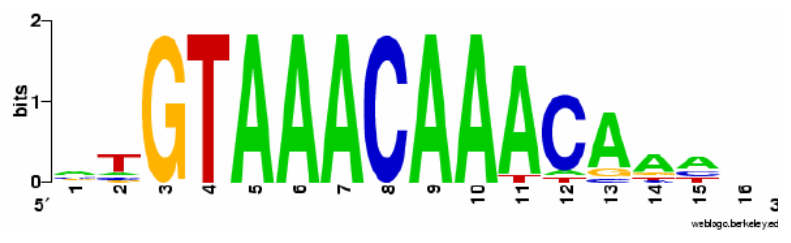

Figure 21. FLEX consensus box. The graph was obtained from the aligment of the FLEX boxes of the ten genes found. The software used was found at http://weblogo.berkeley.edu 


\section{Mei4 and Fkh2 regulation}

To further study the mechanism of splicing regulation in meiosis, we decided to analyse the regulation of the two main factors of this process, Mei4 and Fkh2. We wanted to characterize them at different levels: mRNA and protein levels, postraductional modifications and ability to bind to different promoters.

\section{Transcription of mei4 and $f k h 2$}

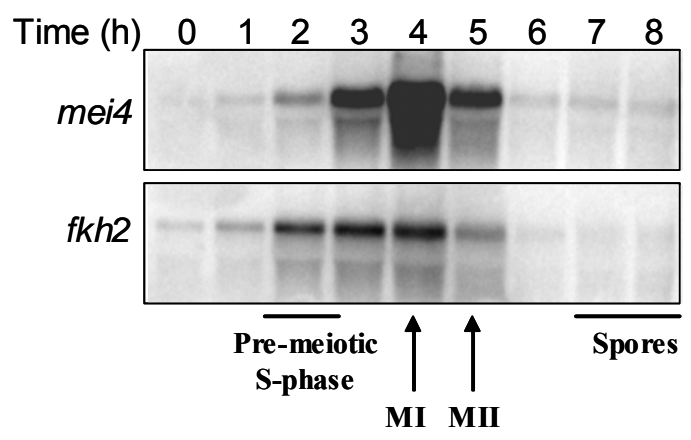

Figure 22. mRNA levels of mei4 and $f k h 2$ during meiosis. Northern blot analysis of mei4 and $f k h 2$ mRNAs with specific radiolabelled probes. Meiotic time-points are indicated.

Mei4 is only expressed in meiosis. mRNA levels in vegetative growing cells are nearly absent because the extremely low levels of mRNA transcribed are eliminated by the mmi1 system (Harigaya et al., 2006). In meiosis, mei4 mRNA is only detectable when pre-meiotic S-phase has finished and until Meiosis II. Concerning fkh2 mRNA, we can detect it from nearly the beginning of meiosis, then it increases slowly until meiosis I and then decreases until being not detectable (Figure 22).

\section{$\underline{\text { Protein expression of Mei4 and Fkh2 }}$}

At the protein level, Mei4 follows a similar patern as its mRNA, reaching the maximum levels at meiosis I. Fkh2 seems to be expressed constitutively, with a minor increase in the protein levels at mid-meiosis as seen on boiled extracts (Figure 23, A). In Mei4, a slow migrating band was observed at $4 \mathrm{~h}$ and since Mei4 has 4 putative phosphorylable sites we wanted to check if it was a mobility shift due to a phosphorylation. We treated the sample with alkaline phosphatase or lambda phosphatase and the result is shown in Figure 23, $B$. The alkaline phospatase had no effect but the lambda phosphatase we could observe that the band disappeared. Then, an assay with phosphatase inhibitor was performed to confirm the result. We could 
A

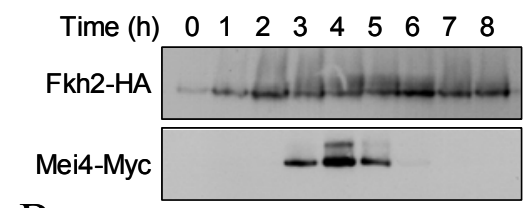

B

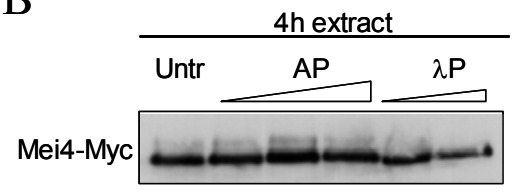

C

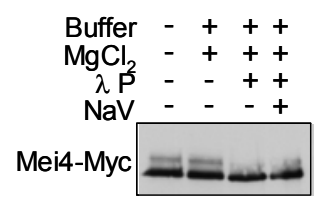

Figure 23. Mei4 and Fkh2 are phosphoproteins. (A) Western blot of boiled extracts at the indicated meiotic time points. (B) Alkaline and lambda phosphatases assay of Mei4-Myc at 4 hours of meiosis. (C) Phosphatase assay of Mei4-Myc at 4 hours of meiosis. observe that the band disappeared and that the mobility of the second band migrated faster. The results on figure 23 indicated that Mei4 suffers at least two phosphorylations.

Regarding Fkh2, it has 18 putative phosphorylable sites in its sequence. The western blot indicates that at mid-meiosis Fkh2 suffers a series of phosphorylation (Fig. 23). It has been reported that Cig2 phosphorylates Fkh2 during premeiotic S-phase (Shimada et al., 2007) but nothing is reported about the multiple phosphorylations at meiosis I.

\section{Phosphorylation by Cig2}
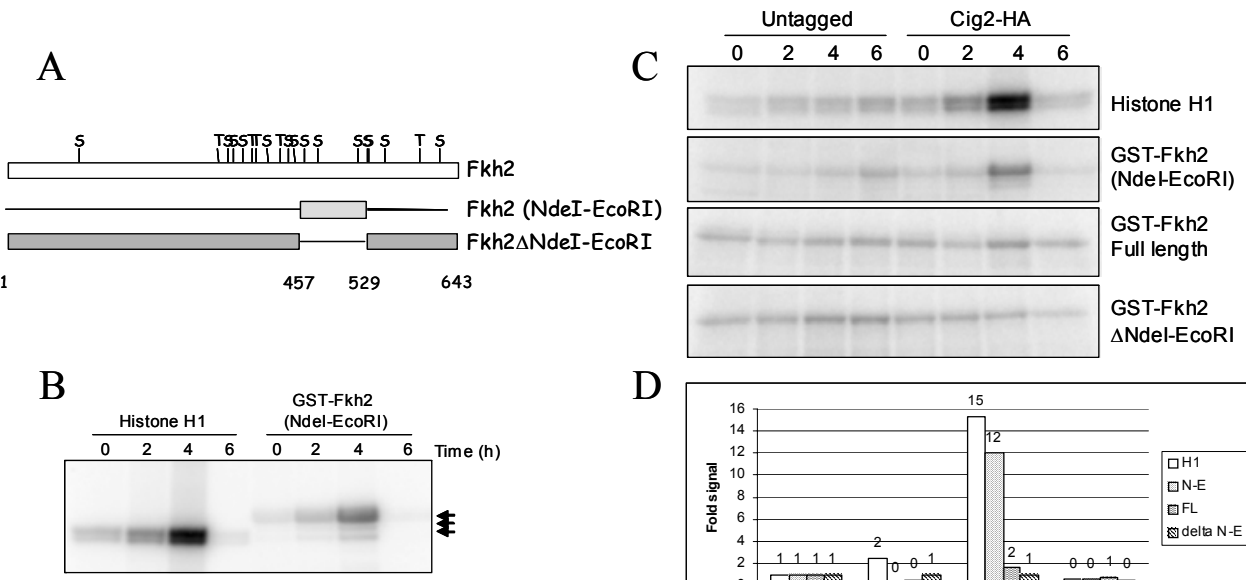

$\mathrm{D}$

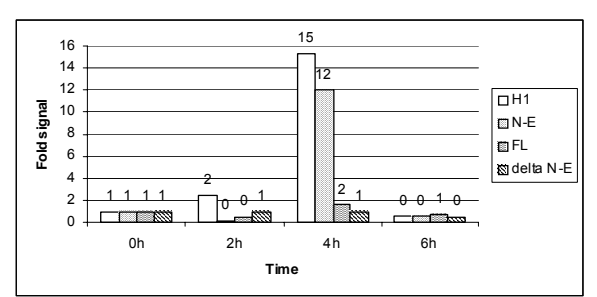

Figure 24. Phosphorylation of Fkh2 by Cig2. (A) Schematic of the contructs used. (B) Kinase assay of immunopurified Cig2-HA at the indicated meiotic time-points over Histone H1 and recombinant GSTFkh2 (NdeI-EcoRI). (C) Kinase assay of the immunopurified from an untagged strain or a strain with tagged Cig2-HA at the indicated meiotic time-points over Histone H1, recombinant GST-Fkh2 (NdeIEcoRI), recombinant GST-Fkh2 (Full length) and recombinant GST-Fkh2 $\Delta$ NdeI-EcoRI. Quantification of the signal obtained in (C, "Cig2-HA"). 
To study if the phosphorylation of Fkh2 was important for the splicing function we tried to find which the kinase responsible for this phosphorylation was. A good candidate was the Cig2/Cdc2 kinase complex, because its activity peaks at 4 hours of meiosis. We constructed several truncated proteins of recombinant GST-Fkh2 to check if there was specific phosphorylation by immunoprecipitated Cig2-HA from meiotic extracts. Fkh2 has 18 putative phosphorylation sites for cyclin/cdks complexes. After many constructs assayed we finally could limit a region whose peptide presented specific phosphorylation. The 73 aminoacids fragment (from Ser457 to Asn529) has 3 putative phosphorylable residues: Ser432, Ser481 and Ser522. The two former present the extended consensus phosphorylation site $[\mathrm{S} / \mathrm{T}-\mathrm{P}-\mathrm{X}-\mathrm{R} / \mathrm{K}]$ while the third one is just SP.

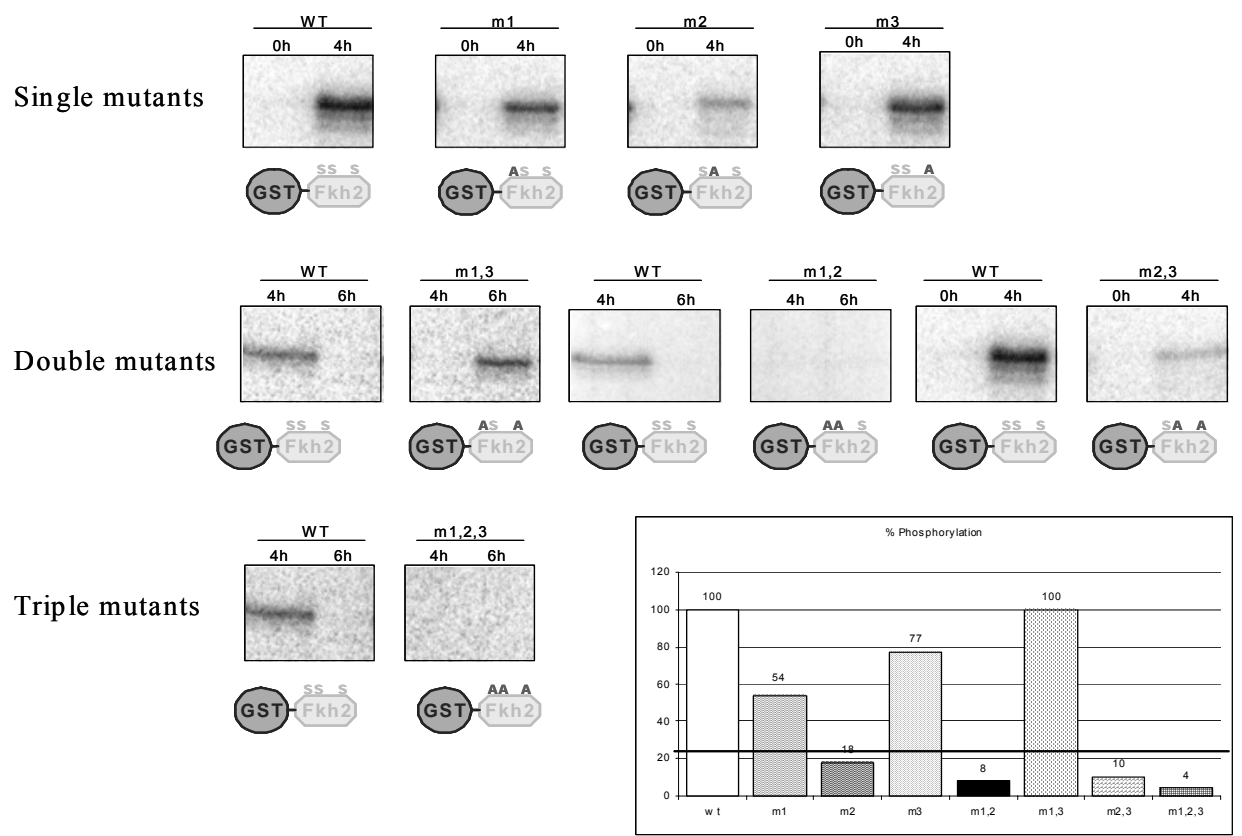

Figure 25. Cig2 phosphorylates Fkh2 at Ser481 in vitro. Kinase assay of immunopurified Cig2-HA at the indicated meiotic time-points over recombinant GST-Fkh2 (NdeI-EcoRI) carrying different point mutations. Quantification of the signal is shown. Data is expressed as relative to the wild-type.

In Figure 24, top left panel, we can observe a map of phosphorylation sites for Fkh2 and the constructs used. Meiotic extracts of an untagged strain and a strain expressing a tagged version of Cig2 (Cig2-HA) were obtained and an $\alpha-\mathrm{HA}$ immunoprecipitation was done to purify Cig2. The different GST-Fkh2 proteins were incubated with the immunoprecipitated Cig2-HA in presence of $\left[\gamma-{ }^{32} \mathrm{P}\right] \mathrm{ATP}$. We used Histone $\mathrm{H} 1$ as a positive substrate control. We can observe specific phosphorylation of 
Fkh2[457-529] (NdeI-EcoRI fragment) at 4 hours of meiosis. Furthermore, we do not observe specific phosphorylation of the complementary protein, Fkh2 $\Delta 457-529$. In the full length protein we can observe a moderate phoshphorylation. In the bottom right panel of figure 24 quantification of the assay is shown.

To check which of the three Serines was/were specifically phosphorylated by Cig2, we performed site-directed mutagenesis in the GST-Fkh2[457-529] fragment to mutate them to the non-phosphorylable aminoacid Alanine $(\mathrm{S} 432 \mathrm{~A} \rightarrow \mathrm{m} 1, \mathrm{~S} 481 \mathrm{~A} \rightarrow$ $\mathrm{m} 2$ and S522A $\rightarrow \mathrm{m} 3)$. We assayed the single, double and triple mutants with extracts from active or inactive Cig2 and, as shown in figure 25 (see quantification), and conclude that the main substrate of $\mathrm{Cig} 2 / \mathrm{Cdc} 2$ phosphorylation was Ser481 (m2). In the absence of S481, Ser432 (m1) was also phosporylated while mutation in S522 (m3) behaved nearly as the wild-type. Regarding the double and triple mutants, in all the cases that S481 $(\mathrm{m} 2)$ remained as wild type the construct presented wild type phosphorylation levels while if it was mutated the phosphorylation levels decreased more that $90 \%$.

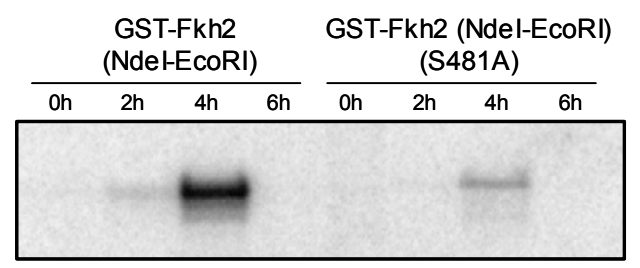

Figure 26. Serine 481 of Fkh2 is necessary for the Cig2 specific phosphorylation at meiosis I. Left panel, kinase assay of immunopurified Cig2-HA at the indicated meiotic time-points over recombinant wt or mutated GST-Fkh2 (NdeI-EcoRI) at Ser481. Right panel, quantification of the signal, the data is represented as relative to the $0 \mathrm{~h}$.

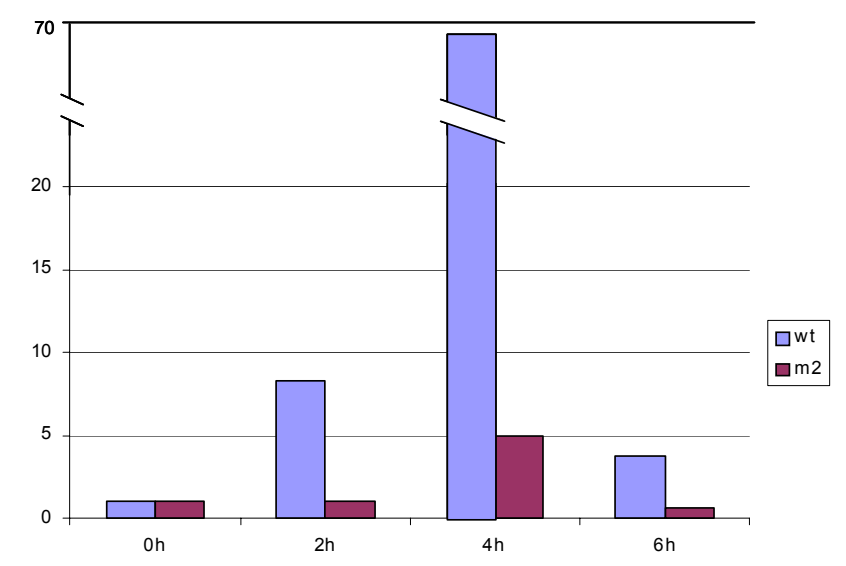

To confirm this result, we performed a complete time-course of meiosis and assayed Cig2-HA kinase activity with the wt and the S481A mutant GST-Fkh2[457-529] fragment. As shown in figure 26, the mutant fragment suffered a 15-fold reduction in the ${ }^{32} \mathrm{P}$ intake indicating an in vitro specific phosphorylation of $\mathrm{Cig} 2 / \mathrm{Cdc} 2$ over this residue at mid-meiosis. 


\section{in silico structure of Mei4 and Fkh2}

To try to understand the differences between these two transcription factors regarding their binding to the DNA, we compared the crystal structure of the DNAbinding domain. The structure of the transcription factor FoxK1a was determined by Kuang-Lei Tsai and coworkers (Tsai et al., 2006). This transcription factor has important aminoacid sequence homology with Mei4 and Fkh2, especially in the DNAbinding domain (Figure 23, A). Thus, we decided to model Mei4 and Fkh2 Forkhead DNA-binding domain by comparison and overlapping with the crystal structucture of the human FoxK1a transcription factor. Using PyMol v0.99 we obtained a 3D structure of our proteins. For both of them, we obtained a well-delimited helix-loop-helix motif,

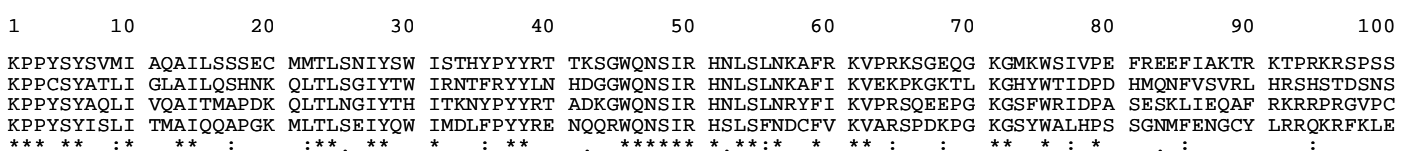
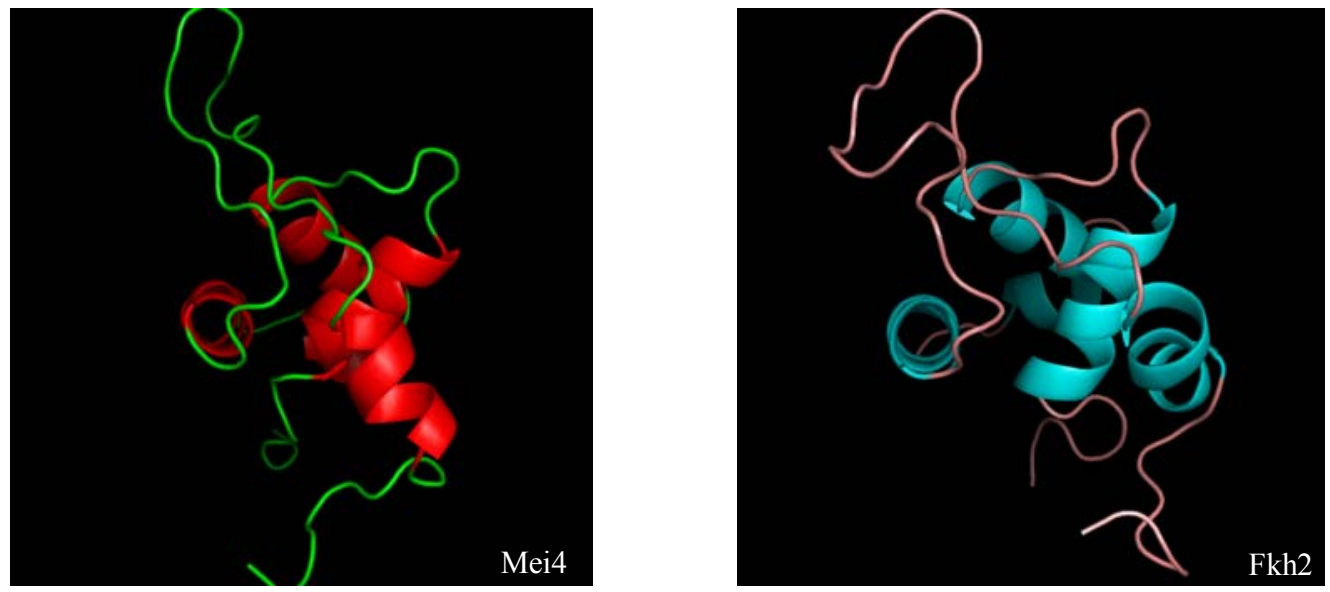

Figure 27. 3D structure of the DNA-binding domain of Mei4 and Fkh2. Aligment of the sequences used to perform the modelling. Bottom panel, result of the modelling for the two transcription factors.

with no significative differences of the core of the domain binding the DNA, which function is to recognize it unspecifically (Figure 27). The two "wings" of the motif, though, have differences regarding the structure and the way they should recognize the DNA.

As can be observed in Figure 28, these differences could explain the different specificity of promoters of the two factors. We could determine the DNA base pairs that can contact the factors but this must be validated experimentally since the modelling is only in silico. The theorical DNA-bindig box as far as this model is 
concerned is TAAACAANACA as shown in Figure 28. Although this experiments do not allow us to conclude anything regarding the binding of the transcription factors to the FLEX boxes, they just give us some hints and possible explanations of the differences of gene specificity for both of them.

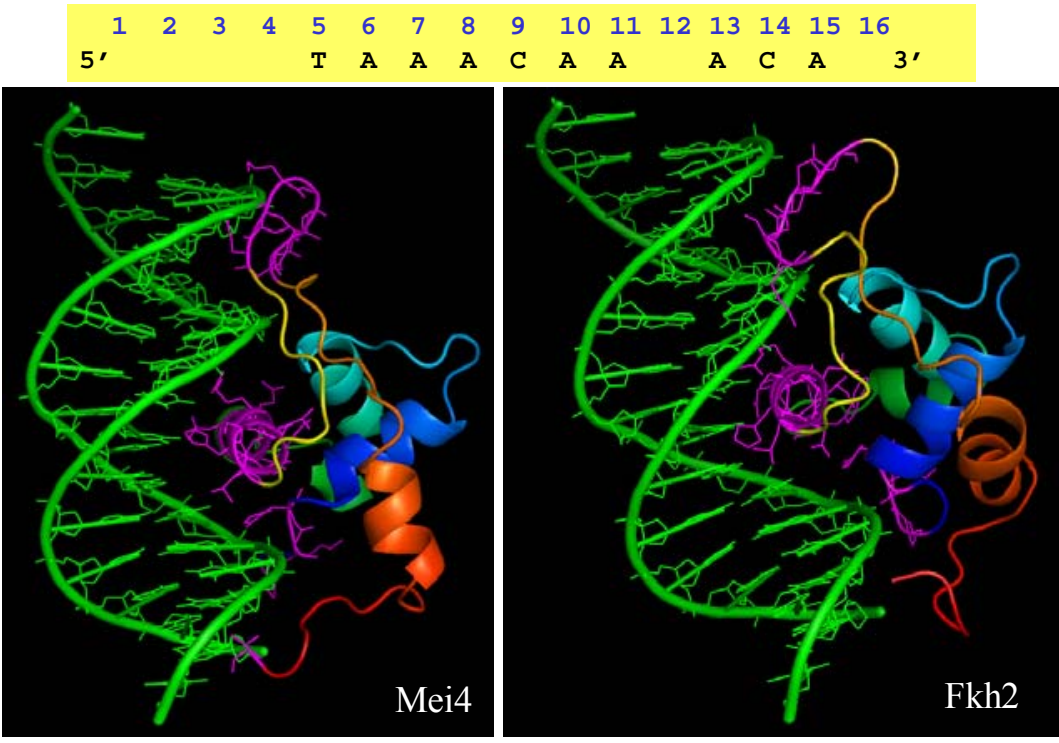

Figure 28. Model of the Mei4 and Fkh2 binding to the DNA. Top panel, nucleotides that directly contact the Forkhead domain. Bottom panel, model of the binding. The differences in how the wings touch the DNA can be appreciated. 


\section{Rem1 function}

Rem1 was initially isolated in silico by homology with other cyclins (Malapeira et al., 2005). The cyclin domain was localized entirely in the second exon of the gene, meaning that only when the mRNA is processed, the cyclin domain will be expressed. The first exon, has no sequence homology with any other known protein and does not seem to have any secondary structure.

\section{Cyclin function}

We started studying the full length protein, its association with Cdks and the associated kinase activity.

To check if Rem1 was associated with de S. pombe CDK Cdc2, we performed Co-Immunoprecipitations with cell expressing HA C-terminus tagged Rem1 from its own locus. Cells were harvested at 0 and $4.5 \mathrm{~h}$ of meiosis and native extracts were incubated with $\alpha$-HA antibody and Protein G-Sepharose. Immunoprecipitated proteins were separated by SDS-PAGE and western blotted with $\alpha$-PSTAIR antibody to detect $\mathrm{Cdc} 2$.

A

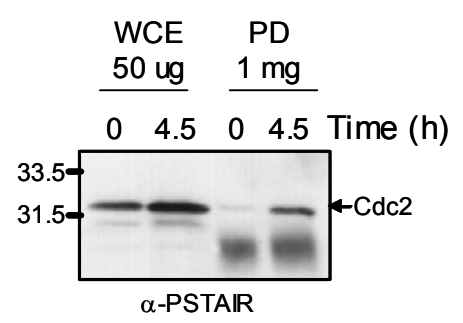

B

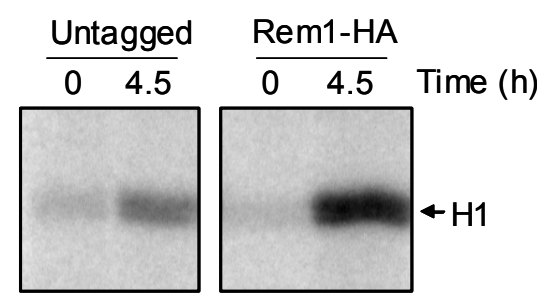

Figure 29. Cyclin function of Rem1. (A) Immunoprecipitation of Rem1-HA and Western Blot to detect $\mathrm{Cdc} 2$. (B) $\alpha-\mathrm{HA}$ immunoprecipitations from Untagged and Rem1-HA tagged strains were used for a kinase assay over Histone H1 (H1).

As shown in Figure 29, Cde2 can be detected when Rem1-HA is Immunoprecipitated. This shows that $\mathrm{Cdc} 2$ and Rem1 form a complex in mid-meiosis. To know if this complex could have kinase activity, in vitro kinase assays were performed with Rem1 purified from cells at different hours of meiosis. Specific phosphorylation of Histone $\mathrm{H} 1$ could be detected at $4.5 \mathrm{~h}$ of meiosis indicating that this complex has specific kinase activity (Figure 29 and (Malapeira et al., 2005)). 


\section{$\underline{\text { Recombination function }}$}

While searching for a phenotype of cells lacking Rem1 we found that it was necessary for meiotic recombination, that is to say, $\Delta$ rem1 cells presented $50 \%$ of intragenic recombination compared to wild type cells (Figure 30 and (Malapeira et al., 2005)).

It was really surprising to find a phenotype limited at $2-3 \mathrm{~h}$ of meiosis (a moment of meiosis when the mRNA is still not processed and the full length protein was not still expressed). This pointed the possibility that the mRNA itself was participating in the recombination events or that a protein encoded by the first exon, without being processed was participating in recombination.

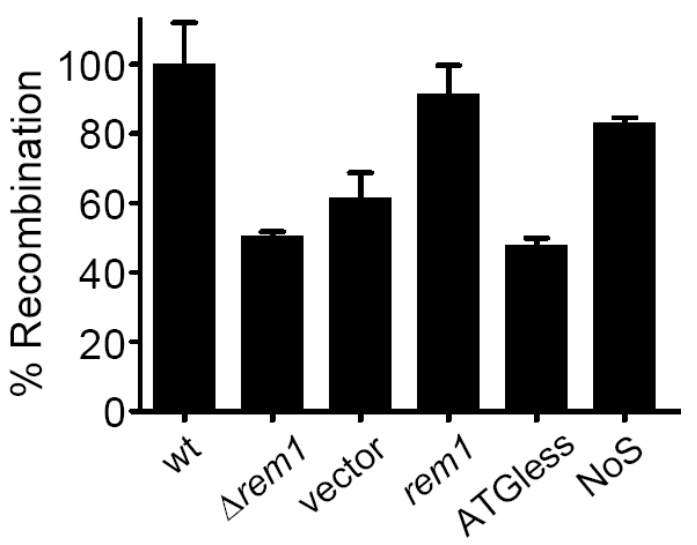

Figure 30. The second exon of Rem1 is not needed to have normal recombination levels. Levels of recombination were mesured in wild-type and $\Delta$ rem 1 strains and in a $\Delta r e m 1$ strain carrying an empty vector (vector), a full length copy of rem1 (rem1), a mutant rem1 without the initiaion codon (ATGless) and a rem1 with the 5' Splice Site mutated (NoS). The values are the mean and standard deviation of five independent experiments

To assay these possibilities recombination of various strains were quantified. We compared the recombination efficiency in the ade locus in different strains, a wildtype strain, a $\Delta$ rem1 strain and $\Delta$ rem1 strains transformed with different plasmids: an empty vector or vectors carrying a complete copy of rem1 genomic region, either with the wild-type sequence, carrying a mutation in the start codon (ATG $\rightarrow$ TAG) or carrying a mutation in the $5^{\prime}$ splice donor site $(\mathrm{GU} \rightarrow \mathrm{AC})$. As shown in Figure $30, \Delta$ rem 1 cells have decreased recombination efficiency compared to wild-type. If we transform it with a vector carrying a copy of rem1, the phenotype is reverted. The recombination is also affected if the protein cannot be expressed (ATGless) meaning that the mRNA directly has no effect on recombination. Even though, if we transform $\Delta$ rem1 cells with a copy lacking the 5 ' splice site, we can recover the recombination efficiency (Figure 26). To elucidate if the full length protein could also recover the phenotype, we transformed the cells with a copy of rem1 lacking the intron, we could observe a mating 
with spore viability bottom than $90 \%$, the spore formation was aberrant with asci contining only two spores or empty asci. This could be due to Rem1 expression toxicity in vegetative growing cells (Malapeira et al., 2005) so we could not conclude anything from this experiment. 
MATERIALS AND METHODS 


\section{Methodology}

Growth and maintainance of S. pombe

All S. pombe strains used are isogenic to wild type $972 \mathrm{~h}^{-}$. Media were prepared as described previously (Moreno et al., 1991).

\section{Cell fixation and DAPI staining}

4',6'-diamine-2-phenylindole (DAPI) is used to stain the DNA, this way, cells' nuclei can be easily observed under the microscope. Aproximately $10^{7}$ cells are harvested from the culture, centrifuged and resuspended in $70 \%$ Ethanol (EtOH). This way cells can remain fixed for a long time. To stain the cells, they should be previously rehidratated. When the desired amount of cells are put on the slide they are dried and $5 \mathrm{mg} / \mathrm{ml}$ DAPI is applied. Under a florescence lamp in the microscope and with a UV filter, nuclei can be easily observed.

\section{$\underline{\text { Flow citometry }}$}

It is used to mesure the relative DNA content of every single cell. $1 \mathrm{ml}$ of Sodium citrate $(50 \mathrm{mM}, \mathrm{pH} 7)$ is added to $100 \mu \mathrm{l}$ of $70 \% \mathrm{EtOH}$ fixed cells to wash them. $0.5 \mathrm{ml}$ of Sodium citrate $(50 \mathrm{mM}, \mathrm{pH} 7)$ with $50 \mathrm{mg} / \mathrm{ml} \mathrm{RNAse}$ are added and incubated over night $(\mathrm{o} / \mathrm{n})$ at $37^{\circ} \mathrm{C} .0 .5 \mathrm{ml}$ of Sodium citrate $(50 \mathrm{mM}, \mathrm{pH} 7)$ with Propidium Iodide is added, mixed vigorously and sonicated smoothly to separate cellular agregates. Samples are now ready to be analyzed in the flow citometer.

\section{$\underline{\text { Transformation of S. pombe }}$}

Cell culture should be grown in rich media until a concentration of $10^{7}$ cells $/ \mathrm{ml}$. Cells should be washed with water and resuspended in Litium Acetate (LiAc-TE: $0.1 \mathrm{M}$ Litium Acetate, $10 \mathrm{mM}$ Tris $\mathrm{pH}$ 7.5, 1mM EDTA). $2 \times 10^{6}$ cells are mixed with $4 \mu \mathrm{g}$ of carrier DNA (SIGMA Herring Sperm DNA (D-7290)) and $1 \mu \mathrm{g}$ of the transformant DNA. After incubating the cells for 10 minutes at room temperature, $260 \mu$ of 
PEG/LiAc-TE (LiAc-TE, 40\% PolyEthilenGlycol) are added and incubated for 1 hour at $25-30^{\circ} \mathrm{C} .43 \mu \mathrm{l}$ Dimethyl Sulfoxide are added and cells are heat shocked at $42^{\circ} \mathrm{C}$ for 5 minutes. After 2 water washes, cells are plated on selective media.

\section{$\underline{\text { Syncronous meiosis }}$}

Nearly all the cells used in this study were temperature sensitive pat1-114 strains so meiosis was performed as follows: $5 \times 10^{6}$ cells $/ \mathrm{ml}$ were starved of nitrogen $\mathrm{o} / \mathrm{n}$ (EMM without $\mathrm{NH}_{4} \mathrm{Cl}$, with $1 \%$ of glucose and $50 \mu \mathrm{g} / \mathrm{ml}$ of Leucine) so that cells block at G1. To induce meiosis to the cells, $25 \mathrm{mM} \mathrm{NH}_{4} \mathrm{Cl}$ and $50 \mu \mathrm{g} / \mathrm{ml}$ of Leucine are added and the culture is shifted to $34.5^{\circ} \mathrm{C}$ in a water bath with vigorous shaking. This way Pat 1 is inactivated sincronously and meiosis starts.

Sometimes, when cells were used for proteic assays, cultures were not nitrogen starved but directly shifted to $34.5^{\circ} \mathrm{C}$ asyncronously to increase protein recovery.

\section{$\underline{\text { RNA purification }}$}

Cells harvested at a concentration od $10^{7}$ cells $/ \mathrm{ml}$ were resuspended in $400 \mu \mathrm{l}$ of AE buffer (50 mM NaAcO pH 5.3, 10 mM EDTA pH 8.0). $40 \mu$ l of 10\% SDS, $350 \mu \mathrm{l}$ of Acid Phenol and $350 \mu \mathrm{l}$ of Chloroform are added. The mix is vortexed and incubated for 1 hour at $65^{\circ} \mathrm{C}$, remixing the cells every 10 minutes. Samples are washed twice with $400 \mu \mathrm{l}$ of premixed Acid phenol-Chloroform. To precipitate the RNA, sample were mixed with 2 volumes of $100 \% \mathrm{EtOH}$ and 1/10 of $3 \mathrm{M}$ Sodium Acetate $\mathrm{pH} 5.3$ and incubated for 30 minutes at $-20^{\circ} \mathrm{C}$. After centrifugation, supernatant (SN) was discarted and RNA pellet was resuspended in DEPC-treated water.

To eliminate the DNA contamination from the samples, $2 \mu \mathrm{g}$ of RNA are incubated with RNAse-free DNAse for 30 minutes at $37^{\circ} \mathrm{C}$. RNA was extracted with the Acid phenol-Chloroform method explaines above.

\section{$\underline{\text { Northen blot }}$}

3-10 $\mu \mathrm{g}$ of RNA are separated in 1\% agarose gel with Formaldehyde. RNA was transferred by capilarity to a GeneScreen Plus (NEN Life Science Products) o/n. 
Hybridization and washes are performed as explained by the manufacturer. DNA probes of the desiered genes were labelled radioactively with the Roche random primer labelling kit. Detection was performed in paralel with Phosphorimager Screen and with films.

\section{$\underline{\text { Reverse Transcriptase-PCR (RT-PCR) }}$}

$8 \mu \mathrm{g}$ of DNAse I-treated RNA is used for the reaction. The RNA is diluted up to $19 \mu \mathrm{l}$ and the samples are incubated at $65^{\circ} \mathrm{C}$ for 10 minutes. Then, the sample is splited in two tubes and the reagents from the Reverse Transcription System (Promega) kit are added (4 $\mu \mathrm{l}$ of 10x Reaction Buffer, $1 \mu \mathrm{l}$ of RNAsin, $8 \mu \mathrm{l}$ of $\mathrm{MgCl}_{2}, 4 \mu \mathrm{l}$ of $10 \mathrm{mM}$ dNTPs and $2 \mu \mathrm{l}$ of $100 \mathrm{mM}$ oligo dT). Then Reverse Transcriptase is added just to one of the duplicates and the reaction is performed as indicated by the manufacter ( 60 minutes at $42^{\circ} \mathrm{C}, 30$ minutes at $52^{\circ} \mathrm{C}$ and 3 minutes at $94^{\circ} \mathrm{C}$ ).

For the PCR reaction $1 \mu \mathrm{l}$ of the cDNA from the previous reaction is used and the oligos are chosen depending on the target gene. Reactions are loaded on a Ethidium Bromide gel to analize the results.

\section{$\underline{\text { Native protein extraction and immunoprecipitations }}$}

Extracts were prepared in NET-N buffer (Malapeira et al., 2005) and immunoprecipitations were performed with $30 \mu \mathrm{l}$ of $\operatorname{IgG}$ sepharose. Immunoprecipitates ( $8 \mathrm{mg}$ ) were done in IPP buffer [10 mM Tris (pH 8.0), $150 \mathrm{mM}$ $\mathrm{NaCl}, 0.1 \%$ NP-40, $1 \mathrm{mM}$ DTT, $0.5 \mathrm{mM}$ PMSF, $5 \mu \mathrm{g} / \mathrm{ml}$ leupeptin, and $5 \mu \mathrm{g} / \mathrm{ml}$ aprotinin] for TAP purification or NET-N for the rest of purifications, washed 3 times with the same buffer, resolved in $8 \%$ SDS-PAGE, transferred to nitrocellulose membranes, and blotted with the indicated antibody.

\section{$\underline{\text { Boiled protein extraction }}$}

Pellet from the culture is resuspended in $200 \mu$ of HB Buffer ( $25 \mathrm{mM}$ MOPS $\mathrm{pH}$ 7.2, $60 \mathrm{mM} \beta$-glycerol phosphate, $15 \mathrm{mM}$ P-nitro phenil phosphate, $15 \mathrm{mM} \mathrm{MgCl}_{2}$, $15 \mathrm{mM}$ EGTA, 1\% Triton X-100, $1 \mathrm{mM}$ DTT and $170 \mathrm{mg} / 1 \mathrm{PMSF}$ ). The mixture is 
boiled for 10 minutes and put back on ice. Glass beads are added and cells are broken up to $80 \%$ in a Minibead-beater. Glass beads are separated and extracts are quantified by Bradford.

\section{$\underline{\text { Wetern blot }}$}

Desired quantity of protein extract is mixed with loading buffer and run on a SDS-PAGE gel (10\% sodium dodecyl sulfatepolyacrilamide gel electrophoreis, 30:0.8 acrilamide:bisacrilamide), gel is transferred to a nitrocellulose membrane 1 hour at 400 $\mathrm{mA}$. The membrane is blocked with 5\% BSA or milk (depending on the primary antibody) for 1 hour and is incubated over night with the antibody. After 3 washes with TBS-T, the membrane is incubated with the secondary antibody, washed 3 times again with TBS-T and developed with ECL reagent kit.

\section{Phosphatase assay}

Phosphatase assay was performed with $30 \mu \mathrm{g}$ of cell native extracts and alkaline (Roche) or lambda phosphatase (New England Biolabs) was used as indicated by the manufacturer.

\section{Electrophoretic mobility shift assay}

Incubate the desired protein or extracts with 1x EMSA Buffer $(5 \mathrm{x}$ : $50 \mathrm{mM}$ HEPES (pH 7.9), $375 \mathrm{mM} \mathrm{KCl,} 12.5 \mathrm{mM} \mathrm{MgCl}_{2}, 0.5 \mathrm{mM}$ EDTA, $5 \mathrm{mM}$ DTT and 15\%

Ficoll), $1 \mu \mathrm{g}$ of polydI/dC, $10 \mu \mathrm{g}$ BSA and $1 \mu \mathrm{l}$ of ${ }^{32} \mathrm{P}$-labeled oligonucleotide probe (10K c.p.m.) in a final volum of $20 \mu \mathrm{l}$. Incubate for 20 minutes and load it on a $5 \%$ polyacrilamide gel with $0.5 \%$ TBE. Dry the gel and develope with autoradiographies.

\section{$\underline{\text { Chromatin ImmunoPrecipitation }}$}

$90 \mathrm{ml}$ of cells at $\mathrm{OD}_{600} 0.5$ (or equivalent) were crosslinked using $1 \%$ formaldehyde (final concentration) for 10 minutes at $25{ }^{\circ} \mathrm{C}$. The pellet was washed twice with PBS. Cells were resuspended in Breaking Buffer (0.1M Tris pH 8.0, 20\% 
glycerol and 1mM PMSF) and broken in a Minibead-beater 3 times at medium intesity. The pellet was washed twice with Lysis Buffer (50 mM Hepes pH7.5, $140 \mathrm{mM} \mathrm{NaCl}, 1$ mM EDTA 1\% Triton X-100, 0.1\% Sodium deoxycholate, 0.1\% SDS, $1 \mathrm{mM}$ PMSF), resuspended in $0.25 \mathrm{ml}$ of Lysis Buffer and sonicated to a mean chromatin fragment size of $500 \mathrm{bp}$ on a Diagenode water Sonicator. The chromatin was centrifuged 15 minutes at $14 \mathrm{krpm}$ and the pellet was discarded. Immunoprecipitations were performed overnight with the same amount of protein (measured by Bradford) with $15 \mu 1$ IgG-Sepharose (Amersham) or a specific antibody [9E10 for Myc-tagged proteins, 12CA5 for HA-tagged proteins, $\alpha$-RNA pol II CTD monoclonal antibody (8WG16, Abcam), $\alpha$-RNA pol II CTD (phospho-Ser5) polyclonal antibody (Abcam) or $\alpha$-RNA pol II CTD (phospho-Ser2) polyclonal antibody (Abcam)]. Immunoprecipated extracts were incubated with $15 \mu \mathrm{l}$ of Protein G Sepharose for 5 hours. Beads were washed once with Lysis buffer, twice with Lysis buffer $500 \mathrm{mM} \mathrm{NaCl}$, twice with Wash Buffer (10 $\mathrm{mM}$ Tris $\mathrm{pH} 8,0.25 \mathrm{M} \mathrm{LiCl}, 0.5 \%$ NP-40, 0.5\% Sodium deoxycholate, $1 \mathrm{mM}$ EDTA, 1 $\mathrm{mM}$ PMSF) and once with TE (10 mM Tris $\mathrm{pH} 8,1 \mathrm{mM}$ EDTA). The beads were

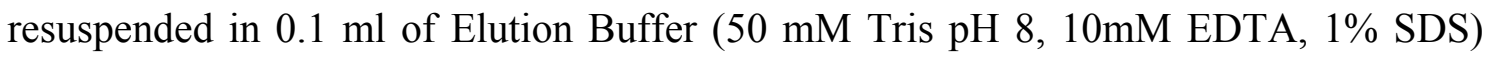
and incubated at $65^{\circ} \mathrm{C}$ for 20 minutes. Then the beads were washed with $0.15 \mathrm{ml}$ of $\mathrm{TE} / 0.67 \%$ SDS and the crosslinking was reversed overnight at $65^{\circ} \mathrm{C}$. To clean up the DNA, $0.25 \mathrm{ml}$ of TE were added, $1 \mu \mathrm{l}$ of $20 \mathrm{mg} / \mathrm{ml}$ glycogen and $7.5 \mu 120 \mathrm{mg} / \mathrm{ml}$ of Proteinase $\mathrm{K}$ and incubated 2 hours at $37{ }^{\circ} \mathrm{C}$. DNA was extracted with 1:1 Phenol/Chloroform and precipitated with $\mathrm{EtOH}$ and sodium acetate for $30 \mathrm{~min}$ at $-20^{\circ} \mathrm{C}$. DNA was pelleted $30 \mathrm{~min}, 14 \mathrm{krpm}$ at $4^{\circ} \mathrm{C}$. The pellet was air dried and resuspended in $100 \mu \mathrm{l}$ of TE. To perform the PCR, SYBR Green kit was used and quantitative real time PCR was performed in an Applied Biosystems Cycler. Data was expressed as percentage of the input.

\section{$\underline{\text { In vitro kinase assay }}$}

0.5-1 $\mathrm{mg}$ of total extract is purified conviniently depending on the protein and/or the tag. After the washes described previously, an addidtional wash with 1x Kinase Buffer (2x Kinase Buffer: 100 mM HEPES pH 7.5, 20 mM MgCl, 4 mM EGTA, 2 mM DTT) is performed. Then, $1 \mathrm{x}$ Kinase Buffer with the substrate and $10 \mathrm{mCi}$ of $\gamma-{ }^{32} \mathrm{P}$ ATP are added and incubated for 20 minutes at $30^{\circ} \mathrm{C}$. To stop the reaction loading 
buffer is added and put it on ice. The samples are then boiled and proteins are separated by SDS-PAGE. The gel is Coomassie-stained and dried. The signal is detected by autoradographies.

\section{$\underline{\text { Recombiantion assays }}$}

Recombination efficiency was determined as described (Malapeira et al., 2005). Basically, intragenic ade6 recombination (gene conversion) was measured in wild-type and $\Delta$ rem1 strains with the ade6 alleles M26 and 52. Ade+ prototrophs/106 viable spores were measured and plotted the efficiency relative (in \%) to a wild type strain.

\section{Microarray experiments and data evaluation}

Global expression analysis utilized custom designed S. pombe microarrays. Array construction, sample labeling, and hybridization, were carried out as described previously (Sinibaldi et al., 2001). The arrays consisted of 8785 70-mer oligonucleotides representing 6918 exons, 1521 introns, and 333 3' UTRs (http://research.stowers-institute.org/microarray/S_pombe/). Briefly, total RNA was prepared from wild type, and $\Delta$ mei4 strains, at 0 and 4 hours into meiosis. Polyadenylated RNA was extracted from total RNA by purification with an oligo(dT) cellulose column. RNA quality was assessed on a Bioanalyzer 2100 machine (Agilent). $2 \mu \mathrm{g}$ of RNA per sample was converted to cDNA by priming with oligo-dT18 and polydN9 in the presence of aminoallyl-dUTP (Ambion), followed by conjugation to Cy5 or Cy3 flourescent dyes. Samples were dye swapped for further technical replication. Labelled samples were mixed for comparative hybridization on poly-L-lysine-coated microarrays printed with 70-mers representing all known S. pombe reading frames, and introns greater than 70 bases in length. The microarrays were scanned with a GenePix 4000B scanner and the images analyzed using GenePix Pro 6.0 software (Molecular Devices, Union City, CA). Data analysis was performed with the R programming language. Differential expression was assessed using the limma package (Smyth, 2004).

Eight microarrays were used, with two experimental factors: time points 0 and 4 hours from meiotic induction and strains wild type and $\Delta$ mei4. Data within arrays was normalized using the print-tip loess method. Data between arrays was normalized using Aquantile normalization. Linear models were fit with coefficients estimated for wt 
0/mei4 0, wt 4/mei4 4, wt 0/mei4 4, and mei4 0/mei4 4. Microarray data are available at ArrayExpress (www.ebi.ac.uk/arrayexpress/) with accession number: E-TABM-465.

\section{Modelling of protein structure}

The modelling of the 3D structure of the DNA-binding domain of Mei4 and Fkh2 was performed with the programme PyMol v0.99. The modelling was based on the crystal structure presented elsewhere (Tsai et al., 2006). 


\section{Strains}

\begin{tabular}{|c|c|c|}
\hline Strain & Genotype & Figure \\
\hline JA95 & $\begin{array}{l}\text { pat1-114/pat1-114 rem1::rem1-HA kan }{ }^{+} / \mathrm{rem}^{+} \\
\text {leu1-32/leu1-32 ade6-M210/ade6-M216 } \mathrm{h}^{-} / \mathrm{h}^{-}\end{array}$ & 17,25 \\
\hline JA124 & ade6-M26 leu1-32 ura4-D18 $\mathrm{h}^{-}$ & 26 \\
\hline JA128 & ade6-M52 leu1-32 ura4-294 $\mathrm{h}^{+}$ & 26 \\
\hline JA163 & nmt41x(-130)rem1-kan+ leu1-32 $\mathrm{h}^{-}$ & 5 \\
\hline JA167 & nmt41x(ATG) rem1-kan+ leu1-32 $\mathrm{h}^{-}$ & 5 \\
\hline JA247 & pat1-114 leu1-32 $\mathrm{h}^{-}$ & $\begin{array}{l}2,6,7,9,10 \\
11,12,14,18 \\
20,25,27,28\end{array}$ \\
\hline JA249 & pat1-114 rem1::ura4+ leu1-32 $\mathrm{h}^{-}$ & $2,3,4,5,8$ \\
\hline JA397 & pat1-114 mfr1::ura4 rem1-HA-Kn leu1-32 ura4-D18 h- & 17 \\
\hline JA406 & pat1-114 rem1:: ura4+ rem1_genomic@leu1 leu1-32 h' & \\
\hline JA416 & pat1-114 mei4::ura4 leu1-32 ura4-D18 $\mathrm{h}^{+}$ & $\begin{array}{l}6,7,9,11,12 \\
14,27,28\end{array}$ \\
\hline JA417 & pat1-114 rem1-GST:Kn leu1-32 & 2 \\
\hline JA463 & pat1-114 sep1::ura4 leu1-32 ura4-D18 $\mathrm{h}^{+}$ & 9 \\
\hline JA480 & pat1-114 fhl1::kan+ leu1-32 $\mathrm{h}^{-}$ & 9 \\
\hline JA489 & rem1::kan leu1-32 ade6-M26 $\mathrm{h}^{-}$ & 26 \\
\hline JA494 & rem1::kan leu1-32 ade6-52 ura4-294 $\mathrm{h}^{+}$ & 26 \\
\hline JA497 & pat1-114 fkh2-HA: kan+ leu1-32 $\mathrm{h}^{+}$ & 13,19 \\
\hline JA508 & pat1-114 fkh2::kan+ leu1-32 $\mathrm{h}^{-}$ & $10,11,28$ \\
\hline JA509 & pat1-114 mei4-13Myc-kn+ leu1-32 $\mathrm{h}^{-}$ & 13,19 \\
\hline JA536 & pat1-114 cig2-HA leu1-32 $\mathrm{h}^{-}$ & 20 \\
\hline JA544 & pat1-114 prp11-TAP- $\mathrm{kn}+\mathrm{leu} 1-32 \mathrm{~h}^{+}$ & 15,16 \\
\hline JA545 & pat1-114 mei4:ura4 pap11-TAP- kn+ leu1-32 & 15 \\
\hline JA546 & pat1-114 cdc5-TAP-kan+ leu1-32 $\mathrm{h}^{+}$ & 15,16 \\
\hline JA548 & pat1-114 mei4::ura4 cdc5-TAP-kan+ leu1-32 ura4-D18 h- & 15 \\
\hline JA551 & pat1-114 mei4-13Myc-kan+ cdc5-TAP-kan+ leu1-32 & 16 \\
\hline JA552 & pat1-114 mei4-13Myc-kan+ prp11-TAP-kan+ leu1-32 & 16 \\
\hline JA558 & pat1-114 fkh2-HA-kan+ prp11-TAP-kan+ leu1-32 & 16 \\
\hline JA559 & pat1-114 fkh2-HA-kan+ cdc5-TAP-kan+ leu1-32 & 16 \\
\hline JA661 & pat1-114 U1 $\Delta 70 \mathrm{~K}-2 \mathrm{XTAP}-\mathrm{kan}+$ leu1-32 $\mathrm{h}^{+}$ & 15,16 \\
\hline JA662 & pat1-114 U1 $\Delta 70 \mathrm{~K}-2 \mathrm{XTAP}-\mathrm{kan}+$ mei4:ura4 leu1-32 & 15 \\
\hline JA728 & pat1-114 U1 $\Delta 70 \mathrm{~K}-2 \mathrm{XTAP}-\mathrm{kan}+$ mei4-13Myc-Nat+ leu1-32 $\mathrm{h}^{+}$ & 16 \\
\hline JA733 & pat1-114 U1 $\Delta 70 \mathrm{~K}-2 \mathrm{XTAP}-\mathrm{kan}+\mathrm{fkh} 2-\mathrm{HA}-\mathrm{kan}+\mathrm{leu} 1-32 \mathrm{~h}^{+}$ & 16 \\
\hline JA699 & pat1-114 fkh2::kan+ mei4::ura4 leu1-32 ura4-D18 h ${ }^{-}$ & 11 \\
\hline
\end{tabular}




\section{Plasmids}

\begin{tabular}{|l|l|l|}
\hline Plasmid & Description & Figure \\
\hline pAY043 & pJK148 & 26 \\
\hline pAY155 & pAY168-1.2 kbp rem1 promoter-rem1 6 652nt & 2 \\
\hline pAY168 & pJK148-1.2 kbp rem1 promoter-rem1-500 bp 3'UTR & $3,4,8,26$ \\
\hline pAY169 & pJK148-1.2 kbp rem1 promoter-rem1 (ATG $\rightarrow$ TAG)-500 bp 3'UTR, ATGless & 4,26 \\
\hline pAY171 & pJK148-1.2 kbp rem1 promoter-rem1 (GT1676AC)-500 bp 3'UTR, NoS & 3,26 \\
\hline pAY278 & pREP-1.2 kbp rem1 promoter +UTR-HA- rem1 & 26 \\
\hline pAY322 & pREP-rem1 prom + UTR (PstI/XhoI)-HA (XhoI/BamHI)-rec6 (BamHI/SmaI) & 6 \\
\hline pAY324 & pREP-rem1 prom + UTR (PstI/XhoI)-HA (XhoI/BamHI)-cdc2 (BamHI/SmaI) & 6 \\
\hline pAY334 & pREP-rem1 promoter-cdc2-nmt term & 6,7 \\
\hline pMV100 & pREP-prom res2-rem1 & 5 \\
\hline pAY344 & pGEX-4T-1 Fkh2 (BamHI/SmaI) & 20, \\
\hline pAY361 & pGEX-4T-1 Fkh2 NdeI to EcoRI & $20,21,22$ \\
\hline pAY363 & pGEX-4T-1 Fkh2 $\Delta$ NdeI-EcoRI & 20 \\
\hline pAY365 & pGEX-4T-1 Fkh2 NdeI to EcoRI (Ser462Ala) m1 & 21 \\
\hline pAY366 & pGEX-4T-1 Fkh2 NdeI to EcoRI (Ser481Ala) m2 & 21,22 \\
\hline pAY367 & pGEX-4T-1 Fkh2 NdeI to EcoRI (Ser522Ala) m3 & 21 \\
\hline pAY368 & pGEX-4T-1 Fkh2 NdeI to EcoRI (Ser481,522Ala) m2,3 & 21 \\
\hline pAY369 & pGEX-4T-1 Fkh2 NdeI to EcoRI (Ser462,481Ala) m1,2 & 21 \\
\hline pAY370 & pGEX-4T-1 Fkh2 NdeI to EcoRI(Ser462,522Ala) m1,3 & 21 \\
\hline pAY371 & pGEX-4T-1 Fkh2 NdeI to EcoRI (Ser462,481,522Ala) m1,2,3 & 21 \\
\hline pAY372 & pAY168 $\triangle$ FLEX1 (has a deletion of the core GTAAACAAA) & 8 \\
\hline pAY374 & pAY168 FLEX2mut (GTAAACA $\rightarrow$ CTAATGA) & 8 \\
\hline pAY375 & pAY168 $\triangle$ FLEX1,FLEX2mut (GTAAACA $\rightarrow$ CTAATGA) & 8 \\
\hline
\end{tabular}




\section{Oligonucleotides}

\begin{tabular}{|c|c|c|}
\hline Oligo & Sequence & Description \\
\hline JA44 & GCAGCTTGAATGGGCTTCCATAG & nmt terminator \\
\hline JA71 & CAAAGTCCTAATTGCAGTGTTTCGG & rem1 (seq +300, RT-PCR) \\
\hline JA174 & GGAGGATGGATCTCTTCATACTTGC & rem1 (RT-PCR) \\
\hline JA218 & CCATATTGAGTAAGGAATGTCC & 5' rec6 \\
\hline JA219 & GTCGAGAAGGGAAGACTCACTG & 3' rec6 \\
\hline JA286 & CACCGTTCACTAGCTGGTAGGTAAAC & 3' cdc2 \\
\hline JA310 & GCTAATAGCGGATCCATGGAG & 5' for RT-PCR rem1-cdc2 \\
\hline JA311 & GGCAATTTGAAGCTAGCAGATTTTGG & 5' mid cdc2 (downstream) \\
\hline JA312 & GCTAGGTTGCTTCTTTTAGTGGTTTGC & 5' UTR cdc2 \\
\hline JA314 & CGACCGTTTCAGCAACGAGAACCAATTC & 5' UTR rem1 (RT-PCR) \\
\hline JA348 & CAGTACAGCGCAACCATAAGC & 5' RT-PCR SPAC4G9.05 \\
\hline JA349 & CCGCATATTATTTGGTCCATGTTG & 3'RT-PCR SPAC4G9.05 \\
\hline JA360 & ATGGTGTCTAGATTTTTTTCTTGG & 5' RT-PCR SPCC1919.11 \\
\hline JA361 & GATTGGCTTTTCCTAATTGCGAC & 3'RT-PCR SPCC1919.11 \\
\hline JA368 & GGCTATCTTTGTAGCGTTCATG & 5'RT-PCR SPBC17D1.07c \\
\hline JA369 & CTTCTAACTAAATCTTTCGTCTCG & 3' RT-PCR SPBC17D1.07c \\
\hline JA376 & CTCAGTGTTAGATTTGACACAAGTC & 5'RT-PCR mde3 \\
\hline JA377 & GTCCATAAACGTCTCCAAGAGATCG & 3' RT-PCR mde3 \\
\hline JA388 & CATCCTCAATTGATGTGTGGTCAG & 5' RT-PCR spo4 \\
\hline JA389 & CTGTTTTGGCCTTTACTCGTTTCG & 3' RT-PCR spo4 \\
\hline JA394 & GGTCATTCAAGGCTCATTTGGG & 5'RT-PCR mde1 \\
\hline JA395 & GACGGTGCATCACGTTCCAGG & 3'RT-PCR mde1 \\
\hline JA398 & CCATTGACCTACACCACTGGTG & 5' RT-PCR meu6 \\
\hline JA399 & GTTTCCAGTACCGGGTTCTATGG & 3' RT-PCR meu6 \\
\hline JA400 & GAGAAAACGGTCTCGTGAAGGG & 5'RT-PCR meu14 \\
\hline JA401 & CTCAGATTACTGGATTTTGCTCCC & 3' RT-PCR meu14 \\
\hline JA406 & GCGCAACACACACGAATTGTTAGC & 5'RT-PCR ppk35 \\
\hline JA407 & GTATTCAGGAGATCCAACAACGG & 3' RT-PCR ppk35 \\
\hline JA412 & GGAAGAAAAGGAGAACGTAAACTTG & 5'RT-PCR SPBC32H8.06 \\
\hline JA413 & GTCTTAACTGCCATGTTTCTGCAC & 3'RT-PCR SPBC32H8.06 \\
\hline JA453 & AGGTAAAGTTTAGTTTTGGGTTGTG & 5' rem1 FLEX box ChIP \\
\hline JA454 & AAGTTGATGGTGAAAATGTTTGTTT & 3' rem1 FLEX box ChIP \\
\hline JA455 & GATTTATGCCTGATTACCGACAT & 5' rem1 Intron ChIP \\
\hline JA456 & ATGTATGCACCCCCACAATC & 3' rem1 Intron ChIP \\
\hline JA459 & GGATTAGTCGACAAGTGCATGA & 5' rem1 3'-end ChIP \\
\hline JA460 & СТTCТСТСТСТTТТСССТССТTTTT & 3' rem1 3'-end ChIP \\
\hline JA488 & TTTGTCAAAAAGTTTTCCCACATAC & 5' Intergenic region ChIP \\
\hline JA489 & GCGGTTTCCCTTTCTAAGAGACT & 3' Intergenic region ChIP \\
\hline JA559 & GCCGATAAAAGATACAAAAGTGAGA & 5' ChIP mde2 \\
\hline JA560 & TTTTCCTATAACAAGCACATCATTG & 3' ChIP mde2 \\
\hline
\end{tabular}




\section{DISCUSSION}




\section{Rem1 regulation}

Rem1 levels and function are regulated at multiple levels. Here we have studied some of them. We have determined that it is regulated at the level of transcription, splicing and protein stability; moreover, we have some hints that it may be also regulated by mRNA degradation. Some other possibilities still not studied are the regulation during the translation of the protein and regulation by post-translational modifications.

We have determined that the promoter is necessary and enough to regulate rem1 expression (Fig. 6 and 7) and that neither the ORF nor the 5'UTR have any role in this regulation (Fig. 5, 6 and 7). Regarding the 3' end of the gene, we could not detect any significant difference at the level of transcription and splicing between a wild type strain and a strain lacking part of the second exon and the 3' end of the gene. Even though, there is a slight stabilization of the mRNA at late meiosis that should be studied deeper to assure whether it has a role in mRNA stability (Fig. 2).

The elements found to be important in the promoter are two FLEX boxes. They bind Forkhead transcription factors in vitro (Fig. 12). We have analysed the effects of the deletion of these boxes, in the absence of FLEX1, we can observe lower levels of transcription although the splicing seems to be normal. In the absence of FLEX2, we could observe an advancement regarding the timing of the transcription and higher levels of mRNA while splicing of rem 1 is nearly normal. In the double mutant, the transcription is seriously impaired and the splicing becomes very inefficient. These results give us some hints about the function of each FLEX box (FLEX1 inducer and FLEX2 repressor) but is not easy to conclude anything probably because they can have some overlapping affinity for the trans factors binding to them. Another possibility is that they are not directly implied in the regulation but we detect the effects derived from the de-structuration of the promoter, like the system reported by the group of John Warner (Rudra et al., 2007).

In figures 6 and 7 we can observe that the regulation is not only positive at midmeiosis but also negative during vegetative growth and early stages of meiosis. That is to say, in mitosis the transcription and splicing are repressed and in mid-meiosis the transcription and splicing are induced. This means that the system has at least two regulators. It is very important that rem1 has this self-lock mechanism of regulation, 
rem1 is not under the regulation of the mmi1 system (Yuriko Hariyaga, personal comunication) and it is very toxic even at low levels in mitotic cycle. Avoiding the splicing of the mRNA, the cell has no mature Rem1 protein protecting itself of the consequences of Rem1 expression (mitotic catastrophe) (Malapeira et al., 2005).

The main regulators of rem1 are the forkhead transcription factors Mei4 and Fkh2 (Fig. 9). In the absence of Mei4, we have some residual transcription of rem1 but we cannot detect spliced mRNA. This way, Mei4 seems to be directly or indirectly (promoting the transcription of other regulators) the main inducer of Rem1 expression. To differentiate between these two possibilities we performed ChIPs of Mei4 to show that it binds to rem1 promoter (Fig. 13). In fact, we can detect Mei4 at rem1 ORF pointing the possibilty that Mei4 can be travelling with the RNA polymerase II. This technic also allowed us to study RNA polymerase II binding to rem1 gene. In Figure 14 we show that RNApol II binding to rem1 is mei4-dependent. We could detect some binding and accumulation of the initiation isoform of the RNApol II (Ser5 of the CTD repeats phosphorylated) in a $\Delta$ mei4 strain but no elongating isoform (Ser2 of the CTD repeats phosphorylated) could be detected in the absence of Mei4. The strongest evidence that Mei4 is playing a direct role in the recruitment of the transcription machinery and the spliceosome is shown in figures 15 and 16 . We could coimmunoprecipitate Mei4 pulling down some components of the spliceosome (U1·70k, Prp11 and Cdc5). This binding is probably indirect because of the weak signal of the CoIPs and because experiments using in vitro translated (ivt) Mei4 cannot bind these factors in vitro. The link between both is probably the RNApolymerase II whose CTD repeats is reported to bind the spliceosome (Kim et al., 1997).

The second component of the system is Fkh2, in the absence of this factor, we can detect spliced mRNA at early stages of meiosis (Fig. 9) and, as shown in figure 10, this is not due to an ectopic expression of Mei4. In the absence of Fkh2 the meiotic induction of rem 1 transcription is also lost. This indicates that Fkh2 is necessary together with Mei4 to induce transcription of rem1.

Fkh2 also binds directly to rem1 gene but its localization seems to be more extendend in time and narrower in space. In figure 13, we can detect an increase in the binding of Fkh2 to rem1 gene slightly earlier that Mei4, moreover, if we observe the results in figure 9, they could explain an earlier, even constitutive binding of Fkh2 to the gene. The ChIP experiment also shows no binding of Fkh2 to the rem1 ORF. 
Regarding localization of the RNApol II and the spliceosome on rem1 gene in cells lacking fkh2, preliminary results indicate that the binding of RNApol II is even lower than in a $\Delta$ mei4 strain (data not shown) and for the spliceosome there are still no results. Interaction of Fkh2 and the spliceosome could not be detected (Figure 16). This can be related to the fact that Fkh2 seems to stay in the promoter instead of travel with the RNApol II in opposition to Mei4. The way Fkh2 is inhibiting the recruitment of the spliceosome is still not known.

It is not well understood the relationship and interactions between Mei4 and Fkh2 in rem1 promoter. Analyses of rem 1 splicing in double mutant $\Delta m e i 4 \Delta f k h 2$ cells by RT-PCR are shown in figure 11. This result was very surprising for us because we expected a similar behaviour to the single $\Delta f k h 2$ mutant but the result was different. It behaves as single mutants in a time-dependent manner: during the first three hours of meiosis it behaves exactly as a $\Delta f k h 2$ strain but on the onset of meiosis (concomitantly to Mei4 expression in a wild type strain) it starts behaving as a $\Delta$ mei4 strain, losing the spliced mRNA and accumulating non-processed mRNA (compare single mutants and double mutant pannels before and after $3 \mathrm{~h}$ of meiosis at figure 11).

Future work would consist in determine the different domains of the Mei4 implicated in this regulation and in search other components of this mechanism of regulation.

At the protein level, we have seen that Rem1 is actively degraded by the proteasome since the absence of meiosis-specific E3-ubiquitin ligase Mfr1, Rem1 is tabilize until the end of meiosis (Fig. 17).

No studies have been done about post-tranlational modifications on Rem1. 


\section{Regulation of other meiotic intron-containing genes}

We have shown that intron retention is a common regulation system for meiotic protein expression in S. pombe. There are at least ten more genes that behave as rem1. (Fig. 19). All of the have at least one FLEX motif in their promoters whose consensus seems to be longer (Fig. 21) that the one reported before (Horie et al., 1998). Although cis differences between FLEX motives with regulated and constitutive splicing could not be determined, future studies about chromatin structure and interaction of the Forkhead transcription factors between them and the DNA will give us more answers about it.

Meiosis, as a differentiation process, has a completely alternative gene expression pattern to the normal mitotic cell cycle. To asssure that overlapping of both gene expression programs is avoided, the transcriptional regulation seems not to be enough. Other save-lock mechanisms exist such as the mmi1 system (Harigaya et al., 2006) or the active repression of intron-containing meiotic genes (Averbeck et al., 2005; Malapeira et al., 2005). We have studied the molecular basis of the latter determining that Fkh2 and Mei4 regulate not only rem1 but other meiotic-specific genes. It is still not determined if all the other genes have different functions depending on the mRNA intron removal.

Searching for genes containing FLEX motives in their promoters in the S. pombe genome allowed us to develop basic software able to be adapted for future searching of any other motif in all $S$. pombe promoters. 


\section{Mei4 and Fkh2 regulation}

During meiosis, $f k h 2$ transcription increases slowly while mei4 has an abrupt induction at mid-meiosis (Fig. 22). At the level of protein Mei4 parallel the patern of its mRNA while Fkh2 seems to have more or less the same quantity of total protein although we can observe a dynamic pattern of slower migrating bands peaking at midmeiosis.

Taking into account the hypothesis that Fkh2 is constitutively bound to rem1 promoter, there are two possibilities two explain its different behaviour without leaving the promoter. One of them is that there could be other factors binding the promoter, the other is that Fkh2 could be suffering post-translational modifications. As shown before, Fkh2 is hyperphosphorylated at mid-meiosis (Fig. 22). A candidate to produce this phosphorylation is the complex $\mathrm{Cdc} 2 / \mathrm{Cig} 2$, which has high levels of kinase activity at mid-meiosis (Borgne et al., 2002). Fkh2 has 18 putative phosphorylable sites by Cyclin/Cdks complexes so we checked if Cig2 purified at different time points of meiosis could phosphorylate Fkh2. Using different truncated proteins we could find a fragment (NdeI-EcoRI) that contains three $\mathrm{S} / \mathrm{T}-\mathrm{P}$ residues which were putative candidates for the modification (Fig. 24). Mutations to Alanine at residue Ser522 had no significant effect on the phsophorylation, mutating Ser432 has minor effects but Ser481Ala mutation resulted in a decrease of $90 \%$ in the phosphorylation levels (Fig. 25 and 26). All these assays were performed in vitro with recombinant Fkh2 so the future work consists on validating these results in vivo and study the relevance of Ser481 on Fkh2 function.

Regarding Mei4, it seems to have constitutive phosphorylation with a lower mobility band of unknown characteristics (it does not disappear with alkaline phosphatase or lambda phosphatase).

The interaction of the two transcription factors at rem1 promoter is still not clear. Physical interaction of both factors could not be demonstrated, the strain used was tagged in both genes with Myc and HA. This strain suffered a slight delay in meiosis progression but not the single tagged strains (data not shown). Maybe this is pointing the possibility that both tags are interfering with Mei4 and Fkh2 function. 

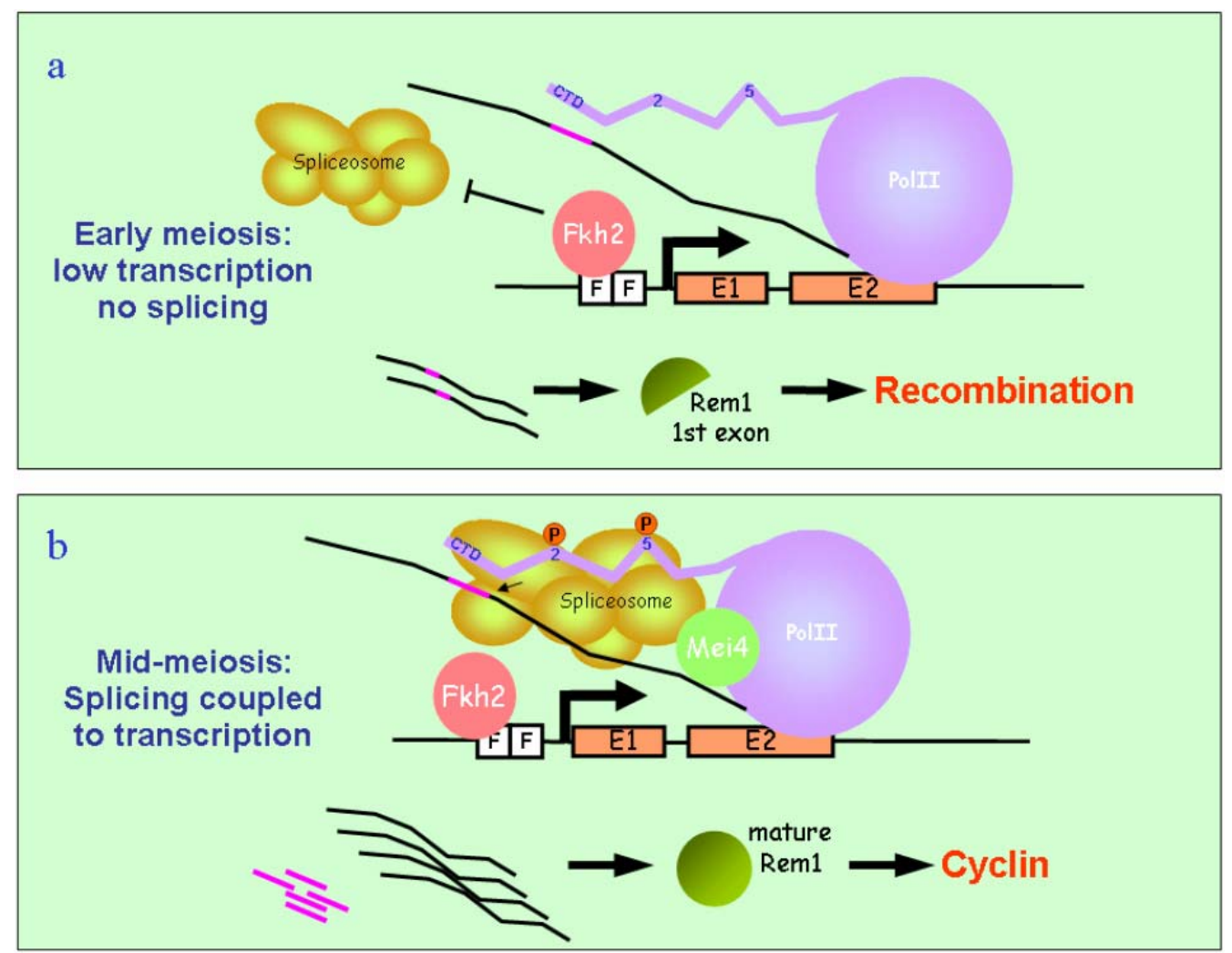

Figure 1. Model of the Fkh2-Mei4 regulation of rem1

The in silico modelling of the DNA-binding domain of both factors (Fig. 27 and 28 ) indicate that they bind differently the FLEX box.

A possible explanation is that Mei4 binding to the promter FLEX boxes is weaker and the interaction with Fkh2 can stabilize it (Fkh2 seems to be constitutively bound to the promoter) through the Fkh2 Forkhead-Associated Domain (FHA) [this domain is known to mediate protein-protein interactions in other proteins]. At the begining of meiosis Fkh2 alone (or in a homodimer form) would avoid RNApol II and spliceosome machinery recrutiment, achieving low transcription levels of unprocessed mRNA. This mRNA will be translated to a truncated protein with a recombination function. At mid-meiosis, Mei4 is expressed and could form a heterodimer Fkh2-Mei4 at rem1 promtorer. This way Mei4 would stabilize the RNA pol II and promote the recruitment of the spliceosomey. Now, transcription will be induced and mRNA will be spliced, coding for the mature Rem1 protein with a function as a cyclin. The hipothesis is shown in the discussion figure 1 


\section{Rem1 function}

We have shown that rem1 gene can have two different protein products with different functions depending on the splicing of its only intron. If the mRNA remains unprocessed, a truncated protein is translated with a function in intragenic recombination (Fig. 30). At the onset of meiosis I, a transcription induction coupled to splicing is produced and the intron containing a stop codon in frame is removed. This processed mRNA is translated to the mature Rem1 with a function as a cyclin (Fig. 29). Although direct targets have not been found for the Cdc2/Rem1 complex, our group saw that Rem1 promotes the degradation od Cdc18. This could induce a cycle without DNA replication what would explain the mitotic catastrophe of cells overexpressing Rem1 and why is so important that Rem1 is only expressed in Meiosis I.

The system reported here could account for athe first case of alternative splicing in a unicellular eukaryote, which when the mRNA is not processed (during the premeiotic S phase) will render a $17 \mathrm{KDa}$ protein that will have a role in recombination and when the mRNA is processed will produce a protein with a described function as a cyclin during meiosis I. 
Conclusions 
rem1 promoter is the most important region for the gene regulation of transcription and splicing, specifically the two FLEX boxes found there. rem1 promoter is necessary and enough to regulate rem 1 expression.

Rem1 regulation is based on, at least, a two factor model. One factor repressing the splicing in vegetative growth and early meiosis and another one inducing the splicing at mid-meiosis.

Fkh2 is the repressor factor, which binds rem1 promoter constituvely.

Mei4 is the activator factor, which binds rem1 promoter only in mid-meiosis and is able to travel with the RNApolymerase II, stablize it and interact physically with the spliceosome to recruit it.

There are at least other 10 genes that are regulated as rem1, which means that intron retention is a general mechanism of regulation for meiotic intron-containing genes.

Mei4 and Fkh2 are phosphoproteins. Cdc2/Cig2 purified from mid-meiosis is able to phosphorylate in vitro Fkh2.

Fkh2 is specifically phosphorylated by Cdc2/Cig2 in Serine 481 .

Rem1 has two different functions: at pre-meiotic S phase, rem1 mRNA is not processed and a truncated $17 \mathrm{kDa}$ Reml is translated with a function in intragenic recombination and at mid-meiosis rem 1 intron is removed and the mature $46 \mathrm{kDa}$ Rem 1 is expressed with a cyclin function.

Rem1 is degradated at late-meiosis by the E3 ubiquitin-ligase Mfr1. 


\section{BIBLIOGRAPHY}


(2004). The Molecular Biology of Schizosaccharomyces pombe (Heidelberg: Springer).

Alfa, C. E., Booher, R., Beach, D., and Hyams, J. S. (1989). Fission yeast cyclin: subcellular localisation and cell cycle regulation. J Cell Sci Suppl 12, 9-19.

Alvarez, B., and Moreno, S. (2006). Fission yeast Tor2 promotes cell growth and represses cell differentiation. J Cell Sci 119, 4475-4485.

Arcangioli, B. (1998). A site- and strand-specific DNA break confers asymmetric switching potential in fission yeast. Embo J 17, 4503-4510.

Asakawa, H., Kitamura, K., and Shimoda, C. (2001). A novel Cdc20-related WD-repeat protein, Fzr1, is required for spore formation in Schizosaccharomyces pombe. Mol Genet Genomics 265, 424-435.

Averbeck, N., Sunder, S., Sample, N., Wise, J. A., and Leatherwood, J. (2005). Negative control contributes to an extensive program of meiotic splicing in fission yeast. Mol Cell 18, 491-498.

Belenguer, P., Pelloquin, L., Baldin, V., Oustrin, M. L., and Ducommun, B. (1995). The fission yeast Nim1/Cdr1 kinase: a link between nutritional state and cell cycle control. Prog Cell Cycle Res 1, 207-214.

Ben-Dov, C., Hartmann, B., Lundgren, J., and Valcarcel, J. (2008). Genome-wide analysis of alternative pre-mRNA splicing. J Biol Chem 283, 1229-1233.

Blanco, M. A., Pelloquin, L., and Moreno, S. (2001). Fission yeast mfr1 activates APC and coordinates meiotic nuclear division with sporulation. J Cell Sci 114, 2135-2143.

Borgne, A., Murakami, H., Ayte, J., and Nurse, P. (2002). The G1/S cyclin Cig2p during meiosis in fission yeast. Mol Biol Cell 13, 2080-2090.

Bottner, C. A., Schmidt, H., Vogel, S., Michele, M., and Kaufer, N. F. (2005). Multiple genetic and biochemical interactions of Brr2, Prp8, Prp31, Prp1 and Prp4 kinase suggest a function in the control of the activation of spliceosomes in Schizosaccharomyces pombe. Curr Genet 48, 151-161.

Buck, V., Ng, S. S., Ruiz-Garcia, A. B., Papadopoulou, K., Bhatti, S., Samuel, J. M., Anderson, M., Millar, J. B., and McInerny, C. J. (2004). Fkh2p and Sep1p regulate mitotic gene transcription in fission yeast. J Cell Sci 117, 5623-5632.

Bulmer, R., Pic-Taylor, A., Whitehall, S. K., Martin, K. A., Millar, J. B., Quinn, J., and Morgan, B. A. (2004). The forkhead transcription factor Fkh2 regulates the cell division cycle of Schizosaccharomyces pombe. Eukaryot Cell 3, 944-954.

Caceres, J. F., and Kornblihtt, A. R. (2002). Alternative splicing: multiple control mechanisms and involvement in human disease. Trends Genet 18, 186-193.

Cartegni, L., Chew, S. L., and Krainer, A. R. (2002). Listening to silence and understanding nonsense: exonic mutations that affect splicing. Nat Rev Genet 3, 285-298.

Clark, K. L., Halay, E. D., Lai, E., and Burley, S. K. (1993). Co-crystal structure of the HNF-3/fork head DNA-recognition motif resembles histone H5. Nature 364, 412420.

Correa-Bordes, J., and Nurse, P. (1995). p25rum1 orders S phase and mitosis by acting as an inhibitor of the p34cdc2 mitotic kinase. Cell 83, 1001-1009.

Cramer, P., Caceres, J. F., Cazalla, D., Kadener, S., Muro, A. F., Baralle, F. E., and Kornblihtt, A. R. (1999). Coupling of transcription with alternative splicing: RNA pol II promoters modulate SF2/ASF and 9G8 effects on an exonic splicing enhancer. Mol Cell 4, 251-258. 
Cramer, P., Pesce, C. G., Baralle, F. E., and Kornblihtt, A. R. (1997). Functional association between promoter structure and transcript alternative splicing. Proc Natl Acad Sci U S A 94, 11456-11460.

Cramer, P., Srebrow, A., Kadener, S., Werbajh, S., de la Mata, M., Melen, G., Nogues, G., and Kornblihtt, A. R. (2001). Coordination between transcription and premRNA processing. FEBS Lett 498, 179-182.

Cho, E. J., Kobor, M. S., Kim, M., Greenblatt, J., and Buratowski, S. (2001). Opposing effects of Ctk1 kinase and Fcp1 phosphatase at Ser 2 of the RNA polymerase II Cterminal domain. Genes Dev 15, 3319-3329.

Dellaire, G., Makarov, E. M., Cowger, J. J., Longman, D., Sutherland, H. G., Luhrmann, R., Torchia, J., and Bickmore, W. A. (2002). Mammalian PRP4 kinase copurifies and interacts with components of both the U5 snRNP and the N-CoR deacetylase complexes. Mol Cell Biol 22, 5141-5156.

Egel, R. (1976a). The genetic instabilities of the mating type locus in fission yeast. Mol Gen Genet 145, 281-286.

Egel, R. (1976b). Rearrangements at the mating type locus in fission yeast. Mol Gen Genet 148, 149-158.

Fisher, D. L., and Nurse, P. (1996). A single fission yeast mitotic cyclin B p34cdc2 kinase promotes both S-phase and mitosis in the absence of G1 cyclins. Embo J 15, 850-860.

Forsburg, S. L. PombeNet at The Forsburg Lab.

Fox, M. E., and Smith, G. R. (1998). Control of meiotic recombination in Schizosaccharomyces pombe. Prog Nucleic Acid Res Mol Biol 61, 345-378.

Gajiwala, K. S., and Burley, S. K. (2000). Winged helix proteins. Curr Opin Struct Biol 10, 110-116.

Gautier, J., Solomon, M. J., Booher, R. N., Bazan, J. F., and Kirschner, M. W. (1991). cdc25 is a specific tyrosine phosphatase that directly activates p34cdc2. Cell 67, 197-211.

Gould, K. L., Feoktistova, A., and Fleig, U. (1998). A phosphorylation site mutant of Schizosaccharomyces pombe $\operatorname{cdc} 2 p$ fails to promote the metaphase to anaphase transition. Mol Gen Genet 259, 437-448.

Gould, K. L., and Nurse, P. (1989). Tyrosine phosphorylation of the fission yeast cdc2+ protein kinase regulates entry into mitosis. Nature 342, 39-45.

Gozani, O., Potashkin, J., and Reed, R. (1998). A potential role for U2AF-SAP 155 interactions in recruiting U2 snRNP to the branch site. Mol Cell Biol 18, 4752-4760.

Grallert, A., Grallert, B., Ribar, B., and Sipiczki, M. (1998). Coordination of initiation of nuclear division and initiation of cell division in Schizosaccharomyces pombe: genetic interactions of mutations. J Bacteriol 180, 892-900.

Habara, Y., Urushiyama, S., Shibuya, T., Ohshima, Y., and Tani, T. (2001). Mutation in the prp12+ gene encoding a homolog of SAP130/SF3b130 causes differential inhibition of pre-mRNA splicing and arrest of cell-cycle progression in Schizosaccharomyces pombe. Rna 7, 671-681.

Habara, Y., Urushiyama, S., Tani, T., and Ohshima, Y. (1998). The fission yeast prp10(+) gene involved in pre-mRNA splicing encodes a homologue of highly conserved splicing factor, SAP155. Nucleic Acids Res 26, 5662-5669.

Harigaya, Y., Tanaka, H., Yamanaka, S., Tanaka, K., Watanabe, Y., Tsutsumi, C., Chikashige, Y., Hiraoka, Y., Yamashita, A., and Yamamoto, M. (2006). Selective elimination of messenger RNA prevents an incidence of untimely meiosis. Nature 442, 45-50. 
Hermann-Le Denmat, S., Werner, M., Sentenac, A., and Thuriaux, P. (1994). Suppression of yeast RNA polymerase III mutations by FHL1, a gene coding for a fork head protein involved in rRNA processing. Mol Cell Biol 14, 2905-2913.

Higuchi, T., Watanabe, Y., and Yamamoto, M. (2002). Protein kinase A regulates sexual development and gluconeogenesis through phosphorylation of the $\mathrm{Zn}$ finger transcriptional activator Rst2p in fission yeast. Mol Cell Biol 22, 1-11.

Horie, S., Watanabe, Y., Tanaka, K., Nishiwaki, S., Fujioka, H., Abe, H., Yamamoto, M., and Shimoda, C. (1998). The Schizosaccharomyces pombe mei4+ gene encodes a meiosis-specific transcription factor containing a forkhead DNA-binding domain. Mol Cell Biol 18, 2118-2129.

Huang, T., Vilardell, J., and Query, C. C. (2002). Pre-spliceosome formation in S.pombe requires a stable complex of SF1-U2AF(59)-U2AF(23). Embo J 21, 55165526.

Iino, Y., Hiramine, Y., and Yamamoto, M. (1995). The role of cdc2 and other genes in meiosis in Schizosaccharomyces pombe. Genetics 140, 1235-1245.

Iino, Y., and Yamamoto, M. (1985). Mutants of Schizosaccharomyces pombe which sporulate in the haploid state. Mol Gen Genet 198, 416-421.

Kadener, S., Cramer, P., Nogues, G., Cazalla, D., de la Mata, M., Fededa, J. P., Werbajh, S. E., Srebrow, A., and Kornblihtt, A. R. (2001). Antagonistic effects of T-Ag and VP16 reveal a role for RNA pol II elongation on alternative splicing. Embo J 20, 5759-5768.

Kambach, C., Walke, S., and Nagai, K. (1999). Structure and assembly of the spliceosomal small nuclear ribonucleoprotein particles. Curr Opin Struct Biol 9, 222-230.

Kaufer, N. F., and Potashkin, J. (2000). Analysis of the splicing machinery in fission yeast: a comparison with budding yeast and mammals. Nucleic Acids Res 28, 30033010 .

Kaufer, N. F., Simanis, V., and Nurse, P. (1985). Fission yeast Schizosaccharomyces pombe correctly excises a mammalian RNA transcript intervening sequence. Nature 318, 78-80.

Kelly, M., Burke, J., Smith, M., Klar, A., and Beach, D. (1988). Four mating-type genes control sexual differentiation in the fission yeast. Embo J 7, 1537-1547.

Kim, E., Du, L., Bregman, D. B., and Warren, S. L. (1997). Splicing factors associate with hyperphosphorylated RNA polymerase II in the absence of pre-mRNA. J Cell Biol 136, 19-28.

Kim, S. H., and Lin, R. J. (1993). Pre-mRNA splicing within an assembled yeast spliceosome requires an RNA-dependent ATPase and ATP hydrolysis. Proc Natl Acad Sci U S A 90, 888-892.

Kitamura, K., Maekawa, H., and Shimoda, C. (1998). Fission yeast Ste9, a homolog of Hct1/Cdh1 and Fizzy-related, is a novel negative regulator of cell cycle progression during G1-phase. Mol Biol Cell 9, 1065-1080.

Kramer, A. (1996). The structure and function of proteins involved in mammalian premRNA splicing. Annu Rev Biochem 65, 367-409.

Kuhn, A. N., and Kaufer, N. F. (2003). Pre-mRNA splicing in Schizosaccharomyces pombe: regulatory role of a kinase conserved from fission yeast to mammals. Curr Genet 42, 241-251.

Kuhn, A. N., Reichl, E. M., and Brow, D. A. (2002). Distinct domains of splicing factor Prp8 mediate different aspects of spliceosome activation. Proc Natl Acad Sci U S A 99, 9145-9149. 
Kumar, R., Reynolds, D. M., Shevchenko, A., Shevchenko, A., Goldstone, S. D., and Dalton, S. (2000). Forkhead transcription factors, Fkh1p and Fkh2p, collaborate with Mcm1p to control transcription required for M-phase. Curr Biol 10, 896-906.

Labib, K., and Moreno, S. (1996). rum1: a CDK inhibitor regulating G1 progression in fission yeast. Trends Cell Biol 6, 62-66.

Lai, M. C., Teh, B. H., and Tarn, W. Y. (1999). A human papillomavirus E2 transcriptional activator. The interactions with cellular splicing factors and potential function in pre-mRNA processing. J Biol Chem 274, 11832-11841.

Le Hir, H., Izaurralde, E., Maquat, L. E., and Moore, M. J. (2000). The spliceosome deposits multiple proteins 20-24 nucleotides upstream of mRNA exon-exon junctions. Embo J 19, 6860-6869.

Lykke-Andersen, J., Shu, M. D., and Steitz, J. A. (2001). Communication of the position of exon-exon junctions to the mRNA surveillance machinery by the protein RNPS1. Science 293, 1836-1839.

Macias, S., Bragulat, M., Tardiff, D. F., and Vilardell, J. (2008). L30 binds the nascent RPL30 transcript to repress U2 snRNP recruitment. Mol Cell 30, 732-742.

Maeda, T., Mochizuki, N., and Yamamoto, M. (1990). Adenylyl cyclase is dispensable for vegetative cell growth in the fission yeast Schizosaccharomyces pombe. Proc Natl Acad Sci U S A 87, 7814-7818.

Makarova, O. V., Makarov, E. M., Liu, S., Vornlocher, H. P., and Luhrmann, R. (2002). Protein $61 \mathrm{~K}$, encoded by a gene (PRPF31) linked to autosomal dominant retinitis pigmentosa, is required for $\mathrm{U} 4 / \mathrm{U} 6 * \mathrm{U} 5$ tri-snRNP formation and pre-mRNA splicing. Embo J 21, 1148-1157.

Malapeira, J., Moldon, A., Hidalgo, E., Smith, G. R., Nurse, P., and Ayte, J. (2005). A meiosis-specific cyclin regulated by splicing is required for proper progression through meiosis. Mol Cell Biol 25, 6330-6337.

Martin-Castellanos, C., Blanco, M. A., de Prada, J. M., and Moreno, S. (2000). The puc1 cyclin regulates the G1 phase of the fission yeast cell cycle in response to cell size. Mol Biol Cell 11, 543-554.

Martin-Castellanos, C., Labib, K., and Moreno, S. (1996). B-type cyclins regulate G1 progression in fission yeast in opposition to the p25rum1 cdk inhibitor. Embo J 15, 839-849.

Martin-Castellanos, C., and Moreno, S. (1996). Regulation of G1 progression in fission yeast by the rum1+ gene product. Prog Cell Cycle Res 2, 29-35.

Mata, J., Lyne, R., Burns, G., and Bahler, J. (2002). The transcriptional program of meiosis and sporulation in fission yeast. Nat Genet 32, 143-147.

Mata, J., Wilbrey, A., and Bahler, J. (2007). Transcriptional regulatory network for sexual differentiation in fission yeast. Genome Biol 8, R217.

Matsumoto, T. (1997). A fission yeast homolog of CDC20/p55CDC/Fizzy is required for recovery from DNA damage and genetically interacts with p34cdc2. Mol Cell Biol 17, 742-750.

Mayeda, A., Badolato, J., Kobayashi, R., Zhang, M. Q., Gardiner, E. M., and Krainer, A. R. (1999). Purification and characterization of human RNPS1: a general activator of pre-mRNA splicing. Embo J 18, 4560-4570.

Mazet, F., Yu, J. K., Liberles, D. A., Holland, L. Z., and Shimeld, S. M. (2003). Phylogenetic relationships of the Fox (Forkhead) gene family in the Bilateria. Gene 316, 79-89.

McCracken, S., Fong, N., Yankulov, K., Ballantyne, S., Pan, G., Greenblatt, J., Patterson, S. D., Wickens, M., and Bentley, D. L. (1997). The C-terminal domain of 
RNA polymerase II couples mRNA processing to transcription. Nature 385, 357361.

McDonald, W. H., Ohi, R., Smelkova, N., Frendewey, D., and Gould, K. L. (1999). Myb-related fission yeast cdc5p is a component of a $40 \mathrm{~S}$ snRNP-containing complex and is essential for pre-mRNA splicing. Mol Cell Biol 19, 5352-5362.

McKinney, R., Wentz-Hunter, K., Schmidt, H., and Potashkin, J. (1997). Molecular characterization of a novel fission yeast gene spUAP2 that interacts with the splicing factor spU2AF59. Curr Genet 32, 323-330.

McLeod, M., and Beach, D. (1988). A specific inhibitor of the ran1+ protein kinase regulates entry into meiosis in Schizosaccharomyces pombe. Nature 332, 509-514.

Mochizuki, N., and Yamamoto, M. (1992). Reduction in the intracellular cAMP level triggers initiation of sexual development in fission yeast. Mol Gen Genet 233, 17-24.

Mondesert, O., McGowan, C. H., and Russell, P. (1996). Cig2, a B-type cyclin, promotes the onset of $\mathrm{S}$ in Schizosaccharomyces pombe. Mol Cell Biol 16, 15271533.

Moreno, S., Klar, A., and Nurse, P. (1991). Molecular genetic analysis of the fission yeast Schizosaccharomyces pombe. Meth Enzymol 194, 795-823.

Moreno, S., and Nurse, P. (1994). Regulation of progression through the G1 phase of the cell cycle by the rum1+ gene. Nature 367, 236-242.

Morillon, A., O'Sullivan, J., Azad, A., Proudfoot, N., and Mellor, J. (2003). Regulation of elongating RNA polymerase II by forkhead transcription factors in yeast. Science 300, 492-495.

Moser, B. A., and Russell, P. (2000). Cell cycle regulation in Schizosaccharomyces pombe. Curr Opin Microbiol 3, 631-636.

Murakami-Tonami, Y., Yamada-Namikawa, C., Tochigi, A., Hasegawa, N., Kojima, H., Kunimatsu, M., Nakanishi, M., and Murakami, H. (2007). Mei4p coordinates the onset of meiosis I by regulating cdc25+ in fission yeast. Proc Natl Acad Sci U S A 104, 14688-14693.

Nurse, P., and Bissett, Y. (1981). Gene required in G1 for commitment to cell cycle and in G2 for control of mitosis in fission yeast. Nature 292, 558-560.

Nurse, P., and Thuriaux, P. (1980). Regulatory genes controlling mitosis in the fission yeast Schizosaccharomyces pombe. Genetics 96, 627-637.

O'Brien, T., Hardin, S., Greenleaf, A., and Lis, J. T. (1994). Phosphorylation of RNA polymerase II C-terminal domain and transcriptional elongation. Nature 370, 75-77.

Partridge, L., and Bruning, J. C. (2008). Forkhead transcription factors and ageing. Oncogene 27, 2351-2363.

Pettigrew, C. A., and Brown, M. A. (2008). Pre-mRNA splicing aberrations and cancer. Front Biosci 13, 1090-1105.

Philips, A. V., and Cooper, T. A. (2000). RNA processing and human disease. Cell Mol Life Sci 57, 235-249.

Prabhala, G., Rosenberg, G. H., and Kaufer, N. F. (1992). Architectural features of premRNA introns in the fission yeast Schizosaccharomyces pombe. Yeast 8, 171-182.

Ribar, B., Banrevi, A., and Sipiczki, M. (1997). sep1+ encodes a transcription-factor homologue of the HNF-3/forkhead DNA-binding-domain family in Schizosaccharomyces pombe. Gene 202, 1-5.

Richert, K., Schmidt, H., Gross, T., and Kaufer, F. (2002). The deubiquitinating enzyme Ubp21p of fission yeast stabilizes a mutant form of protein kinase Prp4p. Mol Genet Genomics 267, 88-95. 
Rudra, D., Mallick, J., Zhao, Y., and Warner, J. R. (2007). Potential interface between ribosomal protein production and pre-rRNA processing. Mol Cell Biol 27, 48154824.

Russell, P., and Nurse, P. (1987). Negative regulation of mitosis by wee1+, a gene encoding a protein kinase homolog. Cell 49, 559-567.

Rustici, G., Mata, J., Kivinen, K., Lio, P., Penkett, C. J., Burns, G., Hayles, J., Brazma, A., Nurse, P., and Bahler, J. (2004). Periodic gene expression program of the fission yeast cell cycle. Nat Genet 36, 809-817.

Schwelnus, W., Richert, K., Opitz, F., Gross, T., Habara, Y., Tani, T., and Kaufer, N. F. (2001). Fission yeast Prp4p kinase regulates pre-mRNA splicing by phosphorylating a non-SR-splicing factor. EMBO Rep 2, 35-41.

Shimada, M., Yamada-Namikawa, C., Murakami-Tonami, Y., Yoshida, T., Nakanishi, M., Urano, T., and Murakami, H. (2007). Cdc2p controls the forkhead transcription factor Fkh2p by phosphorylation during sexual differentiation in fission yeast. Embo J.

Shimoseki, M., and Shimoda, C. (2001). The 5' terminal region of the Schizosaccharomyces pombe mes 1 mRNA is crucial for its meiosis-specific splicing. Mol Genet Genomics 265, 673-682.

Shiozaki, K., and Russell, P. (1997). Stress-activated protein kinase pathway in cell cycle control of fission yeast. Methods Enzymol 283, 506-520.

Sinibaldi, R., O'Connell, C., Seidel, C., and Rodriguez, H. (2001). Gene expression analysis on medium-density oligonucleotide arrays. Methods Mol Biol 170, 211-222.

Smyth, G. K. (2004). Linear models and empirical bayes methods for assessing differential expression in microarray experiments. Stat Appl Genet Mol Biol 3, Article3.

Sugimoto, A., Iino, Y., Maeda, T., Watanabe, Y., and Yamamoto, M. (1991). Schizosaccharomyces pombe ste11+ encodes a transcription factor with an HMG motif that is a critical regulator of sexual development. Genes Dev 5, 1990-1999.

Szilagyi, Z., Batta, G., Enczi, K., and Sipiczki, M. (2005). Characterisation of two novel fork-head gene homologues of Schizosaccharomyces pombe: their involvement in cell cycle and sexual differentiation. Gene 348, 101-109.

Tsai, K. L., Huang, C. Y., Chang, C. H., Sun, Y. J., Chuang, W. J., and Hsiao, C. D. (2006). Crystal structure of the human FOXK1a-DNA complex and its implications on the diverse binding specificity of winged helix/forkhead proteins. J Biol Chem 281, 17400-17409.

Uritani, M., Hidaka, H., Hotta, Y., Ueno, M., Ushimaru, T., and Toda, T. (2006). Fission yeast Tor2 links nitrogen signals to cell proliferation and acts downstream of the Rheb GTPase. Genes Cells 11, 1367-1379.

Urushiyama, S., Tani, T., and Ohshima, Y. (1997). The prp1+ gene required for premRNA splicing in Schizosaccharomyces pombe encodes a protein that contains TPR motifs and is similar to Prp6p of budding yeast. Genetics 147, 101-115.

Van Heeckeren, W. J., Dorris, D. R., and Struhl, K. (1998). The mating-type proteins of fission yeast induce meiosis by directly activating mei3 transcription. Mol Cell Biol 18, 7317-7326.

Wang, C., Chua, K., Seghezzi, W., Lees, E., Gozani, O., and Reed, R. (1998). Phosphorylation of spliceosomal protein SAP 155 coupled with splicing catalysis. Genes Dev 12, 1409-1414.

Weidenhammer, E. M., Ruiz-Noriega, M., and Woolford, J. L., Jr. (1997). Prp31p promotes the association of the U4/U6 $\times$ U5 tri-snRNP with prespliceosomes to form spliceosomes in Saccharomyces cerevisiae. Mol Cell Biol 17, 3580-3588. 
Weisman, R., Roitburg, I., Schonbrun, M., Harari, R., and Kupiec, M. (2007). Opposite effects of tor 1 and tor 2 on nitrogen starvation responses in fission yeast. Genetics 175, 1153-1162.

Wood, V., Gwilliam, R., Rajandream, M. A., Lyne, M., Lyne, R., Stewart, A., Sgouros, J., Peat, N., Hayles, J., Baker, S., et al. (2002). The genome sequence of Schizosaccharomyces pombe. Nature 415, 871-880.

Yamada, H. Y., Matsumoto, S., and Matsumoto, T. (2000). High dosage expression of a zinc finger protein, Grt1, suppresses a mutant of fission yeast slp1(+), a homolog of CDC20/p55CDC/Fizzy. J Cell Sci 113 ( Pt 22), 3989-3999.

Yamaguchi, S., Murakami, H., and Okayama, H. (1997). A WD repeat protein controls the cell cycle and differentiation by negatively regulating Cdc2/B-type cyclin complexes. Mol Biol Cell 8, 2475-2486.

Yamamoto, M. (1996). The molecular control mechanisms of meiosis in fission yeast. Trends Biochem Sci 21, 18-22.

Yan, D., Perriman, R., Igel, H., Howe, K. J., Neville, M., and Ares, M., Jr. (1998). CUS2, a yeast homolog of human Tat-SF1, rescues function of misfolded U2 through an unusual RNA recognition motif. Mol Cell Biol 18, 5000-5009.

Zamore, P. D., and Green, M. R. (1989). Identification, purification, and biochemical characterization of U2 small nuclear ribonucleoprotein auxiliary factor. Proc Natl Acad Sci U S A 86, 9243-9247. 
ARTiCle 
Moldón A, Malapeira J, Gabrielli N, Gogol M, Gómez-Escoda B, Ivanova T, Seidel C, Ayté J. Promoter-driven splicing

regulation in fission yeast.

Nature. 2008 0ct 16;455(7215):997-1000. Epub 2008 Sep 24.

Comment in:

Nature. 2008 oct $16 ; 455(7215): 885-6$. 